\author{
Universidade de São Paulo \\ Escola de Engenharia de São Carlos \\ Programa de Pós-Graduação em Engenharia Elétrica
}

Jason Barbosa Cardoso

\title{
Reconfiguração Ótima para Cortes de Cargas em Sistemas de Distribuição de Energia Elétrica
}



Jason Barbosa Cardoso

\section{Reconfiguração Ótima para Cortes de Cargas em Sistemas de Distribuição de Energia Elétrica}

Dissertação apresentada à Escola de Engenharia de São Carlos da Universidade de São Paulo, como parte dos requisitos para obtenção do título de Mestre em ciências, Programa de Engenharia Elétrica ${ }^{1}$.

Área de Concentração: Sistema Elétrico de Potência

Orientador: Prof. Dr. Geraldo Roberto Martins da Costa

\footnotetext{
${ }^{1}$ Trata-se da versão corrigida da dissertação. A versão original se encontra disponível na EESC/USP que aloja o Programa de Pós-Graduação de Engenharia Elétrica
} 
AUTORIZO A REPRODUÇÃO TOTAL OU PARCIAL DESTE TRABALHO, POR QUALQUER MEIO CONVENCIONAL OU ELETRÔNICO, PARA FINS DE ESTUDO E PESQUISA, DESDE QUE CITADA A FONTE.

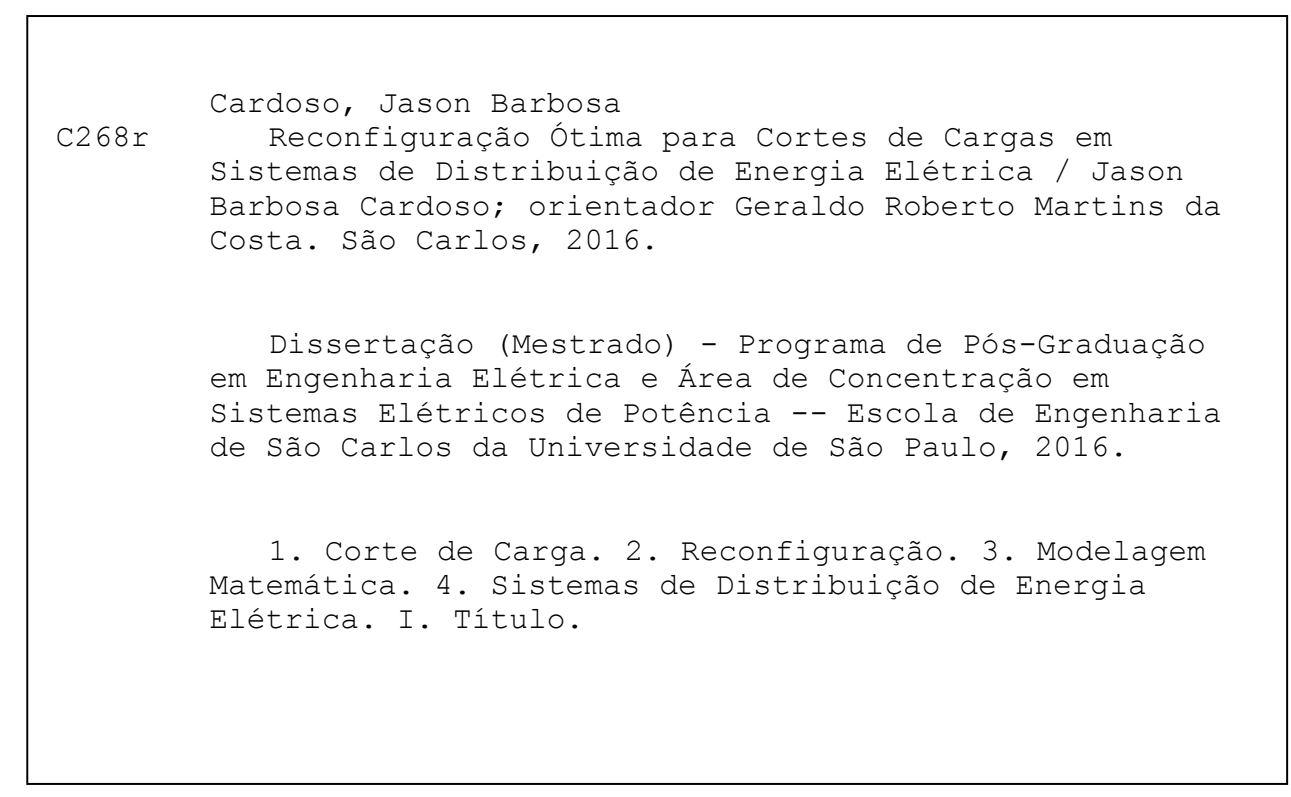




\section{FOLHA DE JULGAMENTO}

Candidato: Engenheiro JASON BARBOSA CARDOSO

Título da dissertação: "Reconfiguração ótima para cortes de cargas em sistemas de distribuição de energia elétrica"

Data da defesa: 28/07/2016

Comissão Julgadora:

Resultado:

Prof. Titular Geraldo Roberto Martins da Costa

seroutso (Orientador)

(Escola de Engenharia de São Carlos/EESC)

Profa. Dra. Vanusa Alves de Souza

(Universidade Federal de São Carlos/UFSCar)

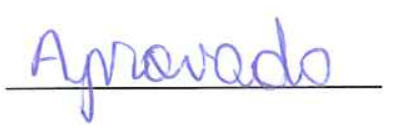

Prof. Dr. Paulo Rogério Politano

APROVAD?

(Universidade Federal de São Carlos/UFSCar)

Coordenador do Programa de Pós-Graduação em Engenharia Elétrica: Prof. Associado Luís Fernando Costa Alberło

Presidente da Comissão de Pós-Graduação:

Prof. Associado Luís Fernando Costa Alberto 
Aos meus pais, Antônio e Socorro,

e irmãs, Lauricele e Larissa, pelo apoio incondicional. 


\section{Agradecimentos}

Primeiramente agradeço aos meus pais, Antônio e Maria do Socorro, por oferecerem essa oportunidade de ampliar meus conhecimentos. E também pelo apoio incondicional, abdicando às vezes de suas conquistas.

Agradeço, imensamente, ao Professor Dr. Geraldo por ter confiado em mim, por acreditar que conseguiria realizar este trabalho. Pela paciência nos momentos mais difíceis da realização deste projeto. Agradeço ao Dr. Benvindo pelas sugestões e orientações, sem as quais, seguramente, seria muito mais difícil atingir o objetivo final.

Às minhas irmãs, Lauricele e Dr. Larissa, pelo apoio, pelo sempre presente aconselhamento e também por compartilhar os momentos de dificuldade.

Agradeço aos meus amigos, Diego (Tião), por me ajudar de todas as formas, ter dividido as dificuldades e alegrias deste momento, e Patrick, pelos conselhos e momentos de descontração. $\mathrm{E}$ a todos os outros amigos e familiares que, de alguma forma, puderam contribuir com a realização deste trabalho.

Agradeço a todos os professores: Dr. Ruy Altafim, Dr. Benvindo e Dr. Eduardo Werley, que contribuíram com seus conhecimentos ministrando disciplinas necessárias para cumprimento dos créditos. E a todos os colegas do grupo de trabalho Lasee.

E por fim, agradeço à Instituição Universidade de São Paulo, por ter disponibilizado o espaço físico para o desenvolvimento dessa dissertação. 


\section{SUMÁRIO}

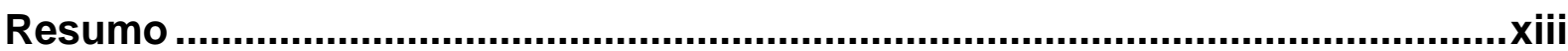

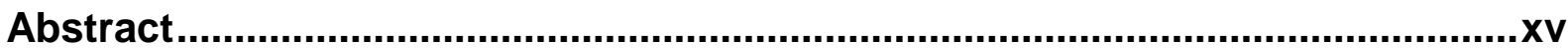

Lista de Siglas e Abreviaturas …...................................................................

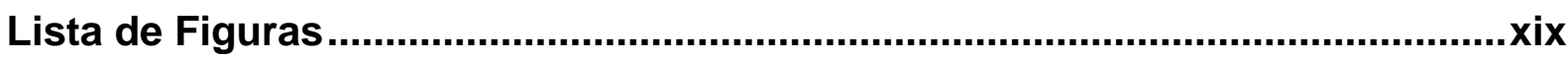

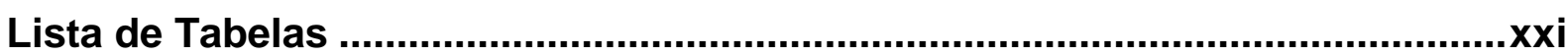

Lista de Símbolos............................................................................................

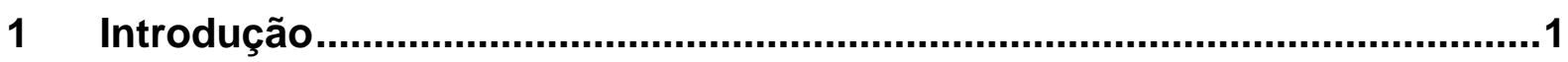

1.1 Histórico do Problema de Reconfiguração ............................................. 1.1.1 Reconfiguração do Sistema de Distribuição de Energia Elétrica para Perdas Ativas...........................................................................5 1.1.2 Reconfiguração do Sistema de Distribuição de Energia Elétrica para Restauração.

1.1.3 Reconfiguração do Sistema de Distribuição de Energia Elétrica para Corte de Carga...........................................................................11

1.2 Motivação do Trabalho....................................................................15

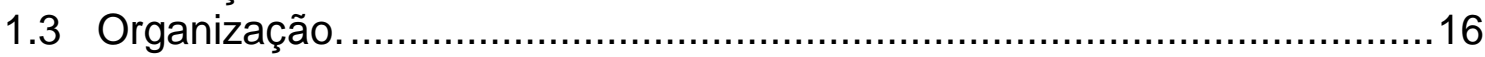

2 Fluxo de Carga e o Problema Cônico de Segunda Ordem ..........................19

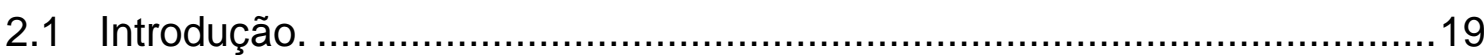

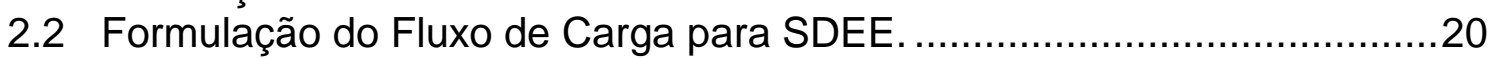

2.3 Formulação da Programação Não-Linear. ............................................22

2.3.1 Teste e Resultados..................................................................23

2.4 Programação Cônica de Segunda Ordem. ..........................................25

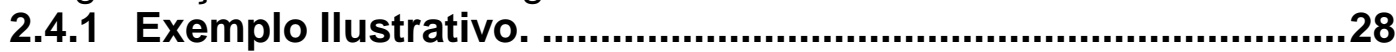

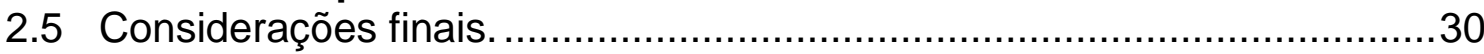

3 Modelagem Cônica de Segunda Ordem Inteira Mista ..................................31

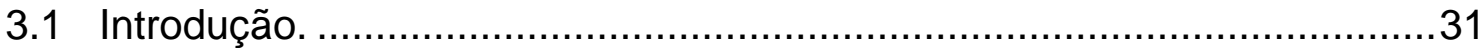

3.2 Modelo Cônico de Segunda Ordem Inteiro Misto.......................................36

3.2.1 Restrição de Corte de Carga. .....................................................38

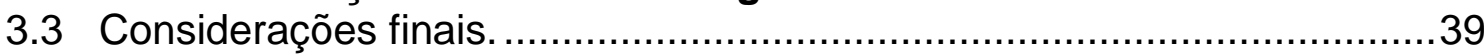

4 Resultados Numéricos ...........................................................................

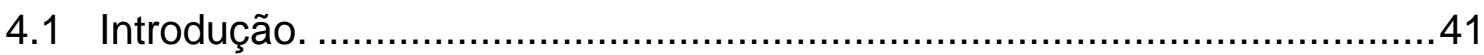

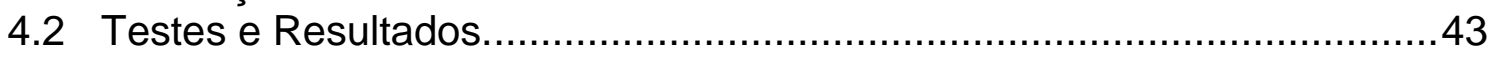

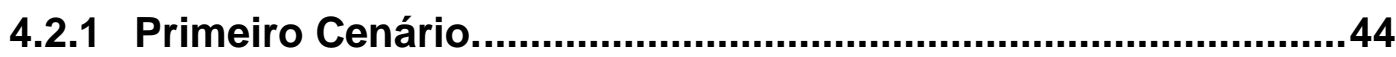

4.2.1.1 Corte de Carga de 1.000 kVA.......................................44

4.2.1.2 Corte de Carga de 2.000 kVA........................................45

4.2.1.3 Corte de Carga de 3.000 kVA.......................................47

4.2.1.4 Corte de Carga de 4.000 kVA.......................................48

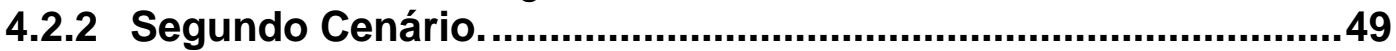

4.2.2.1 Corte de Carga de 1.000 kVA .......................................50

4.2.2.2 Corte de Carga de 2.000 kVA.......................................51

4.2.2.3 Corte de Carga de 3.000 kVA........................................53

4.2.2.4 Corte de Carga de 4.000 kVA.......................................54

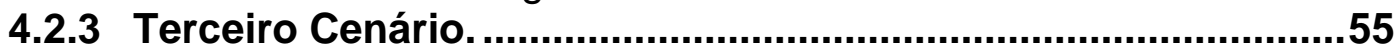


4.2.3.1 Corte de Carga 1.000 kVA. ...................................... 56

4.2.3.2 Corte de Carga 2.000 kVA. ........................................ 57

4.2.3.1 Corte de Carga 3.000 kVA. ...................................... 58

4.2.3.2 Corte de Carga 4.000 kVA.....................................60 60

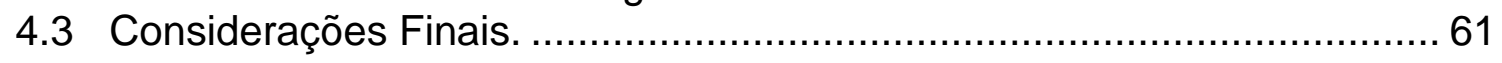

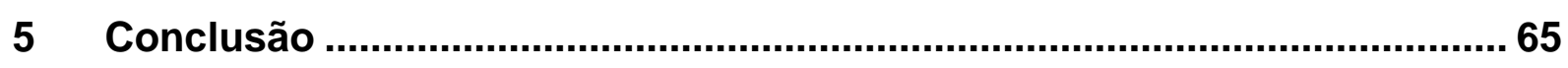

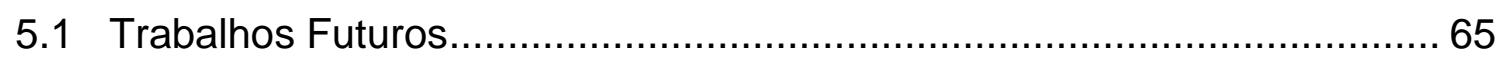

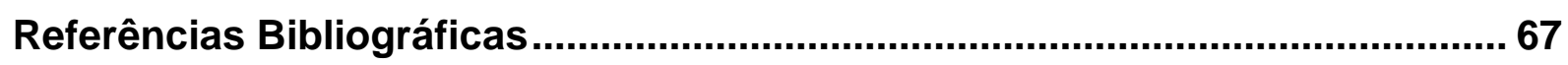

Apêndice A - Dados dos Sistemas de Distribuição. ........................................ 71

Apêndice B - Fluxograma do Programa Desenvolvido. ................................... 77 


\section{Resumo}

Cardoso, J. B. Reconfiguração Ótima para Cortes de Cargas em Sistemas de Distribuição de Energia Elétrica. Dissertação (Mestrado) - Escola de Engenharia de São Carlos, Universidade de São Paulo, São Carlos, 2016.

Neste trabalho é proposta uma modelagem matemática para a otimização do problema de corte de carga em sistemas de distribuição de energia elétrica radiais. $\mathrm{O}$ problema de corte de carga consiste em uma estratégia de reconfiguração topológica da rede elétrica para interrupção do fornecimento de energia elétrica. $O$ objetivo principal é desligar a quantidade mínima de carga do sistema, de forma a manter restrições físicas e operacionais dentro dos limites da rede elétrica. Um segundo objetivo é alterar o mínimo possível a estrutura topológica inicial do sistema. Para isso, é feita a minimização de chaveamentos. Inicialmente foi modelado como uma programação não-linear inteira mista, e transformado em uma programação cônica de segunda ordem inteira mista, que pode ser resolvida de forma eficiente usando vários solver comerciais. O modelo matemático foi implementado dentro do ambiente de programação matemática GAMS e resolvido utilizando o solver comercial CPLEX. Testes foram realizados no sistema de distribuição de 53 barras. Os resultados encontrados evidenciam a consistência e a eficiência da modelagem proposta neste trabalho.

Palavras Chave: Sistema de Distribuição de Energia Elétrica, Reconfiguração, Modelagem Matemática, Corte de Carga. 


\section{Abstract}

Cardoso, J. B. Optimal Reconfiguration to Load Shedding Distribution System of Electric Power. Dissertation (Master Degree) - School Engineering, University de São Paulo, São Carlos, 2016.

This research proposed a mathematical model to optimize the load shedding problem in radial distribution power systems. The load shedding problem consists in a topological reconfiguration strategy of the power grid in order to interrupt the power supply. The main goal is to disconnect the minimum amount of system loads while respecting the physical and operational restrictions of the grid. The second goal of this research was to modify as little as possible the initial topological structure of the system. To achieve this, a switching minimization was performed. First, the problem was modeled as a mixed integer nonlinear programming, and then it was transformed into a mixed integer second order cone programming using various commercial solvers. The mathematical model was implemented in the mathematical programming environment GAMS and solved using the CPLEX commercial solver. Tests were performed at the 53 nodes distribution system. The test results showed the consistency and efficiency of the model proposed in this dissertation.

Keywords: Electrical Power Distribution System, Reconfiguration, Mathematical Modeling, Load Shedding. 


\section{Lista de Siglas e Abreviaturas}

SDEE Sistema de Distribuição de Energia Elétrica

DISTOP Distribution Network Optimization

PAO Preserve Ancestor Operator

CAO Change Ancestor Operator

MAS Multi-Agent System

GE Geração Eólica

PSO Particle Swarm Optimization

PRODIST Procedimentos de Distribuição de Energia Elétrica no Sistema Elétrico Nacional

GAMS General Algebraic Modeling System

ANEEL Agência Nacional de Energia Elétrica.

ONS Operador Nacional do Sistema Elétrico.

MQ Mínimos Quadrados.

PQ Programação Quadrática.

PC Programação Cônica.

PCSO Programação Cônica de Segunda Ordem.

PNLIM Problema Não-Linear Inteiro Misto.

PCSOIM Problema Cônico de Segunda Ordem Inteiro Misto. 


\section{Lista de Figuras}

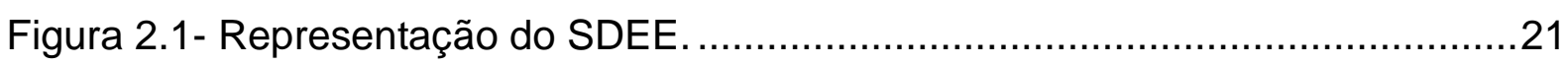

Figura 2.2 - Diagrama unifilar do sistema 53 barras.............................................24

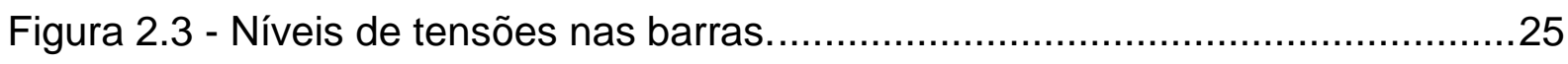

Figura 2.4 - Magnitude de corrente nos ramos...............................................26

Figura 2.5 - Sistema composto de dois nós e um circuito. ......................................28

Figura 2.6 - Representação das restrições (24) e (25).........................................29

Figura 4.1 - Estrutura inicial do sistema de 53 nós..................................................42

Figura 4.2 - Corte de carga de 1.000 kVA sem prioridade e minimização de chaveamento.

Figura 4.3 - Corte de carga de 2.000 kVA sem prioridade e minimização de chaveamento.

Figura 4.4 - Corte de carga de 3.000 kVA sem prioridade e minimização de chaveamento.

Figura 4.5 - Corte de carga de 4.000 kVA sem prioridade e minimização de chaveamento.

Figura 4.6 - Corte de carga de 1.000 kVA com minimização de chaveamento e sem prioridade.

Figura 4.7 - Corte de carga de 2.000 kVA com minimização de chaveamento e sem prioridade.

Figura 4.8 - Corte de carga de 3.000 kVA com minimização de chaveamento e sem prioridade.

Figura 4.9 - Corte de carga de 4.000 kVA com minimização de chaveamento e sem prioridade.

Figura 4.10 - Corte de carga de 1.000 kVA com prioridade e minimização de chaveamento.

Figura 4.11 - Corte de carga de 2.000 kVA com prioridade e minimização de chaveamento.

Figura 4.12 - Corte de carga de 3000 kVA com prioridade e minimização de chaveamento. 
Figura 4.13 - Corte de carga de 4.000 kVA com prioridade e minimização de

Figura B.1 - Fluxograma do programa desenvolvido no GAMS. 


\section{Lista de Tabelas}

Tabela 2.1 - Capacidade das subestações. ......................................................26

Tabela 4.1 - Conjunto das chaves aberta e fechadas. .........................................50

Tabela 4.2 - Pesos para prioridade dos nós de carga.............................................56

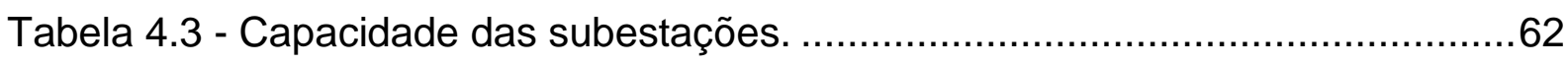

Tabela 4.4 - Número de chaveamento para cada cenário de corte de carga............63

Tabela A.1 - Dados relacionados aos cabos......................................................

Tabela A.2 - Capacidade de Carregamento das Subestações .................................71

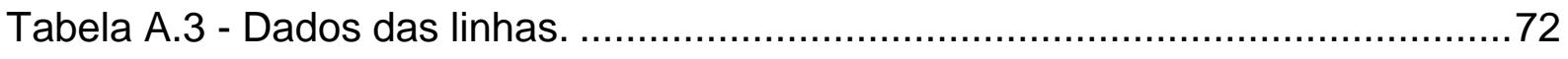

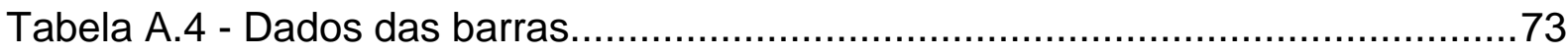

Tabela A.5 - Dados das impedâncias das linhas..................................................73 


\section{Lista de Símbolos}

\section{Conjuntos:}

$\Omega_{l} \quad$ Conjunto dos ramos.

$\Omega_{b} \quad$ Conjunto dos nós.

$\Omega_{a a} \quad$ Conjunto das chaves abertas.

$\Omega_{a f} \quad$ Conjunto das chaves fechadas.

$\Omega_{h} \quad$ Conjunto dos circuitos fictícios.

\section{Variáveis:}

$P_{i j} \quad$ Fluxo de potência ativa no ramo $i j$.

$Q_{i j} \quad$ Fluxo de potência reativa no ramo $i j$.

$I_{i j}^{s q r} \quad$ Quadrado da magnitude do fluxo de corrente no ramo $i j$.

$P_{i}^{G} \quad$ Geração de potência ativa no nó $i$.

$Q_{i}^{G} \quad$ Geração de potência reativa no nó $i$.

$V_{i}^{s q r} \quad$ Quadrado da magnitude de tensão no nó $i$.

$a_{i j} \quad$ Variável auxiliar usada na modelagem no estado do ramo $i j$.

$H_{i j} \quad$ Fluxo de potência artificial no ramo $i j$.

$H_{i}^{G} \quad$ Geração de potência artificial no nó $i$.

$\vec{V}_{i} \quad$ Fasor tensão no nó $i$.

$\vec{I}_{i j} \quad$ Fasor corrente no ramo $i j$.

$I_{i j}^{2} \quad$ Quadrado da magnitude da corrente no ramo $i j$.

$\theta_{i} \quad$ Ângulo de fase da barra $i$.

$V_{i}^{2} \quad$ Quadrado da magnitude de tensão no nó $i$.

ST Potência aparente total. 
$I_{i j}^{2} \quad$ Quadrado da magnitude de corrente no ramo $i j$.

\section{Constantes:}
$\alpha_{i}$
Prioridade de desconexão de carga.
$\beta_{i j}$
Parâmetro relacionado com os interruptores normalmente aberto.
$\mu_{i j}$
Parâmetro relacionado com os interruptores normalmente aberto.
$P_{i}^{D} \quad$ Demanda de potência ativa no nó $i(\mathrm{~kW})$.
$Q_{i}^{D} \quad$ Demanda de potência reativa no nó $i(\mathrm{kVAr})$.
$R_{i j} \quad$ Resistência do circuito $i j(\Omega)$.
$X_{i j} \quad$ Reatância do circuito $i j(\Omega)$.
$\overline{I_{i j}} \quad$ Corrente máxima do circuito $i j(\mathrm{~A})$.
V $\quad$ Limite mínimo de Tensão $(\mathrm{kV})$.
$\bar{V} \quad$ Limite máximo de Tensão $(\mathrm{kV})$. 


\section{Introdução}

No dia 19 de janeiro de 2015, ocorreu um apagão de grandes proporções que suspendeu o fornecimento de energia em onze estados brasileiros e no Distrito Federal. Os estados atingidos foram: São Paulo, Minas Gerais, Rio de Janeiro, Santa Catarina, Rio Grande do Sul, Paraná, Goiás, Espírito Santo, Mato Grosso, Mato Grosso do Sul, Rondônia e Distrito Federal. Em algumas localidades a suspensão do fornecimento de energia durou até duas horas, de acordo com (BORBA et al., 2015).

Segundo, ("Boletim Mensal de Monitoramento do Sistema Elétrico Brasileiro", 2015), o Sistema Interligado Nacional (SIN) possuia condições favoráveis a geração, até mesmo com folga de geração. Porém, conforme ("Boletim Mensal de Monitoramento do Sistema Elétrico Brasileiro", 2015) surgiram problemas nas restrições de transferência de energia das regiões Norte e Nordeste para o Sudeste, e não foi esclarecido se essas restrições foram problemas nas linhas de transmissão ou em subestações. O aumento da demanda no horário de pico devido ao forte calor, adicionado ao problema de transferência de energia provocou redução na frequência de operação do sistema.

Devido à queda na frequência do sistema, ocorreu a perda de unidades geradoras: Angra I, Volta Grande, Amador Aguiar II, Sá Carvalho, Guilman Amorim, Canoas II, Viana e Linhares, Cana Brava, São Salvador e Governador Ney Braga totalizando 2.200 MW. Com isso, a frequência elétrica caiu a valores da ordem de 59 $\mathrm{Hz}$, quando o normal é $60 \mathrm{~Hz}$, segundo Operador Nacional do Sistema Elétrico (ONS). 
A ONS impôs uma ordem as distribuidoras para que as mesmas efetuassem o desligamento de cargas. Algumas delas divulgaram a quantidade de energia, por exemplo: a Eletropaulo realizou um corte de carga em mais de $700 \mathrm{MW}$, a CPFL cortou aproximadamente $800 \mathrm{MW}$, a AES Sul cortou $172 \mathrm{MW}$, a Copel efetivou um corte de $320 \mathrm{MW}$. Outras companhias não divulgaram a quantidade de cargas que foram cortadas.

No entanto, aconteceram situações em que os desligamentos de cargas não foram feitos de forma correta, conforme o módulo 4 do Procedimento de Distribuição de Energia Elétrica no Sistema Elétrico Nacional (PRODIST), que estabelece:

"As distribuidoras devem definir critérios para classificação e priorização das unidades consumidoras, para fins de controle de carga, respeitadas as cargas de serviços essenciais na forma da regulamentação", ou seja, não houve uma prioridade para desligamento das mesmas."

Como exemplos, há o desligamento da Unidade Básica Distrital de Saúde (UBDS) em Ribeirão Preto - SP. Na mesma região, o Hospital São Francisco e a maternidade Sinhá Junqueira também tiveram seu fornecimento de energia suspenso. Apesar da não ocorrência de problemas maiores, na maior cidade do país, São Paulo - SP, a suspensão de energia foi a de maior impacto, pois realizou a interrupção de energia no transporte público (metrô), causando transtornos à população que depende dele para sua locomoção (BORBA et al., 2015).

Diante da indecisão de quais cargas devem ter seu fornecimento de energia interrompido, situações como esta abrem espaço para novas linhas de pesquisa aplicadas ao sistema elétrico de potência (SEP). Uma maneira de tratar este tipo de problema é a reconfiguração do sistema de distribuição de energia elétrica (SDEE), pois alterando-se a topologia da rede durante o período de sobrecarga, pode-se 
minimizar os efeitos do corte de carga. Muitos trabalhos envolvendo o SDEE têm sido desenvolvidos, tratando o problema do corte de carga para o restabelecimento da energia. Nesse sentido esses trabalhos se combinam (WEI et al., 2012), (GOUIN; ALVAREZ-HERAULT; RAISON, 2015), (SOUZA, 2009). A reconfiguração de SDEE tem sido uma grande fonte de estudos, dado que pode ser aplicada a diversos problemas relacionados ao SDEE. Dentre eles destacam-se a aplicação à redução de perdas, restauração do SDEE devido às contingências ou manutenções preventivas e estudos de confiabilidade. No entanto, no Brasil, o corte de carga tem sido utilizado como solução para situações de sobrecarga.

Este trabalho tem por objetivo reconfigurar o SDEE, de forma a atender ao corte de carga em ocasiões de sobrecarga ou por imposição de órgãos reguladores. Porém, deve-se colocar em evidência que a metodologia desenvolvida não tem por finalidade obter uma ferramenta capaz de solucionar todo este problema, de forma que a resposta seja absoluta, mas abrir espaço para um grande debate sobre o tema. Uma vez que o tema é um tanto delicado, pois envolve fatores que não são meramente matemáticos, como exemplo, o político.

Os SDEE, em sua maioria, operam de maneira radial, com o propósito de evitar problemas com a coordenação da proteção e atenuação de correntes de curtocircuito. No entanto, a estrutura radial pode resultar em problemas do ponto de vista operacional, como por exemplo, desligar cargas sem necessidade. Por este e outros motivos, os SDEE são sistemas malhados, com operação radial. Isso faz com que, alternativas para o fornecimento de energia em situações de contingências ou sobrecargas sejam possíveis, através de manobras de isolamento do defeito ou corte de carga, com provável ilhamento de cargas. 
O objetivo da reconfiguração de rede de distribuição elétrica é buscar uma nova topologia para atender a um determinado objetivo. Isto é feito atuando sobre chaves já existentes no sistema, ou seja, abrindo-as/fechando-as para transferir as demandas do sistema entre os diferentes alimentadores, o que se torna um atrativo para empresas do ramo, pois os investimentos são baixos. Além disso, a reconfiguração também pode se concentrar na redução das perdas de energia do sistema, equilibrar a carga entre os alimentadores, restaurar cargas que foram desligadas por uma falta acidental ou realizar corte de carga quando o sistema se encontrar em situação de elevado estresse. Portanto, a execução de uma reconfiguração pode proporcionar soluções para situações de emergência, bem como condições para aumentar a confiabilidade, qualidade e níveis de operação de segurança.

Geralmente, o problema de reconfiguração pode ser definido como um problema de otimização, que consiste em encontrar uma configuração que maximize/minimize uma determinada função objetivo sujeita a um conjunto de restrições como limites de tensão nos nós do SDEE, limites de correntes dos circuitos, balanço de potências ativa e reativa, operação radial do SDEE, dentre outras.

Entre as muitas funções objetivos possíveis estão a minimização das perdas de potência ativa ou minimização do corte de carga. Este é um problema de difícil solução, uma vez que o número de configurações candidatas cresce exponencialmente, com o número de chaves disponíveis, levando a uma explosão combinatória e um esforço computacional impraticável para atingir a configuração ótima. Muitos métodos heurísticos/meta-heurísticos têm sido propostos na literatura. Eles costumam encontrar soluções de qualidade (PEPONIS, 1995),(LAVORATO et al., 2012). 
Neste trabalho será proposta uma metodologia para reconfiguração de sistemas de distribuição a partir de algoritmos de otimização. A proposta deste trabalho visa realizar um corte de carga através da reconfiguração, quando o sistema estiver em condições de sobrecarga ou por imposição das agências reguladoras. Além do mais, deverá ser considerada a prioridade das cargas a serem desligadas, por exemplo, hospitais, transportes público terão prioridade sobre indústrias em geral, que, por conseguinte, terão prioridade sobre prédios residenciais e comerciais.

\subsection{Histórico do Problema de Reconfiguração}

Nesta seção foram apresentados artigos, dissertações e teses que abordaram problemas do sistema de distribuição de energia elétrica, em que a reconfiguração foi utilizada como ferramenta para solução. Nestes trabalhos verificou-se que a reconfiguração foi aplicada de diversas maneiras para otimizar determinado objetivo, como por exemplo, perdas de energia, restauração de cargas e corte de carga.

\subsubsection{Reconfiguração do Sistema de Distribuição de Energia Elétrica para Perdas Ativas.}

$\mathrm{Na}$ década de 80 surgiu um dos primeiros trabalhos envolvendo reconfiguração. (Merlin e Back 1975) desenvolveram pesquisas que abrangeram a minimização de perdas de energia através da reconfiguração de sistemas de distribuição de energia elétrica. Um algoritmo heurístico foi utilizado e nele considerava-se que todas as chaves do sistema estavam inicialmente fechadas, fazendo com que o sistema se tornasse malhado. A técnica para encontrar as soluções iniciou-se com a abertura das chaves que possuíssem os menores valores de perdas nos ramos, após serem submetidas a um processo de avaliação através do fluxo de carga. Essa ação repete-se até obter uma topologia radial para o sistema. 
Com o objetivo de reduzir a perda de energia em alimentadores de distribuição, (CINVALAR et al., 1988) propuseram um método heurístico conhecido como branch-exchange. Partindo-se de uma topologia radial, a estrutura era alterada fechando-se uma chave e abrindo-se outra, para que se fosse sempre mantida a configuração radial. Uma técnica para evitar que se tivesse um número abundante de operações de abertura e fechamento, baseou-se na estimação de perdas para as chaves abertas, de modo que se eliminasse casos que não produzissem a redução de perdas de energia.

Para minimizar as perdas nas linhas, (SHIRMOHAMMADI; HONG, 1989) descreveram um método heurístico baseado em (Merlin \& Back 1975), porém sem as desvantagens apresentadas no método utilizado como referência. $O$ algoritmo inicialmente fechava todas as chaves, convertendo o sistema radial em malhado. $A$ partir dessa nova topologia, todas as chaves fechadas funcionavam como fontes de corrente fictícias. Adiante foi realizado o fluxo ótimo e a chave com valor de corrente menor foi aberta até que se tivesse uma estrutura radial. Para simulação do problema utilizou-se o Distribution Network Optimization (DISTOP), pois dessa forma eliminavase os limites de tensão. Posteriormente, essa metodologia foi melhorada por (GOSWAMI; BASU, 1992).

Com o intuito de minimizar as perdas dos alimentadores, (MANTOVANI; CASARI; ROMERO, 2000) propuseram um algoritmo heurístico que realizava a reconfiguração de redes de distribuição de energia para obter um conjunto de configurações. A queda de tensão neste trabalho foi utilizada como classificador de configuração, ou seja, as configurações que não obedecessem qualquer restrição eram descartadas e, caso contrário, incluídas no conjunto de possíveis soluções. E para diminuir o esforço computacional foi implementado e validado um método de 
cálculo de fluxo de carga, um método aproximado semelhante a (BARAN; WU, 1989). A perda mínima foi obtida com o auxílio das seguintes restrições: níveis de tensão, confiabilidade, balanço de carga, variáveis inteiras e reais e radialidade, e esta última foi baseada nos conceitos de inteligência artificial e busca em árvore de decisão (1 em 1, 2 em 2 até $\mathrm{n}$ em $\mathrm{n}$, onde n é o número de alimentador).

Para reduzir as perdas ativas em SDEE sem infringir as restrições impostas, (PEREIRA, 2010) propôs uma nova abordagem para a reconfiguração de sistema de distribuição de energia. Um algoritmo baseado no comportamento de colônia de formigas foi usado para determinar a melhor topologia. Para o estudo do fluxo de potência, a metodologia usada foram os métodos clássico de Newton e Gauss, porém em SDEE existe um problema devido à alta relação entre a resistência e reatância $(r / x)$ podendo o sistema, às vezes, não convergir. Para isso, é feita uma associação entre o método de Newton e da função penalidade, que soluciona o problema de mal condicionamento da matriz Jacobiana. A validação da nova abordagem foi testada em sistemas de 5, 16, 33, 69 e 136 barras, e os resultados foram eficazes ao se comparar com metodologias existentes na literatura.

(RUPOLO, 2013) baseou-se na metaheuristica busca dispersa para reconfigurar o sistema de energia elétrica e reduzir as perdas ativas nos alimentadores. Este trabalho foi implementado em linguagem $\mathrm{C}++$ e foram usados dois modelos de cargas: constante e exponencial, sendo este de forma mais realista. A metodologia foi modelada baseada em um problema não-linear inteiro misto e foram consideradas as seguintes restrições: confiabilidade, níveis de tensão, fluxo de corrente máxima nos ramos, fluxo de potência ativa nos alimentadores e radialidade. Para contornar a restrição de radialidade utilizou-se a estrutura denominada representação nó profundidade, com o auxílio dos operadores Preserve Ancestor Operator (PAO) e 
Change Ancestor Operator (CAO), que permitem gerar soluções sempre radiais. Para o fluxo de carga, utilizou-se o método de varredura forward/backward de (SHIRMOHAMMADI; HONG, 1989), por ser mais indicado para este tipo de sistema. O modelo foi validado com testes realizados em sistemas de 14, 84, 136 e 202 barras. Os resultados obtidos foram eficientes, pois foram capazes de atender as restrições impostas ao sistema.

Poucas referências na literatura abordam a técnica de otimização clássica aplicada em problema de reconfiguração de SDEE. (ROMAIS, 2013) desenvolveu um modelo cônico de segunda ordem para solucionar o problema de perda de energia em SDEE. Neste trabalho são apresentadas todas restrições pertinentes a uma formulação de um problema do sistema de distribuição, porém, o que distingue a modelagem cônica de modelos não-lineares é que a equação de igualdade não-linear é transformada em uma equação de desigualdade. Além disso, o problema foi solucionado por solver comercial, que, neste caso, foi o CPLEX e implementado na linguagem AMPL. Os resultados foram testados em sistemas de 33, 70, 136, 202 e 400 barras e foram eficazes quando comparados com outras técnicas já existentes.

\subsubsection{Reconfiguração do Sistema de Distribuição de Energia Elétrica para Restauração.}

Nesta seção serão apresentadas metodologias que foram utilizadas para solucionar problemas que ocorrem no sistema de distribuição de energia elétrica, como por exemplo: falhas acidentais causadas por fenômenos naturais, manutenção do sistema, alimentadores sobrecarregados, etc.

(AOKI et al., 1989) propuseram um novo algoritmo que realiza a transferência de cargas desenergizadas para outros alimentadores em etapas. Inicialmente, todas as cargas desenergizadas são transferidas para alimentadores que estão na mesma 
região. Diante disso, foi feita a implementação, de modo que, na primeira fase as cargas são transferidas do alimentador principal aos alimentadores de primeira fase. $\mathrm{Na}$ segunda fase, foram transferidas dos alimentadores de primeira fase a outros alimentadores secundários. O Corte de carga também é considerado quando se torna impossível transferir todas as cargas desenergizadas para outros alimentadores, sem causar violações das restrições no sistema. O algoritmo desenvolvido consiste de quatro etapas. Na primeira etapa as cargas desenergizadas, que estão em uma área isolada, são conectadas a um alimentador mais próximo. Na segunda etapa se analisa as restrições de funcionalidade imposta, que são: radialidade, queda de tensão e limite de capacidade da linha. Mas nessa fase há ainda uma divisão de mais duas fases, a primeira buscou eliminar as violações dos limites de operação, devido ao acréscimo de carga, a segunda realizou uma transferência de carga mais refinada, porém se ao fim dessa fase ainda existirem violações, as cargas serão desligadas na terceira fase. E na última fase foi feita uma tentativa de transferir as cargas que foram desligadas na fase anterior. A convergência deste método é feita com o auxílio do método gradiente efetivo dual. Para validar o método proposto foram realizados testes para sistemas de pequeno e grande porte, e os resultados foram eficientes quando comparado com resultados encontrados na literatura.

(NAGATA et al., 2000) propuseram um método baseado na abordagem de programação matemática. A metodologia usada foi dividida em duas fases. Cada fase foi modelada como programação não-linear inteira mista e inserido o custo operacional da restauração de cada ramo. Isto foi feito para tornar o algoritmo mais eficaz. Na primeira fase, foi maximizada a quantidade de energia disponível para o serviço da rede e foram consideradas as seguintes restrições de operação do SDEE: radialidade, limite da capacidade de geração e balanço de potência. Com o resultado 
da fase anterior, iniciou-se a outra fase, que determina o mínimo de carga não suprida da região sem fornecimento de energia, obedecendo as mesmas restrições anteriores. Contudo, no balaço de potência foi acrescentado uma variável binária que identifica quais cargas devem ser desligadas ou devem permanecer ligadas. Após encontrar a solução ótima do sistema, o próximo passo foi determinar a sequência de operação para restauração, dessa forma, fornecendo energia as cargas que não tem necessidade de permanecerem desligadas. A metodologia foi capaz de obter uma configuração ótima em todos os casos. Além disso, o tempo de computação obteve uma redução percentual considerável ao se comparar com métodos disponíveis na literatura.

Segundo, (GHORBANI; CHOUDHRY; FELIACHI, 2014) um Multi-Agent System (MAS) foi desenvolvido para estabelecer a energia para cargas de alta prioridade após a ocorrência de alguma interrupção, seja ela acidental ou por ordem técnica. Depois da falha ser descoberta, MAS tenta encontrar a reconfiguração ideal para re-energizar as zonas livres de problemas encontrados no sistema. Mesmo com ajuda de sistemas de geração eólica (GE), disponibilizando mais energia, ainda torna o problema mais complicado, pois essas gerações são de natureza estocástica. Quando há potência disponível suficiente faz-se o processo de otimização de restauração, transferindo as cargas para alimentadores, caso contrário, é feita uma estimação com métodos de modelos fuzzy para o corte de carga. A partir de simulações, o algoritmo proposto foi capaz de tomar decisões para que a quantidade mínima de carga de alta prioridade não fosse desligada.

Em (ROMERO et al., 2015) desenvolveu-se um modelo matemático para resolver o problema de restauração em SDEE radiais. O modelo original é um problema de programação não-linear inteira mista. No entanto, este modelo é 
transformado em um problema de programação cônica de segunda ordem inteira mista. A principal importância na função objetivo é encontrar a maior demanda possível para restaurar o sistema e, se necessário, abrir/fechar chaves, que podem ser manuais ou automáticas. As chaves automáticas têm prioridade sobre as manuais. As seguintes restrições foram consideradas: balanço de potência, limites operacionais tanto de tensão como de corrente e radialidade. Para atender a essa última restrição, foi desenvolvida uma modelagem de subestação fictícia, que tem por finalidade manter a radialidade das cargas desligadas. Esta modelagem é feita de modo que a região que sofre alguma falta será atendida por completo ou desconectada por completo, sem desconexão parcial, porém priorizando a desconexão de demandas mais baixas. Os resultados foram comparados com outros algoritmos propostos anteriormente. Estes mostram que o modelo matemático é robusto, eficiente, flexível e apresenta excelente desempenho na busca de soluções ótimas.

\subsubsection{Reconfiguração do Sistema de Distribuição de Energia Elétrica para Corte de Carga.}

A maior parte das publicações que abordaram o assunto corte de carga estão relacionadas com a eliminação da sobrecarga através do monitoramento da magnitude de frequência e tensão das barras do sistema, gerando ações de chaveamento automatizadas ou manuais nos sistemas de transmissão e distribuição. O corte de carga realizado de forma automática busca manter a estabilidade do sistema elétrico. Nessa área de pesquisa, diversos trabalhos se combinam (REPORT, 1955), (GREWAL; KONOWALEC; HAKIM, 1998),(CUTSEM; MOORS; LEFEBVRE, 2002), (RAO; RAO, 2003), (ANDERSSON et al., 2004) e(PARNIANI; NASRI, 2006).

Diferente do que é esperado, em que o corte de carga é aplicado na sua grande maioria no SDEE, existem trabalhos bastantes dinâmicos voltados para 
execução de corte de carga em sistemas industriais. (SHOKOOH et al., 2005) aplicaram um sistema digital inteligente com armazenamento e processamento de dados de modo que possam antever situações de sobrecarregamento e realizar o corte de carga.

Outro caso foi apresentado por (CHEN et al., 2011), que buscaram restaurar o estado estável da rede devido a uma falta. O sistema que conta com geração eólica (GE) tem por objetivo efetuar o desligamento de carga de pouca prioridade conforme as cargas do alimentador e a velocidade do vento, de maneira a não deixar que a GE dispare devido a sub frequência.

Ao contrário dos trabalhos anteriores, alguns métodos abordados na literatura serão mostrados a seguir, com outras frentes: metas de continuidade cobradas pelo órgão regulador, custo da interrupção para os consumidores e controle de tensão e de níveis de carregamento.

Com o intuito de avaliarem o desempenho de confiabilidade do SDEE, (A. M. LEITE DA SILVA, A.M. CASSULA, R. BILLINTON, 2001) apresentaram uma nova metodologia que consideram diferentes prioridades da limitação de carga entre alimentadores. O melhor desempenho que apresentasse os custos mínimos de interrupção seria contabilizado como uma opção, além de obedecer às normas e indicadores envolvidos na distribuição de energia. Dependendo das características do sistema de geração, transmissão e distribuição integrada, pode-se optar por uma alternativa que não produz o menor custo da interrupção, mas que privilegia outro parâmetro, como por exemplo, frequência de falhas e duração, necessárias para o funcionamento de determinados processos.

(GAULKE, 2007), propôs desenvolver uma metodologia para otimização multicritério das ações de corte de carga, cujo o objetivo era trazer melhoria na 
qualidade do fornecimento aos consumidores e ganhos da concessionária em sistemas de distribuição de energia elétrica. Ou seja, realizou um procedimento para corte de carga que estabeleceu de forma otimizada quais alimentadores devem ser desligados, para se reduzir a demanda solicitada pela operação na região delimitada. A função objetivo deste trabalho consiste na minimização da demanda desconectada considerando as restrições de balanço de potência e limites de geração. A partir dos dados dos alimentadores, foi feita uma análise da quantidade de demanda ativa que precisa ser reduzida no sistema para que possa ser obtida uma solicitação de corte de carga. Neste ponto, a metodologia apresentou dois módulos independentes: o primeiro realizou uma regulação de tensão de modo que o conjunto das possíveis cargas a serem cortadas fosse reduzido, e não realizando o desligamento de cargas desnecessariamente. Já o segundo, executou a otimização propriamente dita das ações de corte de carga, indicando o conjunto de alimentadores que devem ser desligados para se completar o corte solicitado. Neste módulo se utilizou a ferramenta de inteligência artificial e o algoritmo genético para otimização multicritério. Para validar a metodologia adotada foram executados alguns testes com dados reais de sistemas distribuição de energia, que demonstraram a eficácia da metodologia desenvolvida e os ganhos conseguidos com a sua aplicação.

Em (WANG; BILLINTON, 2000), descreveu-se uma técnica para minimizar o corte de carga sujeito as restrições de segurança do sistema, tendo em vista a ocorrência de uma falta. Para isso desenvolveram uma função objetivo que considera o corte de carga. Também se abordou o mínimo custo de interrupção para os clientes.

Seguindo a mesma ideia do trabalho anterior e com o intuito de obter o menor custo e diminuir a quantidade de alimentador durante uma situação de emergência, (WANGDEE; BILLINTON, 2005) desenvolveram um algoritmo que determina a 
prioridade dos alimentadores que devem ser desligados. Para isso, foi utilizada uma taxa de avaliação de tempo dependente de energia interrompida. Cada alimentador é dependente de um parâmetro designado como índice de prioridade custo-alimentador. Sendo esse índice dividido em duas categorias. Uma é o índice de prioridade de elevado custo, que representa o dia; a outra é o índice de prioridade de baixo custo, que representa a noite. Então, esse critério adotado é adequado para determinar o conjunto de corte de carga ótimo para uma situação crítica específica, em que o alimentador, ou o conjunto deste, está com alguma deficiência.

Os temas controle de tensão e níveis de carregamento da rede estão muito ligados, uma vez que, se o sistema estiver sobrecarregado, se afeta negativamente os níveis de tensão nos barramentos e vice-versa. Com legislação rígida sobre os níveis de tensão, unidades distribuidoras devem se atentar a esse fato, já que a agência reguladora, no caso do Brasil, a ANEEL, pode aplicar severas punições.

Em (JALILZADEH; HOSSEINI; DERAFSHIAN-MARAM, 2010), se fez o uso de uma combinação de métodos heurísticos como Análises Modal e Particle Swarm Optimization (PSO) para minimizar o corte de carga. Além disso, se realizou um melhoramento no perfil de tensão e na margem de estabilidade. A análise Modal é um método que tem por finalidade realizar a avaliação estática da estabilidade de tensão, por isso foi aplicada, pois esta determina as características das tensões. Com isso, se disponibilizou o quanto de carga deve ser desligada. Tendo como base o índice acima mencionado, bem como perfil de tensão e margem de estabilidade, pode ser calculado a aplicação de um problema de otimização multi-objetivo baseado no PSO. Testes com sistemas reais foram realizados e os resultados se mostraram eficientes ao serem comparados com os resultados da literatura. 
(PANASETSKY et al., 2014) propuseram um novo algoritmo inteligente para realizar o corte de carga, para eliminar a sobrecarga nas redes de distribuição de energia. $\mathrm{O}$ algoritmo proposto manteve um balanço entre a complexidade e a precisão das ações de controle, e proporcionou um elevado nível de tolerância a falhas e uma elevada velocidade no diagnóstico.

\subsection{Motivação do Trabalho.}

Devido a fatores climáticos que ocorreram em 2015 no Brasil, a disponibilidade de energia elétrica foi diminuída. O calor excessivo neste mesmo ano contribuiu para a elevação do consumo de energia, de tal forma que o horário de pico de demanda, que antes era no início da noite, mudou-se para o meio do período vespertino.

O que este trabalho irá contribuir, resulta do seu foco no estado da arte, visando o desenvolvimento de tecnologias capazes de atender à crescente demanda por energia elétrica. De fato, o constante surgimento de sobrecarga do sistema faz com que seu estado de funcionamento opere fora dos limites estabelecidos pelos órgãos regulamentadores, necessitando assim de uma ferramenta dinamicamente adaptável a situações de corte de carga.

Com isso, os surgimentos desses fatos apresentam desafios acerca de quais alimentadores devem ser desligados e quais tipos de unidades consumidoras devem ter seu fornecimento suspenso. Nesse contexto, uma técnica de otimização clássica assume um papel importante para minimizar a quantidade de energia não suprida. Neste trabalho, investigamos a interrupção de carga realizada propositalmente, uma vez que, $\S 3^{\circ}$ do artigo $6^{\circ}$ da lei 8987/1995, diz "Não se caracteriza como 
descontinuidade do serviço a sua interrupção em situação de emergência ou após prévio aviso".

Ao longo desta dissertação, serão simuladas algumas implementações de sistemas de distribuição de energia elétrica radial, realizando-se o corte de carga para que o sistema funcione dentro dos limites operacionais e seu desempenho seja avaliado. Os objetivos gerais do trabalho consistem no estudo e implementação da técnica de otimização de energia não suprida. Já os objetivos específicos, podem ser definidos como:

1) Estudo do fluxo de carga em sistema de distribuição de energia elétrica com mais de uma subestação;

2) Estudo das técnicas de otimização clássica aplicada a SDEE para corte de carga;

3) Análise do corte de cargas com maior e menor prioridade e

4) Análise da minimização de comutação de chaves.

\subsection{Organização.}

O trabalho está organizado em cinco capítulos. Desta forma, o Capítulo 1 é direcionado a introduzir o tema desta pesquisa, estudo de metodologias presentes na literatura, bem como a apresentar as motivações e justificativas que levaram a realização da pesquisa.

O Capítulo 2 destina-se a descrever a formulação de um problema de otimização para uma modelagem não-linear utilizada para calcular o ponto de operação em regime permanente de um sistema de distribuição radial. Ainda neste capítulo são realizadas as primeiras simulações para comprovar esta metodologia e a descrição da programação cônica de segunda ordem. 
No capítulo 3 é proposta a modelagem adotada para a realização do corte de carga. Inicialmente, descreve-se a programação não-linear inteira mista do problema proposto, tal como sua transformação em uma programação cônica de segunda ordem inteira mista e a restrição necessária para o corte de carga.

No Capítulo 4 são apresentados os resultados numéricos das simulações computacionais para a modelagem proposta. Três cenários de estudo de corte de carga são apresentados visando comprovar a eficiência e consistência do modelo matemático.

Por fim, o Capítulo 5 fornece as conclusões obtidas deste trabalho e propõe, em linhas gerais, alguns trabalhos futuros. 


\section{Fluxo de Carga e o Problema Cônico de Segunda Ordem}

Neste capítulo, é apresentado o sistema de equações não-lineares utilizado para determinar o estado estacionário de um sistema de distribuição radial, além de se abordar os principais aspectos teóricos que consolidam um problema de programação cônico de segunda ordem.

\subsection{Introdução.}

A análise do fluxo de carga em sistemas de distribuição de energia é uma ferramenta que permite obter várias informações relevantes, como por exemplo: as magnitudes de tensão, os ângulos em fases de todos os nós, os fluxos de potências ativa e reativa, a magnitude de corrente nos circuitos, perdas de potência ativa e reativa, dentre outras grandezas elétricas.

A formulação de um problema de FC foi desenvolvida a partir de um conjunto de equações algébricas não-lineares (MONTICELLI, 1983). O desenvolvimento do estudo do FC foi baseado no Método de Newton, sendo gerados muitos algoritmos para resolver este tipo de problema, em específico nas versões desacopladas, utilizados basicamente em sistemas de transmissão de energia elétrica.

A utilização destes métodos em SDEE deve ser usada com ressalvas, pois estes apresentam características muito peculiares: Eles operam de forma radial, apesar de apresentarem estrutura malhada, não exibindo laços ou malhas, o que constitui uma vantagem, pois torna o problema de FC mais fácil de ser resolvido e 
melhora a coordenação da proteção. $E$, alguns SDEE, apresentam uma relação $R / X$ muito elevada quando comparados com valores típicos encontrados nos sistemas de transmissão e sub-transmissão. Essa é uma desvantagem, pois os métodos desenvolvidos para sistema de transmissão podem apresentar resultados inconclusivos, ou seja, resultados que de fato representem FC.

\subsection{Formulação do Fluxo de Carga para SDEE.}

A maioria dos estudos de FC, para sistemas de distribuição, tem normalmente utilizado a técnica chamada de varredura de (SHIRMOHARMNADI et al., 1988), com o intuito de representar o funcionamento estático de um sistema de distribuição de energia. Diante disto, as relações a seguir serão formuladas com base em demandas de potências constantes e o sistema é representado pelo seu monofásico equivalente.

Na Figura 2.1 têm-se os termos $\vec{V}_{i}$ e $\vec{I}_{i j}$ que representam os fasores tensão do nó e corrente no circuito, respectivamente. $R_{i j} I_{i j}^{2}$ e $X_{i j} I_{i j}^{2}$ representam as perdas de potências ativa e reativa do circuito, respectivamente.

A partir do circuito $i j$, como é mostrado na Figura 2.1, a queda de tensão é definida pela lei de Ohm em (1), sendo $\Omega_{l}$ o conjunto dos ramos.

$$
\vec{V}_{i}-\vec{V}_{j}=\vec{I}_{i j}\left(R_{i j}+j X_{i j}\right) \quad \forall i j \in \Omega_{l}
$$

A corrente $\vec{I}_{i j}$ de cada circuito está representada em (2).

$$
\vec{I}_{i j}=\left(\frac{P_{i j}+j Q_{i j}}{\vec{V}_{j}}\right)^{*} \quad \forall i j \in \Omega_{l}
$$

Substituindo (2) em (1), obtém (3).

$$
\left(\vec{V}_{i}-\vec{V}_{j}\right) \vec{V}_{j}^{*}=\left(P_{i j}+j Q_{i j}\right)\left(R_{i j}+j X_{i j}\right) \quad \forall i j \in \Omega_{l}
$$




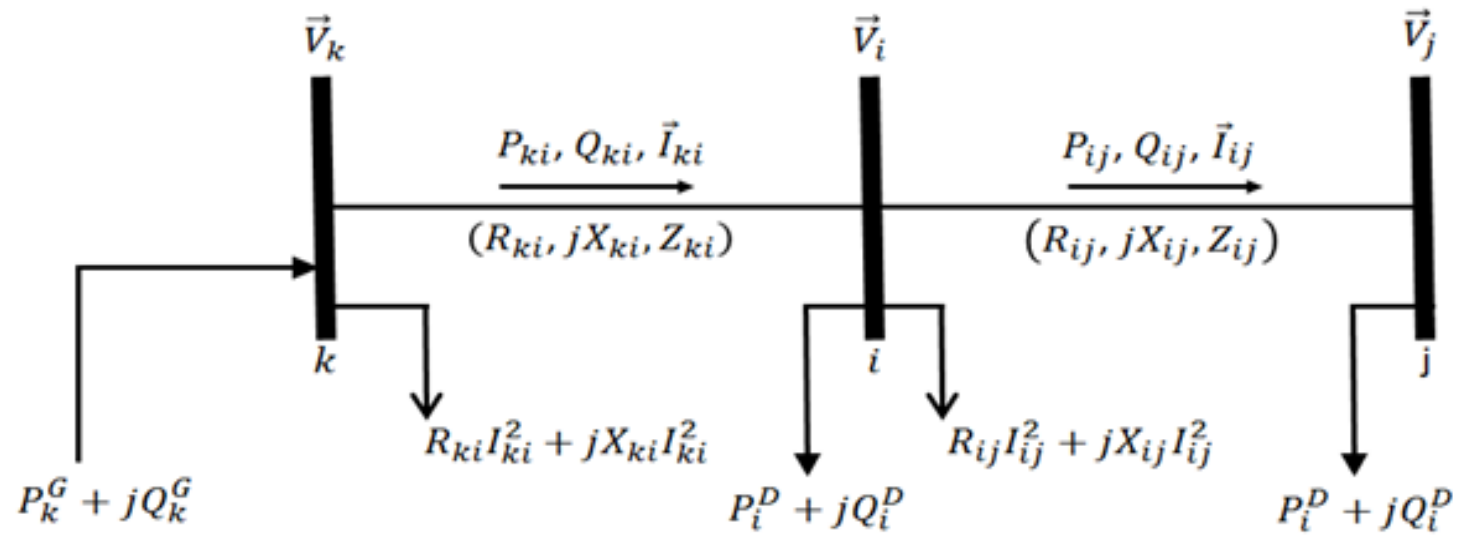

Figura 2.1- Representação do SDEE.

Uma forma de apresentar as variáveis fasoriais podem ser a polar, deste modo, $\vec{V}_{i}=V_{i} \angle \theta_{i}, \vec{V}_{j}=V_{j} \angle \theta_{j}$ e $\theta_{i j}=\theta_{i}-\theta_{j}$, em que $\theta_{i}$ é o ângulo de fase da tensão no nó $i$. Sendo assim, (3) pode ser escrita como mostrado na equação (4).

$$
V_{i} V_{j}\left[\cos \theta_{i j}+j \sin \theta_{i j}\right]-V_{j}^{2}=\left(P_{i j}+j Q_{i j}\right)\left(R_{i j}+j X_{i j}\right) \quad \forall i j \in \Omega_{l}
$$

Fazendo a separação da parte real e imaginária em (4), tem-se (5) e (6) sendo as partes real e imaginária, respectivamente.

$$
\begin{array}{cc}
V_{i} V_{j} \cos \theta_{i j}=V_{j}^{2}+\left(R_{i j} P_{i j}+X_{i j} Q_{i j}\right) & \forall i j \in \Omega_{l} \\
V_{i} V_{j} \sin \theta_{i j}=R_{i j} P_{i j}-X_{i j} Q_{i j} & \forall i j \in \Omega_{l}
\end{array}
$$

Elevando ao quadrado as equações (5) e (6), e depois se somando e aplicando a identidade trigonométrica entre as funções seno e cosseno, que é definida como $\sin \theta_{i j}^{2}+\cos \theta_{i j}^{2}=1$, obtém-se (7).

$$
V_{i}^{2}-V_{j}^{2}-2\left(R_{i j} P_{i j}+X_{i j} Q_{i j}\right)-Z_{i j}^{2} I_{i j}^{2}=0 \quad \forall i j \in \Omega_{l}
$$

A magnitude de corrente $i j$ é representada por (8).

$$
I_{i j}^{2}=\frac{P_{i j}{ }^{2}+Q_{i j}{ }^{2}}{V_{j}^{2}} \quad \forall i j \in \Omega_{l}
$$

Nota-se em (7) que não há a dependência na diferença entre os ângulos de fases das tensões, então a magnitude de tensão do último nó $\left(V_{j}\right)$ é obtida em função 
da magnitude do nó inicial $\left(V_{i}\right)$, do fluxo de potência ativa $\left(P_{i j}\right)$, do fluxo de potência reativo $\left(Q_{i j}\right)$, da corrente $\left(I_{i j}\right)$ e dos parâmetros elétricos pertinentes ao ramo.

Analisando a Figura 2.1, determina-se as equações de balanço de carga convencional, que são mostradas em (9) e (10).

$$
\begin{array}{ll}
P_{k i}-\sum_{i j \in \Omega_{l}}\left(P_{i j}+R_{i j} I_{i j}^{2}\right)+P_{i}^{G}=P_{i}^{D} & \forall i j \in \Omega_{l} \\
Q_{k i}-\sum_{i j \in \Omega_{l}}\left(Q_{i j}+X_{i j} I_{i j}^{2}\right)+Q_{i}^{G}=Q_{i}^{D} & \forall i j \in \Omega_{l}
\end{array}
$$

Como pode ser visto em (9) e (10), o índice $k$ representa a barra anterior ao nó $i$. O sistema de equações não-lineares das equações (7) - (10) determinam a operação estática de um sistema de distribuição radial. Na literatura há vários métodos para se resolver este sistema de equações (BARAN; WU, 1989), (CESPEDES, 1990), dentre estes o mais utilizado é o método da varredura (SHIRMOHARMNADI et al., 1988).

Com a formulação do SDEE em regime permanente, fez-se uma análise de (7) - (10), e observou-se que pode representar a programação não-linear para determinar o ponto estacionário do FC. O estudo da formulação não-linear é necessário para poder continuar com o desenvolvimento de uma formulação nãolinear inteira mista a ser desenvolvida nesta dissertação.

\subsection{Formulação da Programação Não-Linear.}

Para desenvolver a formulação não-linear, será feita uma mudança de variável da magnitude de tensão $V_{i}^{2}$ e de corrente $I_{i j}^{2}$, para eliminar esses termos elevado ao quadrado das equações. Sendo assim, $V_{i}^{s q r}$ e $I_{i j}^{s q r}$ representam o quadrado da magnitude de tensão e corrente, respectivamente. Em (11) - (17) está a 
formulação de um problema não-linear para determinação do FC, conforme (ALVES, 2012).

$$
\min v=\sum_{i j \in \Omega_{l}} R_{i j} I_{i j}^{s q r}
$$

S. a:

$$
\begin{array}{cc}
\sum_{i j \in \Omega_{l}} P_{k i}-\sum_{i j \in \Omega_{l}}\left(P_{i j}+R_{i j} I_{i j}^{s q r}\right)+P_{i}^{S}=P_{i}^{D} & \forall i \in \Omega_{b} \\
\sum_{i j \in \Omega_{l}} Q_{k i}-\sum_{i j \in \Omega_{l}}\left(Q_{i j}+X_{i j} I_{i j}^{s q r}\right)+Q_{i}^{S}=Q_{i}^{D} & \forall i \in \Omega_{b} \\
V_{i}^{s q r}-2 *\left(P_{i j} R_{i j}+Q_{i j} X_{i j}\right)-Z_{i j}^{2} I_{i j}^{s q r}-V_{j}^{s q r}=0 & \forall i j \in \Omega_{l} \\
V_{j}^{s q r} I_{i j}^{q d r}=P_{i j}^{2}+Q_{i j}^{2} & \forall i j \in \Omega_{l} \\
\underline{V}^{2} \leq V_{j}^{s q r} \leq \bar{V}^{2} & \forall j \in \Omega_{b} \\
0 \leq I_{i j}^{s q r} \leq{\overline{I_{i j}}}^{2} & \forall i j \in \Omega_{l}
\end{array}
$$

Em que, (11) representa a função objetivo, que é a equação de perda de potência ativa, (12) e (13) são as equações de balanço de potência ativa e reativa, respectivamente, (14) representa a segunda lei de Kirchhoff, (15) é a magnitude do fluxo de corrente, a qual torna o problema não-linear, devido ao produto entre $V_{j}^{q d r}$ e $I_{i j}^{q d r}$, e por fim, (15) e (16) são os limites de tensão e corrente, respectivamente.

\subsubsection{Teste e Resultados.}

Para exemplificar a modelagem proposta, nesta seção são apresentados os resultados obtidos para um sistema de 53 nós, sendo que destes, três são subestações. Os demais dados físicos e operacionais são apresentados no Apêndice A - Dados dos Sistemas de Distribuição. De forma a mostrar a eficiência da técnica de solução proposta para calcular o ponto estacionário de um SDEE radial. 
Este sistema será testado considerando apenas um único nível de demanda e, em condições normais de operação, sendo o total de demanda potência ativa e reativa $45.668,70 \mathrm{~kW}$ e $22.118,24 \mathrm{kVAr}$, respectivamente, equivalente a 50.742,95 kVA. Tensão nominal de 13,8 kV e os limites dos níveis de tensão superior e inferior são 1,0 e 0,95 pu, respectivamente. O modelo matemático proposto por (ALVES, 2012), foi implementado no software GAMS, solucionado pelo solver comercial KNITRO. Os testes foram simulados em um microcomputador, em que está instalado o sistema operacional Windows XP, com processador Intel(R) Core (TM) 2 Quad, memória Ram de 4GB. A Figura 2.2 mostra o diagrama unifilar do sistema em estudo.

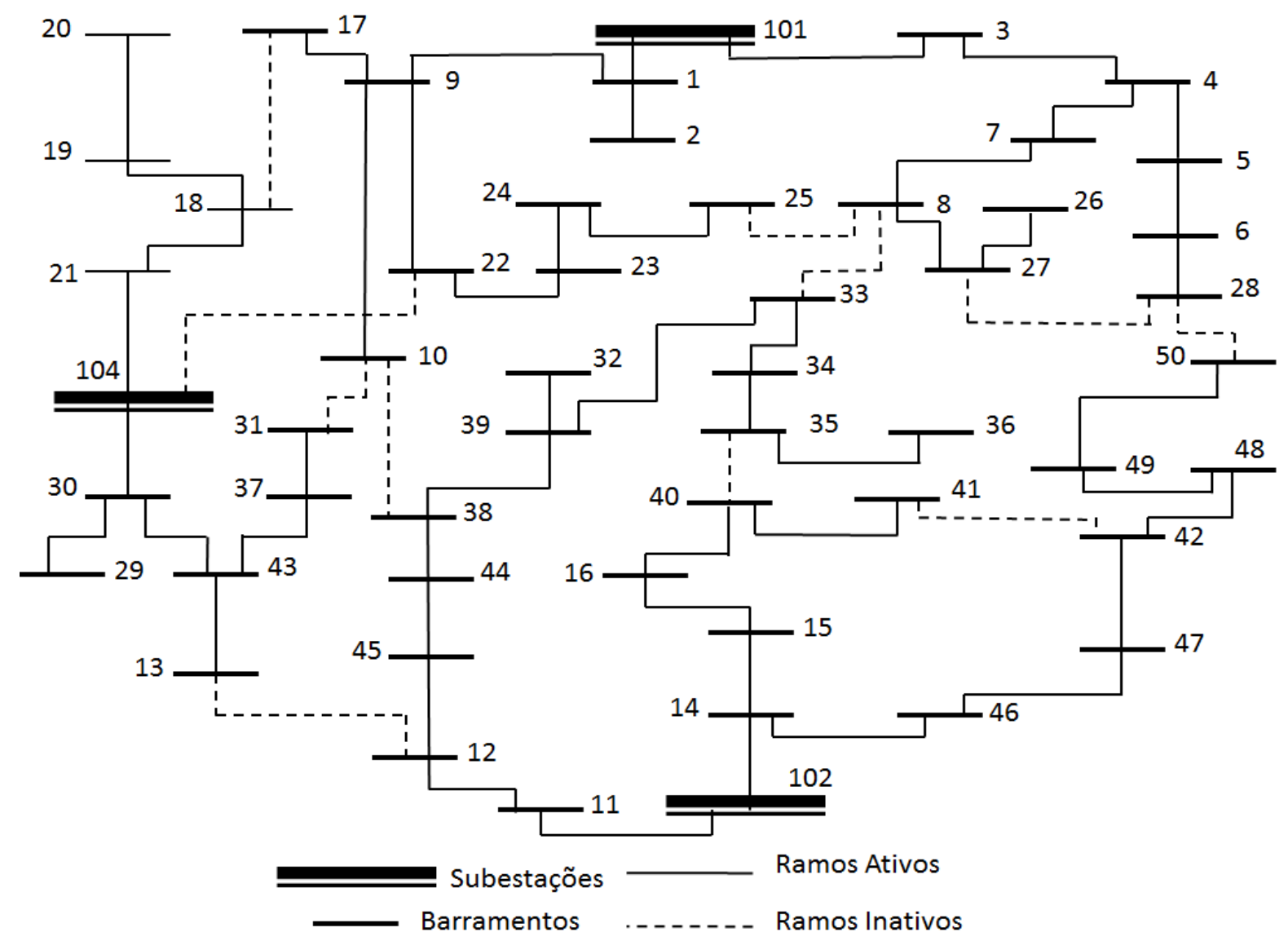

Figura 2.2 - Diagrama unifilar do sistema 53 barras.

Na Figura 2.3, estão representados os níveis de tensão. Percebe-se que todas as tensões dos alimentadores estão dentro do limite estabelecido, sendo o nó 36 com a menor tensão, $0,9714 \mathrm{pu}$, o tempo computacional para obter a solução foi de 0.16 
segundos. A Figura 2.4 mostra os resultados para as correntes nos ramos, com seus respectivos limites máximos. Os gráficos da corrente do fluxo de carga e da corrente máxima estão sobrepostos.

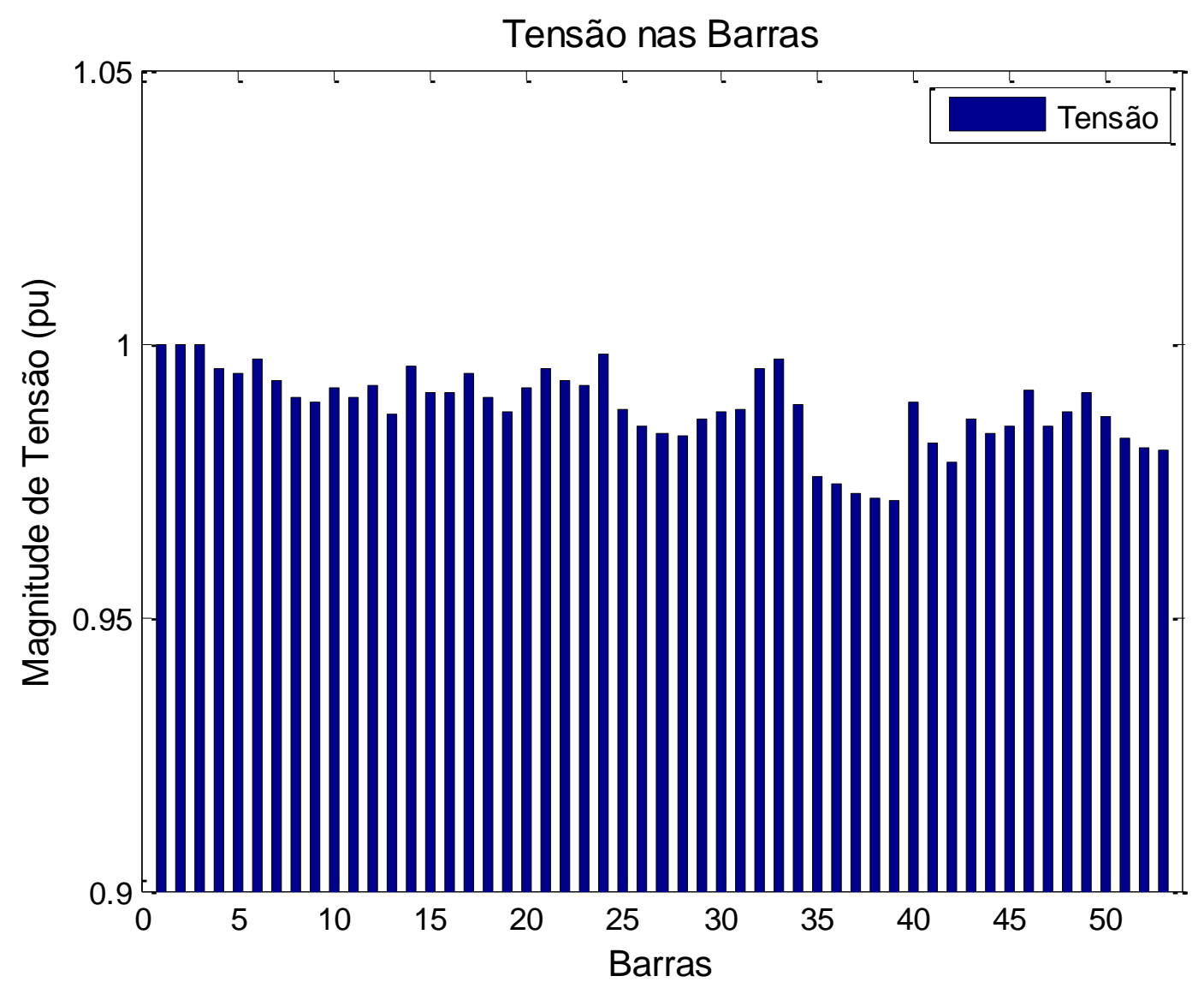

Figura 2.3 - Níveis de tensões nas barras.

Por fim, é feita a análise da capacidade de fornecimento de energia das subestações. Sendo seus valores expressos na Tabela 2.1, com seus respectivos limites. Nota-se que não ocorreu violação dos limites.

\subsection{Programação Cônica de Segunda Ordem.}

O processo de otimização é uma técnica matemática, que está inserida em todas as áreas do conhecimento. Dentro deste contexto, surge a otimização convexa que abrange um conjunto de problemas de programação, onde a função objetivo e as 
restrições de desigualdade são convexas e as restrições de igualdades são afins. Em (18) é definida a função convexa.

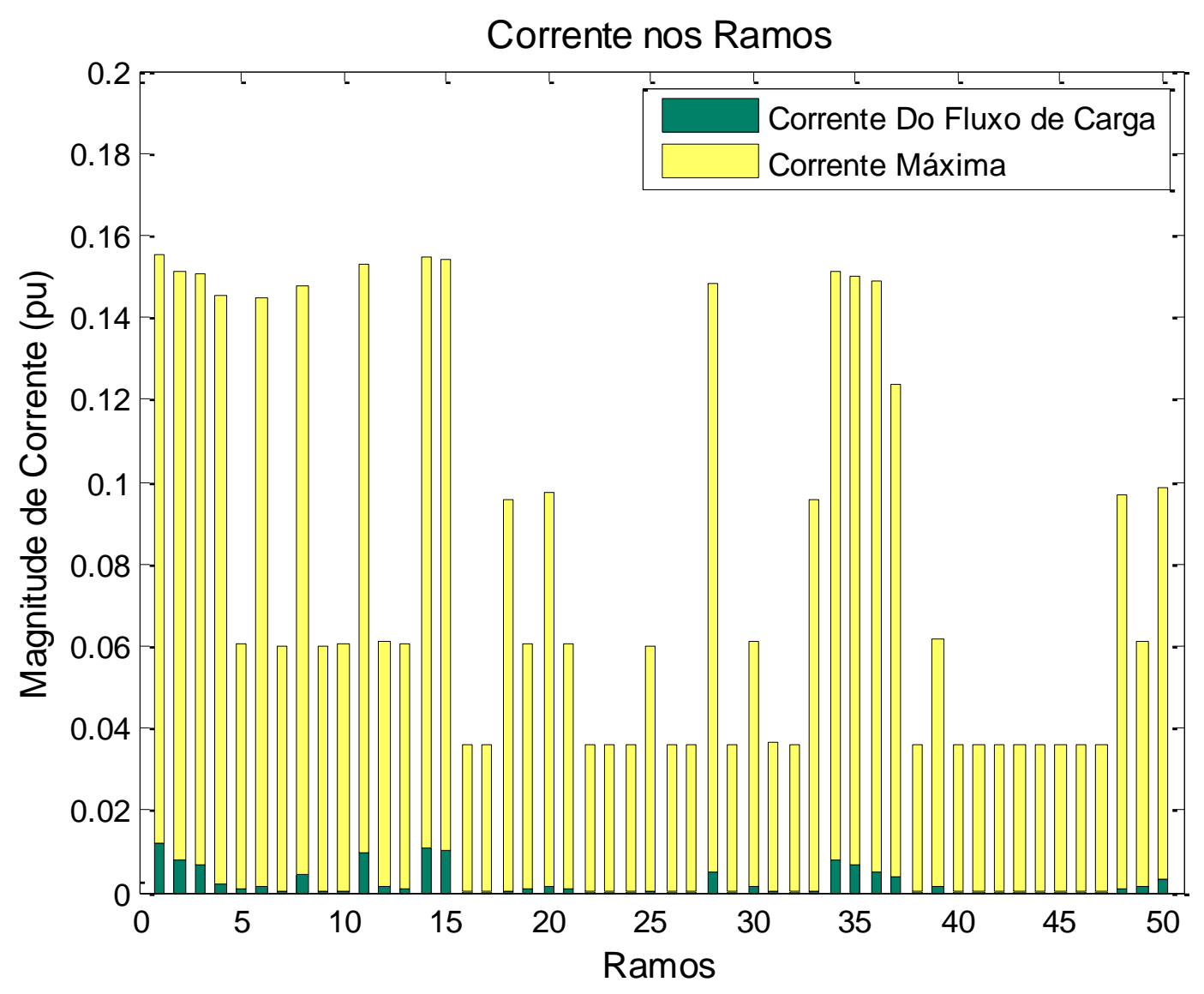

Figura 2.4 - Magnitude de corrente nos ramos.

Tabela 2.1 - Capacidade das subestações.

\begin{tabular}{ccc}
\hline Subestações & $\begin{array}{c}\text { Capacidade máxima de } \\
\text { fornecimento (kVA). }\end{array}$ & $\begin{array}{c}\text { Capacidade das subestações } \\
\text { simuladas (kVA). }\end{array}$ \\
\hline $\mathbf{1 0 1}$ & 33400 & 19722 \\
102 & 30000 & 20393 \\
104 & 22000 & 11136 \\
\hline
\end{tabular}


Definição 1: Dado um conjunto convexo não vazio $S \subseteq \mathbb{R}^{n}$ e uma função $f: S \rightarrow \mathbb{R}$ convexa sobre $S$. Dizemos que $f$ é uma função convexa se (18) for satisfeita para todo $x_{1}, x_{2} \in S$ e $\lambda \in[0,1]$ (BAZARAA; SHETTY, 1943)

$$
f\left(\lambda x_{1}+(1-\lambda) x_{2}\right) \leq f\left(x_{1}\right)+(1-\lambda) f\left(x_{2}\right)
$$

Dentro dos problemas da otimização convexa, pode-se citar alguns existentes na literatura: Programação Linear (PL), Mínimos Quadrados (MQ), Programação Quadrática (PQ), Programação Cônica (PC), Programação Cônica de Segunda Ordem (PCSO), etc.

Desta forma, serão expostas as características e aspectos teóricos, dentro da otimização convexa, a fim de destacar a PCSO que foi utilizada para o desenvolvimento deste trabalho.

Os problemas de programação cônica, de uma forma geral, são definidos com uma função objetivo linear, restrições lineares e restrições de cone quadrático, que pode ser definida como uma programação linear, porém com pelo menos uma restrição cônica. A restrição cônica é um conjunto de variáveis importante que determina um cone convexo. O cone convexo é um conjunto não-vazio definido a seguir:

- Um conjunto $C$ é um cone se para todo $x \in C$ e $\alpha \geq 0, \alpha x \in C$.

- Um cone convexo é um conjunto $C$ tal que, para todo $x_{1}, x_{2} \in C \mathrm{e}$ $\alpha_{1}, \alpha_{2} \geq 0, \alpha_{1} x_{1}+\alpha_{2} x_{2} \in C$.

Definição 2: Um conjunto $C \subseteq \mathbb{R}^{n+1}$ é chamado de cone de segunda ordem quando é um cone normado na norma Euclidiana (19).

$$
C=\left\{(x, t) \in \mathbb{R}^{n} x \mathbb{R},\|x\| \leq t\right\} \subseteq \mathbb{R}^{n+1}
$$


Onde, $\|x\|=\left(x^{T} \cdot x\right)^{\frac{1}{2}}$. O cone C é conhecido como cone de Lorentz, (LOBO et al., 1998), (DELGADO, 2015).

Diante dessas definições estabelecidas anteriormente, o problema de otimização cônica de segunda ordem pode ser definido. A sua representação está escrita conforme (DELGADO, 2015) em (20) - (22).

$$
\text { Minimizar } f^{T} x
$$

S. a:

$$
\begin{gathered}
\left\|A_{i} x+b_{i}\right\| \leq c_{i}^{T} x+d_{i} \\
F x=g
\end{gathered}
$$

Em que $x \in \mathbb{R}^{n}$ é variável a ser otimizada, e as demais variáveis são parâmetros do problema que são: $f \in \mathbb{R}^{n}, A_{i} \in \mathbb{R}^{\left(n_{i}-1\right) \times n}, b_{i} \in \mathbb{R}^{n_{i}-1}, c_{i} \in \mathbb{R}^{n}, d_{i} \in \mathbb{R}$, $F \in \mathbb{R}^{m \times n}, g \in \mathbb{R}^{m}$.

A seguir, será apresentado um exemplo ilustrativo conforme (RIBEIRO, 2013), afim de esclarecer o funcionamento da otimização cônica de segunda ordem.

\subsubsection{Exemplo llustrativo.}

Dado o sistema mostrado na Figura 2.5, com dois nós, determinar a mínima perda de energia ativa nesse circuito.

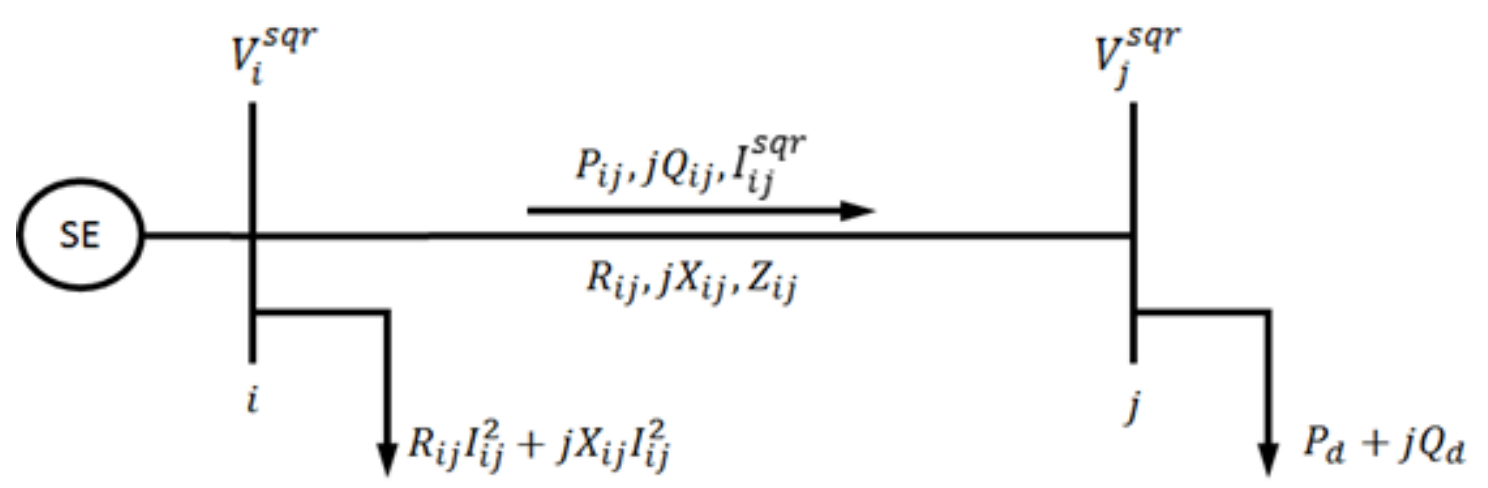

Figura 2.5 - Sistema composto de dois nós e um circuito. 
Nas equações (23) - (25) é formulado um problema cônico de segunda ordem.

Sujeito a:

$$
\min R_{i j} I_{i j}^{s q r}
$$

$$
\begin{gathered}
V_{i}^{s q r}-V_{j}^{s q r}-2\left(R_{i j} P_{d j}+X_{i j} Q_{d j}\right)-Z_{i j}^{2} I_{i j}^{s q r}=0 \\
V_{i}^{s q r} I_{i j}^{s q r} \geq P_{d j}^{2}+Q_{d j}^{2}
\end{gathered}
$$

A Figura 2.6 mostra a representação das restrições (24) e (25), graficamente.

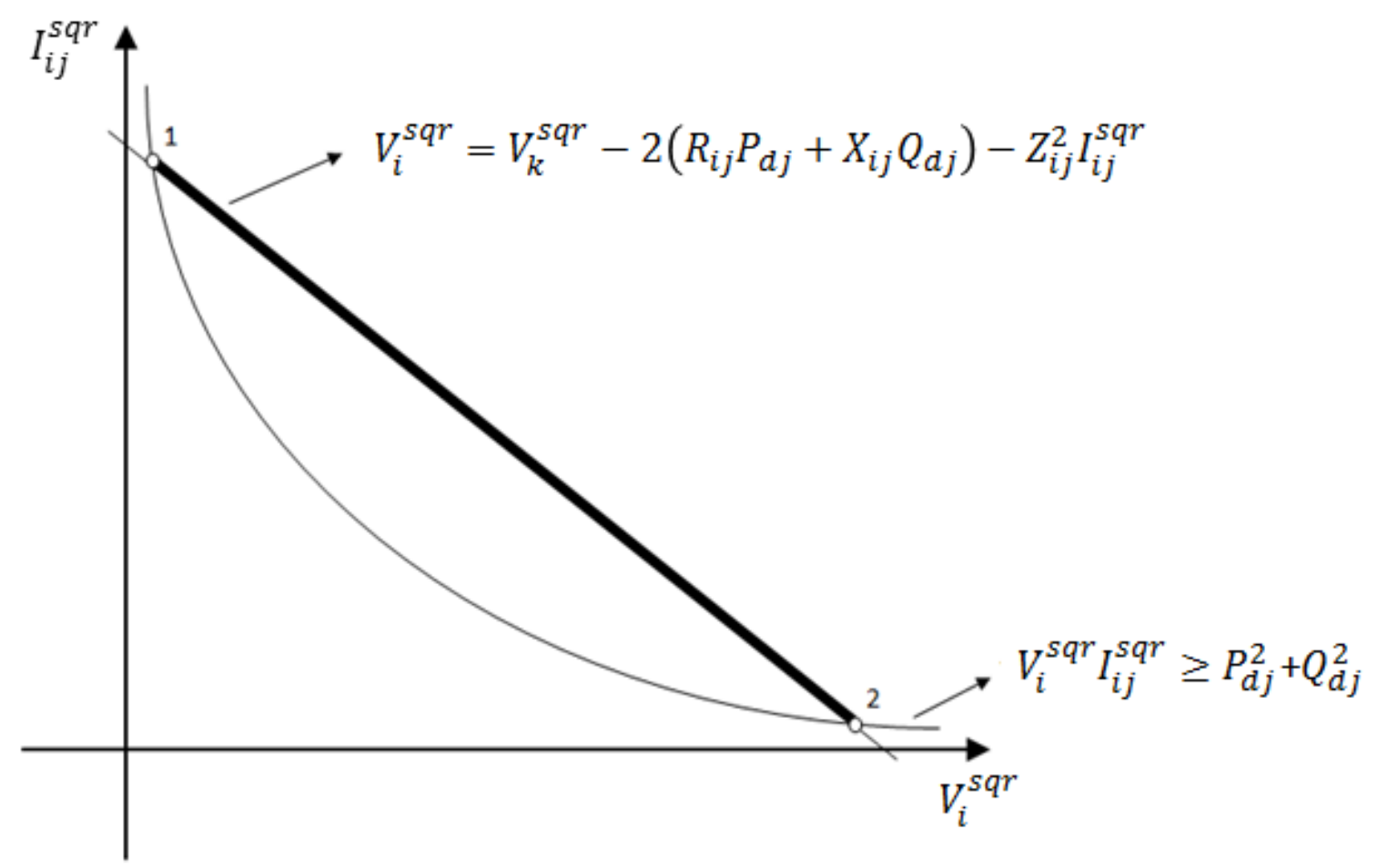

Figura 2.6 - Representação das restrições (24) e (25).

Fonte: (RIBEIRO, 2013).

Tendo em vista que o objetivo neste exemplo é minimizar a perda de potência ativa, a solução para este problema será determinada graficamente. Verifica-se na Figura 2.6, que a região factível encontrada pelas restrições (24) e (25) é formada pela reta determinada pelos pontos 1 e 2 . Sendo assim, a solução encontrada é satisfeita no ponto 2. 


\subsection{Considerações finais.}

Neste capítulo foi apresentada a formulação para calcular o ponto de operação em regime permanente de um sistema de distribuição, sendo este modelo implementado na linguagem de programação matemática GAMS. O teste foi realizado com um sistema de 53 barras ( 3 subestações e 50 nós de carga). O modelo garantiu a convergência usando solver comercial CPLEX. Ainda, foi proposta a teoria da programação cônica de segunda ordem, a qual será utilizada na resolução da modelagem para corte de carga em SDEE, que se encontra no capítulo 3. 


\section{Modelagem Cônica de Segunda Ordem Inteira Mista}

Neste capítulo é apresentado o problema de reconfiguração do sistema de distribuição radial, com a finalidade de realizar o corte de carga. Primeiramente é modelado como problema não-linear inteiro misto (PNLIM), que posteriormente foi transformado em um problema cônico de segunda ordem inteiro misto (PCSOIM), por fim, a nova restrição de corte de carga é incorporada ao modelo.

\subsection{Introdução.}

A reconfiguração é uma forma de se adequar a topologia de um SDEE para atender a um determinado objetivo. Nesta seção é apresentada a metodologia que envolve um problema não-linear inteiro misto para reconfiguração, aplicado ao sistema de distribuição de energia elétrica. O modelo matemático proposto está baseado na proposta de restauração de (ROMERO et al., 2015). O trabalho destes autores foi revisado na seção 1.1.2. A restauração utilizada em SDEE busca reestabelecer o fornecimento de energia, devido a algum fato que retirou o sistema de seu estado normal de funcionamento, ainda assim considerando um possível corte de carga. Deste modo, a metodologia desenvolvida não pode ser admitida como uma restauração, pois aqui visa efetuar a suspensão do fornecimento de energia para situação de excessivo carregamento ou por imposição de órgãos competentes.

O modelo matemático proposto tem por objetivo resolver o problema de corte de carga, de modo que esta ação cause o menor impacto no sistema de distribuição. 
É importante frisar que o sistema elétrico se encontra em elevado estado de estresse, níveis de tensões e frequência nominal diminuindo, podendo, portanto, causar um grande colapso. Para a elaboração do plano de reconfiguração, barras que serão desligadas, é necessário que circuitos adjacentes a estas barras sejam indisponibilizados. Nos testes a serem realizados, considera-se que todas as chaves do sistema são automáticas, assim permite-se uma análise mais completa do sistema.

Dessa forma, a modelagem apresentada do problema não-linear inteiro misto (PNLIM) está apresentada nas relações (26) - (45). Na proposta da função objetivo (26) do problema de reconfiguração, é ponderada a importância do corte de cargas de forma a manter o fornecimento de energia adequado, ou seja, todos os limites operacionais do SDEE serão atendidos. Assim,

$$
\min v=\sum_{i j \in \Omega_{a a}} \beta_{i j} x_{i j}+\sum_{i j \in \Omega_{a f}} \mu_{i j}\left(1-x_{i j}\right)+\sum_{i j \in \Omega_{b}} \alpha_{i} y_{i j} \sqrt{\left(P_{i}^{D}+Q_{i}^{D}\right)}+\sum_{i j \in \Omega_{l}} R_{i j} I_{i j}^{s q r}
$$

Sendo que, $\Omega_{a a}$ é o conjunto das chaves automáticas normalmente abertas e $\Omega_{a f}$ é o conjunto das chaves automáticas normalmente fechadas, $\Omega_{b}$ é o conjunto de todas as barras, tanto barras de demanda como barras de geração e $\Omega_{l}$ é o conjunto de todos os ramos do sistema. A variável binária $x_{i j}$ representa o estado operativo do circuito $i j$, de modo que o circuito $i j$ esteja operando (fechado) quando o valor for igual a 1, caso contrário, é inoperante (aberto). A variável binária $y_{i}$ representa a barra ligada quando o valor é 0 (zero) ou desligado com valor 1 (um). Nesta formulação, os dois primeiros termos estão ponderados a minimização de chaveamento, eles estão relacionados à possibilidade de abertura ou fechamento das chaves, sendo possível incorporar o custo em unidade monetária dos chaveamentos. Sendo as variáveis $\beta_{i j}$ e $\mu_{i j}$, parâmetros relacionados com abertura e fechamento de chaves no processo da reconfiguração, que foram adotados de acordo com (ROMERO et al., 2015). O terceiro 
termo é o mais importante, pois está relacionado aos consumidores que terão o fornecimento de energia suspenso, sendo estes representados pela potência aparente demandada em um nó de carga. A variável $\alpha_{i}$ representa a prioridade de desconexão de carga do sistema. E o último termo foi inserido para controlar os elevados valores de corrente, pois poderia interferir na determinação da menor quantidade de carga cortada. Esse termo funciona como uma penalidade, direcionando a corrente a atingir a igualdade em (46).

Neste trabalho foram realizados dois estudos com relação a variável $\alpha_{i}$. O primeiro estudo está vinculado à análise de corte de carga com todas as cargas tendo o mesmo peso para desconexão, ou seja, todas as cargas têm a mesma prioridade de serem desligadas. O outro estudo realizado é determinar o corte da carga considerando a prioridade de carga, ou seja, cada carga terá um peso para ser desligada. Para isso, foram adotados critérios para as prioridades de cargas, divididos em três categorias com valores de 1 a 3 sendo: 1, carga de menor relevância, como prédios residenciais, supermercados; 2, cargas de média relevância, como industrias em geral, e 3, cargas com maior relevância, como hospitais, transporte público, centro de inteligência policial, etc. Segundo ("Boletim Mensal de Monitoramento do Sistema Elétrico Brasileiro", 2015), os cortes de cargas ocorridos no dia 19 de Janeiro de 2015 não foram superiores a $5 \%$, sendo assim, o valor máximo de corte de carga estudado estará próximo a este valor.

As restrições para o problema não-linear inteiro misto, segundo (ROMERO et al., 2015), são apresentadas em (27) - (45). O presente modelo tem uma peculiaridade, o que é devido a presença de uma subestação fictícia. Com isso, um sistema radial fictício é formado pelos circuitos artificiais e as cargas desligadas do sistema. 


$$
\begin{aligned}
& \sum_{i j \in \Omega_{l}} P_{k i}-\sum_{i j \in \Omega_{l}}\left(P_{i j}+R_{i j} I_{i j}^{s q r}\right)+P_{i}^{G}=P_{i}^{D}\left(1-y_{i j}\right) \quad \forall i \in \Omega_{b} \\
& \sum_{i j \in \Omega_{l}} Q_{k i}-\sum_{i j \in \Omega_{l}}\left(Q_{i j}+X_{i j} I_{i j}^{s q r}\right)+Q_{i}^{G}=Q_{i}^{D}\left(1-y_{i j}\right) \quad \forall i \in \Omega_{b} \\
& V_{i}^{s q r}-2 *\left(P_{i j} R_{i j}+Q_{i j} X_{i j}\right)-Z_{i j}^{2} I_{i j}^{s q r}-V_{j}^{s q r}-a_{i j}=0 \quad \forall i j \in \Omega_{l} \\
& V_{j}^{s q r} I_{i j}^{s q r}=P_{i j}^{2}+Q_{i j}^{2} \quad \forall i j \in \Omega_{l} \\
& \underline{V}^{2} \leq V_{j}^{s q r} \leq \bar{V}^{2} \quad \forall i \in \Omega_{b} \\
& I_{i j}^{s q r} \leq I_{i j}^{2} x_{i j} \quad \forall i j \in \Omega_{l} \\
& \left|a_{i j}\right| \leq\left(\bar{V}^{2}-\underline{V}^{2}\right)\left(1-x_{i j}\right) \quad \forall i j \in \Omega_{l} \\
& \sum_{i j \in \Omega_{l} \cup \Omega_{h}} x_{i j}=\left|\Omega_{b}\right|-n_{s} \\
& \sum_{i j \in \Omega_{l} \cup \Omega_{h}} H_{k i}-\sum_{i j \in \Omega_{l} \cup \Omega_{h}} H_{i j}+H_{i}^{G}=y_{i} \quad \forall i \in \Omega_{b} \\
& H_{i}^{G}=0 \quad \forall i \in \Omega_{b}, i \neq S^{f} \\
& \left|H_{i j}\right| \leq M x_{i j} \quad \forall i j \in \Omega_{l} \cup \Omega_{h} \\
& P_{S^{f}}^{G}=0 \\
& Q_{S^{f}}^{G}=0 \\
& \sum_{i j \in \Omega_{l} \cup \Omega_{h}} x_{i j}+\sum_{k i \in \Omega_{l} \cup \Omega_{h}} x_{k i} \geq 1 \\
& \left|P_{i j}\right| \leq \bar{V} \bar{I}_{i j} x_{i j} \\
& \left|Q_{i j}\right| \leq \bar{V} \bar{I}_{i j} x_{i j}
\end{aligned}
$$




$$
\begin{array}{cc}
\left|y_{i}-y_{j}\right| \leq\left(1-x_{i j}\right) & \forall i j \in \Omega_{l} \\
x_{i j} \in\{0,1\} & \forall i j \in \Omega_{l} \cup \Omega_{h} \\
y_{i} \in\{0,1\} & \forall i \in \Omega_{b}
\end{array}
$$

Sendo $\Omega_{h}$ o conjunto dos ramos fictícios, ressalta-se que o modelo matemático dispõe das seguintes informações: $P_{i}^{D}$ e $Q_{i}^{D}$ são as demandas de potência ativa e reativa na barra $i$, respectivamente (não existe demanda na barra da subestação, portanto, $P_{i}^{D}$ e $Q_{i}^{D}$ da subestação são nulos); $P_{i}^{G}$ e $Q_{i}^{G}$ são, respectivamente, geração de potência ativa e de potência reativa na barra $i$, ocorrem apenas na barra da subestação (não existe geração nas barras de carga, portanto, $P_{i}^{G}$ e $Q_{i}^{G}$ nas barras de cargas são nulos). No modelo, $n_{s}$ é o total de subestações do SDEE. Adicionalmente, as variáveis $H_{i j}$ e $H_{i}^{G}$ são inseridas para representar o fluxo de carga fictício no ramo $i j$ e a geração artificial no nó $i$, respectivamente. Finalmente, $V_{i}^{s q r}, V$ e $\bar{V}$ representam, na mesma ordem, o quadrado do módulo de tensão na barra $i$ e as tensões mínima e máxima permitidas para operação do sistema; $I_{i j}^{s q r}$ representa o quadrado da magnitude de corrente no circuito $i j$ cuja capacidade máxima de fluxo de corrente é $\bar{I}_{i j}$; os fluxos de potência ativa e reativa entre as barras $i$ e $j$, são representados por $P_{i j}$ e $Q_{i j}$, respectivamente.; dados de resistência, reatância e impedância do ramo correspondem a $R_{i j}, X_{i j}$ e $Z_{i j}$; e $b_{i j}$ é uma variável auxiliar.

Segue a descrição do modelo matemático: As restrições (27) e (28) são as equações de balanço de potência ativa e reativa, respectivamente. Em (29) é apresentada a segunda lei de Kirchhoff, que representa a queda da magnitude de tensão nos ramos. Nota-se que a variável $a_{i j}$ é adicionada à formulação convencional a fim de satisfazer a condição, em que o ramo não se encontra ativo, e o controle 
desta variável é realizado através de (33). Para determinação da magnitude de corrente em (30), é obtida a relação entre tensão e potência aparente, relação esta que, ao ser transformada, torna-se um problema cônico de segunda ordem, que será mais discutida na seção 3.2. Os limites de tensão e de corrente são representados por (31) e (32), respectivamente. O limite da variável auxiliar $a_{i j}$ é apresentado em (33), permitindo que (29) tenha solução.

Conforme (LAVORATO et al., 2012) a combinação das restrições (27), (28), (34) e (35) garante que o sistema, após a reconfiguração, atinja sua forma radial; isto é, o sistema é ligado, sem malhas. A restrição (35) representa o balanço de fluxo de potência artificial, no sistema fictício, permitindo que os nós desligados formem um sistema radial (ROMERO et al., 2015). Em (36) é representado a geração do fluxo de potência artificial para a subestação fictícia. O limite do fluxo de potência artificial no ramo é dado por (37), e depende do seu estado de operação. A geração na subestação fictícia é nula; garantida por (38) e (39).

Uma restrição não necessária é representada por (40) e indica que pelo menos um circuito deve ser ligado a um nó de carga, tornando o processo mais ágil. As restrições (41) e (42) são os limites de potência ativa e reativa no ramo, respectivamente, as quais serão zero caso a chave do circuito esteja aberta. A restrição (43) assegura que se o circuito $i j$ está operando, as variáveis $y_{i}$ e $y_{j}$ têm os mesmos valores. As variáveis de decisão $x_{i j}$ e $y_{i}$, são binárias e estão representadas em (44) e (45).

\subsection{Modelo Cônico de Segunda Ordem Inteiro Misto.}

A presente seção apresenta um modelo matemático alternativo para o problema original com o intuito de tornar o problema mais simples na nova formulação, 
isto é, tratando a formulação com menor complexidade de resolução e, consequentemente, tornando o modelo matemático de fácil resolução pelos métodos conhecidos de otimização clássica, cuja solução é a mesma do problema original.

Devido a alguns fatos, como: o tamanho do sistema, as variáveis binárias de decisão, normalmente tornam muito difíceis a resolução do problema. No modelo matemático de PCSOIM, a relação (30) foi modificada para assumir a forma cônica de segunda ordem (46). O conjunto de restrições do modelo não-linear foi transformado em um modelo cônico de segunda ordem inteiro misto, em que sua equivalência está demonstrada em (ROMAIS, 2013) e (RIBEIRO, 2013).

$$
V_{j}^{s q r} I_{i j}^{s q r} \geq P_{i j}^{2}+Q_{i j}^{2} \quad \forall i j \in \Omega_{l}
$$

Sendo assim, o problema de reconfiguração para o corte de carga no SDEE pode ser representado pelo modelo cônico de segunda ordem inteiro misto. Este modelo é definido pelas equações (27) - (47) realizando a substituição de (30) pela nova restrição (46), com isso, o problema pode ser resolvido por solver comerciais disponíveis no mercado.

Segundo (SOUZA, 2009), a formulação cônica apresenta uma ótima vantagem, pois o problema se torna convexo, de forma que a solução ótima global do modelo cônico equivale a solução ótima do problema não-linear inteiro misto. Outro fato é que o tempo computacional para a resolução pelo modelo cônico é menor que a versão não-linear. Considerando que as técnicas de otimização não-linear podem não ser tão eficazes na resolução de um problema dessa natureza, que dependendo de suas características, pode ter uma solução factível não encontrada. 


\subsubsection{Restrição de Corte de Carga.}

Para tornar o modelo matemático proposto por (ROMERO et al., 2015) apto de corte de carga, a restrição (39) deve ser inserida ao conjunto de restrições (26) (45). Neste conjunto de equações foi realizada a substituição de (30) por (46). A nova restrição (47) é uma condição necessária para realizar o corte de carga no SDEE, uma vez que o sistema está operando em condições anormais. Assim, o somatório das cargas desligadas deve ser maior ou igual ao valor de corte de carga solicitado (ST).

$$
\sum_{i \in \Omega_{b}} y_{i} \sqrt{\left(P_{i}^{D}+Q_{i}^{D}\right)} \geq S T \quad \forall i \in \Omega_{b}
$$

Em que $P_{i}^{D}$ e $Q_{i}^{D}$ são as demandas potências ativas e reativas, respectivamente. Desta forma, o modelo completo para a realização do corte de carga fica definido em (48) - (68).

$$
\min v=\sum_{i j \in \Omega_{a a}} \beta_{i j} x_{i j}+\sum_{i j \in \Omega_{a f}} \mu_{i j}\left(1-x_{i j}\right)+\sum_{i j \in \Omega_{l}} \alpha_{i} y_{i j} \sqrt{\left(P_{i}^{D}+Q_{i}^{D}\right)}+\sum_{i j \in \Omega_{l}} R_{i j} I_{i j}^{s q r}
$$

S.a

$$
\begin{array}{cc}
\sum_{i j \in \Omega_{l}} P_{j i}-\sum_{i j \in \Omega_{l}}\left(P_{i j}+R_{i j} I_{i j}^{s q r}\right)+P_{i}^{G}=P_{i}^{D}\left(1-y_{i j}\right) & \forall i \in \Omega_{b} \\
\sum_{i j \in \Omega_{l}} Q_{j i}-\sum_{i j \in \Omega_{l}}\left(Q_{i j}+X_{i j} I_{i j}^{s q r}\right)+Q_{i}^{G}=Q_{i}^{D}\left(1-y_{i j}\right) & \forall i \in \Omega_{b} \\
V_{i}^{s q r}-2 *\left(P_{i j} R_{i j}+Q_{i j} X_{i j}\right)-Z_{i j}^{2} I_{i j}^{s q r}-V_{j}^{s q r}-a_{i j}=0 & \forall i j \in \Omega_{l} \\
V_{j}^{s q r} I_{i j}^{s q r} \geq P_{i j}^{2}+Q_{i j}^{2} & \forall i j \in \Omega_{l} \\
\underline{V}^{2} \leq V_{j}^{s q r} \leq \bar{V}^{2} & \forall i \in \Omega_{b} \\
I_{i j}^{s q r} \leq \bar{I}_{i j}^{2} x_{i j} & \forall i j \in \Omega_{l}
\end{array}
$$




$$
\begin{aligned}
& \left|a_{i j}\right| \leq\left(\bar{V}^{2}-\underline{V}^{2}\right)\left(1-x_{i j}\right) \\
& \forall i j \in \Omega_{l} \\
& \sum_{i j \in \Omega_{l} \cup \Omega_{h}} x_{i j}=\left|\Omega_{b}\right|-n_{s} \\
& \sum_{i j \in \Omega_{l} \cup \Omega_{h}} H_{k i}-\sum_{i j \in \Omega_{l} \cup \Omega_{h}} H_{i j}+H_{i}^{G}=y_{i} \\
& H_{i}^{G}=0 \\
& \left|H_{i j}\right| \leq M x_{i j} \\
& P_{S^{f}}^{G}=0 \\
& Q_{S^{f}}^{G}=0 \\
& \sum_{i j \in \Omega_{l} \cup \Omega_{h}} x_{i j}+\sum_{k i \in \Omega_{l} \cup \Omega_{h}} x_{k i} \geq 1 \\
& \left|P_{i j}\right| \leq \bar{V} \bar{I}_{i j} x_{i j} \\
& \left|Q_{i j}\right| \leq \bar{V} \bar{I}_{i j} x_{i j} \\
& \left|y_{i}-y_{j}\right| \leq\left(1-x_{i j}\right) \\
& x_{i j} \in\{0,1\} \\
& \forall i j \in \Omega_{l} \cup \Omega_{h} \\
& \mathcal{Y}_{i} \in\{0,1\} \\
& \forall i \in \Omega_{b} \\
& \sum_{i \in \Omega_{b}} y_{i} \sqrt{\left(P_{i}^{D}+Q_{i}^{D}\right)} \geq S T \\
& \forall i j \in \Omega_{l} \cup \Omega_{h} \\
& \forall i \in \Omega_{b} \\
& \forall i \in \Omega_{b}, i \neq S^{f}
\end{aligned}
$$

\subsection{Considerações finais.}

Esse capítulo se dedicou a apresentar uma modelagem matemática com a proposta de reconfiguração, que tem por objetivo encontrar a mínima quantidade de 
carga desligada do SDEE, de forma a causar o menor impacto. O modelo matemático considera o parâmetro $\alpha_{i}$ abordando duas situações para prioridade de carga. Além da formulação proposta para o objetivo de minimizar o corte de carga quando o sistema estiver com elevado carregamento. O capítulo apresentou também a formulação para a função objetivo, que busca minimizar o número de operações de chaveamento necessárias para a efetivação da suspenção do fornecimento de energia.

Portanto, a modelagem proposta necessita ser testada para garantir a eficiência do seu desempenho, o que é feito no capítulo 4. 


\section{Resultados Numéricos}

Neste capítulo são apresentados os resultados obtidos a partir da aplicação na modelagem desenvolvida, que busca realizar o corte de carga no sistema de distribuição de energia elétrica. Uma vez que essa ferramenta, juntamente com a experiência desenvolvida ao longo de anos dos operadores, agrega importantes informações que auxiliam a tomada de decisão sobre a melhor forma de atender ao corte de carga. O sistema de 53 barras foi utilizado nos três estudos de casos, de modo que suas particularidades são discutidas ao longo desse capítulo.

\subsection{Introdução.}

O sistema teste de 53 nós tem 3 subestações e 50 nós de carga e 61 ramos e, em condições normais, possui uma demanda de potência ativa de 45.668,7 kW e potência reativa de 22.118,24 kVAr, totalizando 50.742,95 kVA. A tensão nominal do sistema é de 13,8 kV (1 pu), enquanto os limites máximo e mínimo de tensão são $14,49(1,05)$ e $13,11 \mathrm{kV}(0,95 \mathrm{pu})$, respectivamente. A metodologia proposta foi implementada em GAMS (ROSENTHAL, 2015), e foi utilizado o solver comercial CPLEX (IBM, 2009) para solucionar o modelo matemático. No Apêndice B encontrase o fluxograma para implementação da modelagem proposta. A capacidade nominal de cada subestação nos nós 101, 102 e 104 são 33.400, 30.000 e 22.000 kVA, respectivamente. Os demais dados elétricos encontram-se no Apêndice A. Na Figura 4.1 está ilustrada a topologia para o estado normal do sistema com a representação das chaves abertas e fechadas. Os testes foram simulados em um microcomputador, 
em que está instalado o sistema operacional Windows XP, com processador Intel (R) Core (TM) 2 Quad, memória Ram de 4GB.

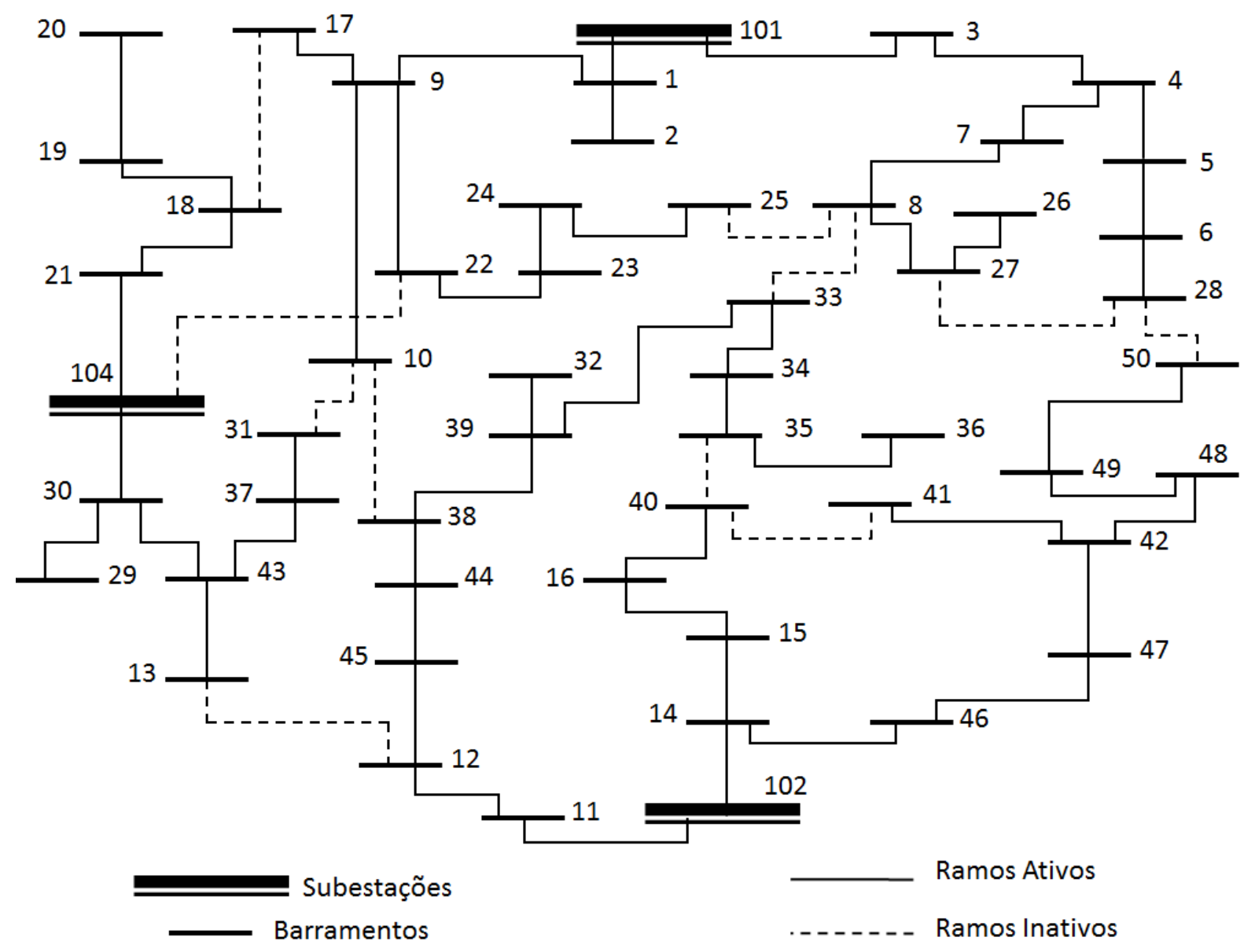

Figura 4.1 - Estrutura inicial do sistema de 53 nós.

Para as chaves pertencentes ao sistema, admite-se que todas são automáticas e que cada circuito existente tem uma chave, permitindo a abertura ou fechamento da mesma. Os testes foram realizados para três casos de corte de carga que foram testados com base na modelagem proposta. $E$ em cada caso foi considerado o corte de carga de 1.000, 2.000, 3.000 e 4.000 kVA.

- Primeiro Caso: Este primeiro cenário do corte de carga visou efetuar a suspensão do fornecimento de energia sem prioridade de carga. Neste caso a minimização de chaveamento não foi considerada. 
- Segundo Caso: Este segundo cenário de corte de carga foi relacionado com a suspensão do fornecimento de energia sem prioridade de carga. No entanto, a minimização de chaveamento foi considerada. O que torna um estudo de grande relevância destinado, principalmente, a empresas distribuidoras de energia, uma vez que, a este estudo pode ser relacionado o custo de realizar o chaveamento.

- Terceiro Caso: Neste último cenário de corte de carga foi considerado o desligamento de cargas, tanto com prioridade de carga quanto minimização de chaveamento. Os critérios para as prioridades de carga foram discutidos na seção 3.1.

Finalmente, a partir das informações mencionadas acima, o modelo matemático de programação cônica de segunda ordem inteiro misto propõe a reconfiguração ideal para o sistema em cada situação de corte de carga. Os resultados dos testes são apresentados nas seções seguintes, onde são também analisados.

\subsection{Testes e Resultados.}

Nesta seção são apresentados os resultados obtidos para a avaliação da metodologia proposta, que busca efetuar o corte de carga de sistemas de distribuição radiais. Em cada um dos cenários de estudo foram destacados a tensão mínima encontrada, seu respectivo nó e a reconfiguração obtida após a efetivação do corte de carga.

A variável $S T$ definida no modelo proposto assumiu quatro situações para os cortes de cargas: $1.000,2.000,3.000$ e 4.000 kVA. Sendo esta quantidade máxima 
de carga a ser desligada adotada próximo ao valor percentual, de 5\%, utilizado pela ONS no dia 19 de janeiro de 2015.

\subsubsection{Primeiro Cenário.}

Nesta seção, apresentam-se os cortes de carga para o cenário em que não há prioridade de carga. Para isso, será adotado $\alpha_{i j}=1$, e a minimização de chaveamento não é considerada, desta forma os conjuntos $\Omega_{a a}$ e $\Omega_{a f}$, que estão inseridos na função objetivo, terão seu espaço de busca igual ao conjunto $\Omega_{l}$, podendo tornar a topologia final do SDEE bem distinta da condição inicial.

\subsubsection{Corte de Carga de 1.000 kVA.}

Neste primeiro teste, o corte de carga foi de 1.000 MVA. Ao comparar a Figura 4.1 com a Figura 4.2, observa-se que ocorre uma reconfiguração do sistema de forma a obter uma topologia radial para atender o corte de carga. Porém, nota-se que muitas alterações das chaves foram realizadas quando comparadas com o estado original do sistema testado.

Observa-se que os nós 20 e 49 estão desligados do sistema, totalizando uma quantidade de carga de 1.000,98 kVA. Para se obter esta nova condição de operação, foram realizadas as seguintes modificações na topologia:

- Chaves que estavam fechadas foram abertas: 19-20, 104-21, 13-43, 9-22, 48-49 e 49-50.

- Chaves que estavam abertas foram fechadas: 104-22, 17-18, 12-13 e 28-50.

- As demais chaves tiveram seu estado inalterado. 
A topologia do sistema após o corte de carga agora possui 51 nós (sendo que 48 são nós de carga e 3 subestações) e 48 circuitos. O nó com a menor tensão foi o nó 36, com tensão de 0,9706 pu. A solução ótima foi encontrada em 15,84 segundos.

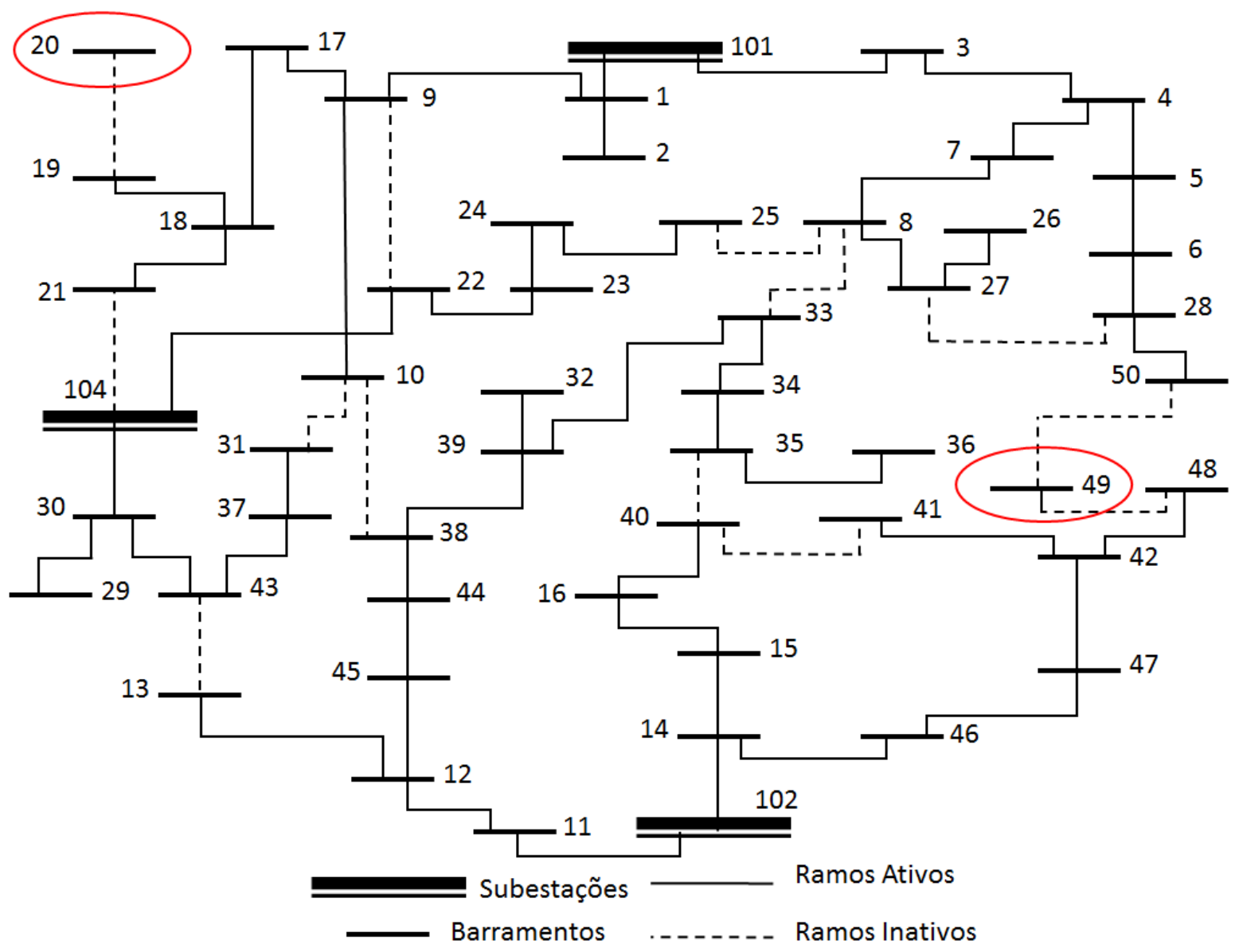

Figura 4.2 - Corte de carga de 1.000 kVA sem prioridade e minimização de chaveamento.

\subsubsection{Corte de Carga de 2.000 kVA.}

Nesta seção foi analisado o corte de carga fixado em 2.000 kVA. De maneira análoga a situação anteriormente analisada, o sistema obteve uma reconfiguração, que é mostrada na Figura 4.3, para que a menor quantidade de carga seja desligada da rede. Os nós que ficaram desenergizados foram 29 e 34, totalizando uma quantidade de carga de 2.001,99 kVA desconectada do sistema. Para se chegar a essa condição de operação as modificações realizadas foram: 
- Chaves que estavam fechadas foram abertas: 9-17, 22-23, 30-29, 30-43, 31 37, 33-39, 38-44, 33-34 e 34-35.

- Chaves que estavam abertas foram fechadas: 12-13, 17-18, 10-31, 10-38, $8-25,8-33,35-40$.

- As demais chaves tiveram seu estado inalterado.

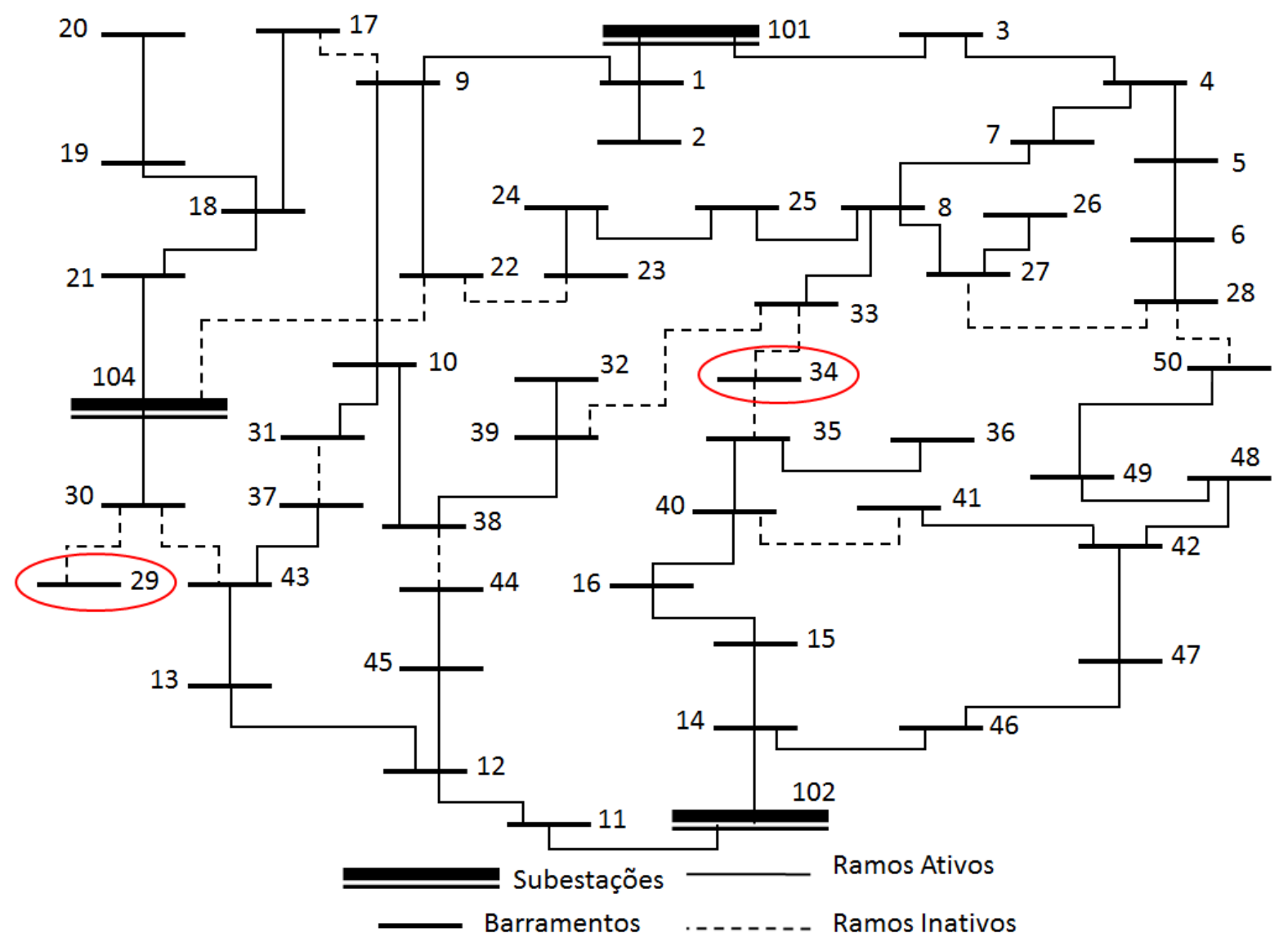

Figura 4.3 - Corte de carga de 2.000 kVA sem prioridade e minimização de chaveamento.

Dezesseis chaveamentos foram realizados no processo ( 9 chaves abriram e 8 fecharam). Com isso, o sistema passa a operar com 51 nós (sendo que 48 são nós de carga e 3 subestações) e 48 circuitos. O nó com a menor tensão foi o nó 32, com tensão de 0,9700 pu. A solução ótima foi encontrada em 7,11 segundos. 


\subsubsection{Corte de Carga de 3.000 kVA.}

Neste caso, foi analisado o corte de carga fixado em 3.000 kVA. Como é mostrado na Figura 4.4, os nós que ficaram desenergizados foram 17, 28, 29, 36 e 50 , totalizando uma quantidade de carga sem fornecimento de energia de $3.002,98$ kVA. As alterações propostas pelo modelo matemático são:

- Chaves que estavam fechadas foram abertas: 9-17, 1-9, 30-29, 33-39, 33$34,35-36,6-28$ e 49-50.

- Chaves que estavam abertas foram fechadas: 104-22, 8-33, 35-40.

- As demais chaves tiveram seu estado inalterado.

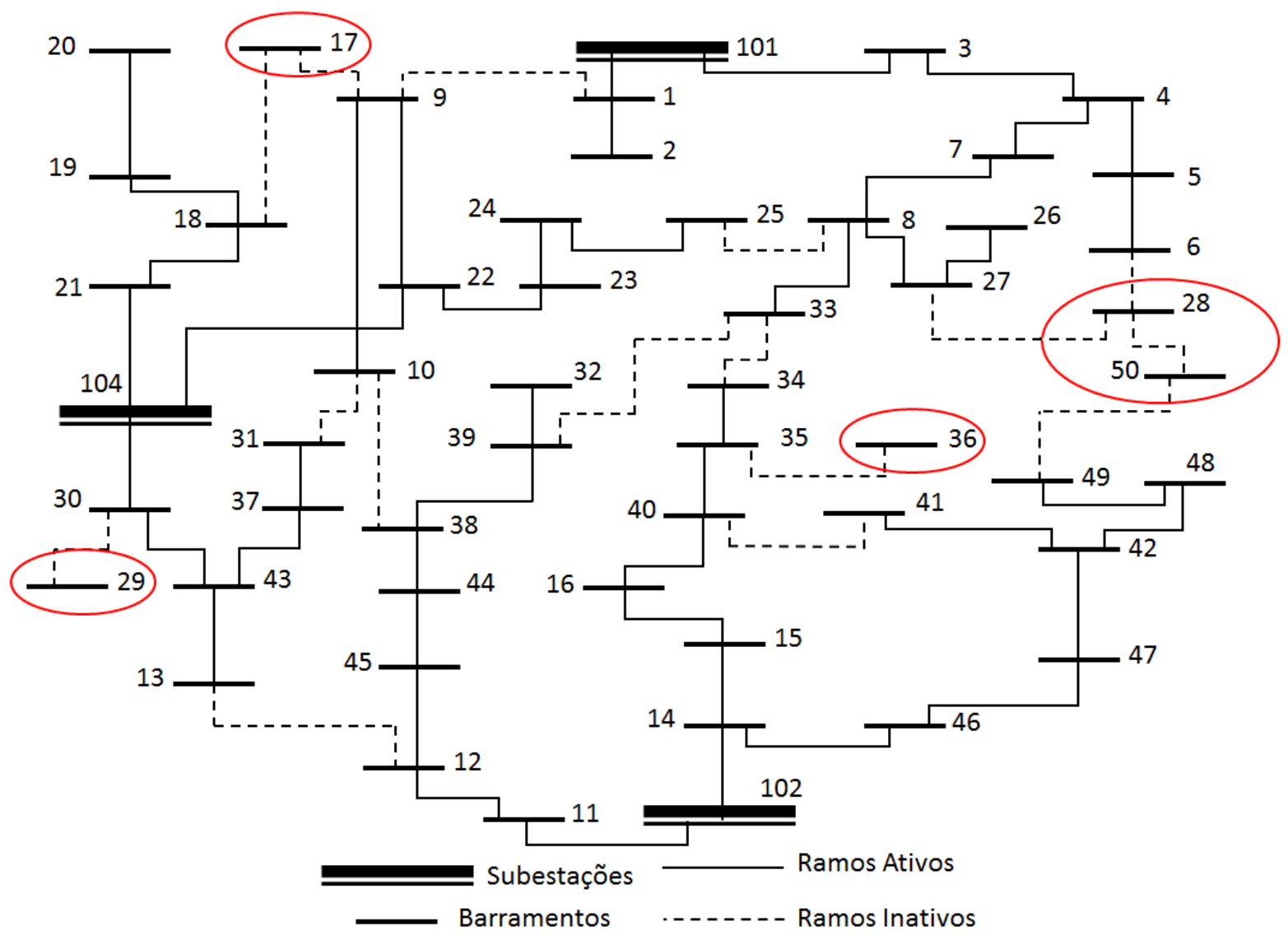

Figura 4.4 - Corte de carga de 3.000 kVA sem prioridade e minimização de chaveamento.

Para essa situação, onze chaveamentos foram realizados no processo (8 chaves abriram e 3 fecharam). Com isso, o sistema passa a operar com 48 nós (sendo 
que 45 são nós de carga e 3 subestações) e 45 circuitos. O nó com a menor tensão foi o nó 34, com tensão de 0.9779 pu. A solução ótima foi encontrada em 37,25 segundos.

\subsubsection{Corte de Carga de 4.000 kVA.}

Neste último caso, o corte de carga foi de 4.000 kVA. A reconfiguração obtida é mostrada na Figura 4.5. Para este caso os nós que ficaram desenergizados foram $25,26,32,41$ e 49, totalizando um corte de carga de 4.003,99 kVA. A nova topologia foi obtida através das seguintes manobras:

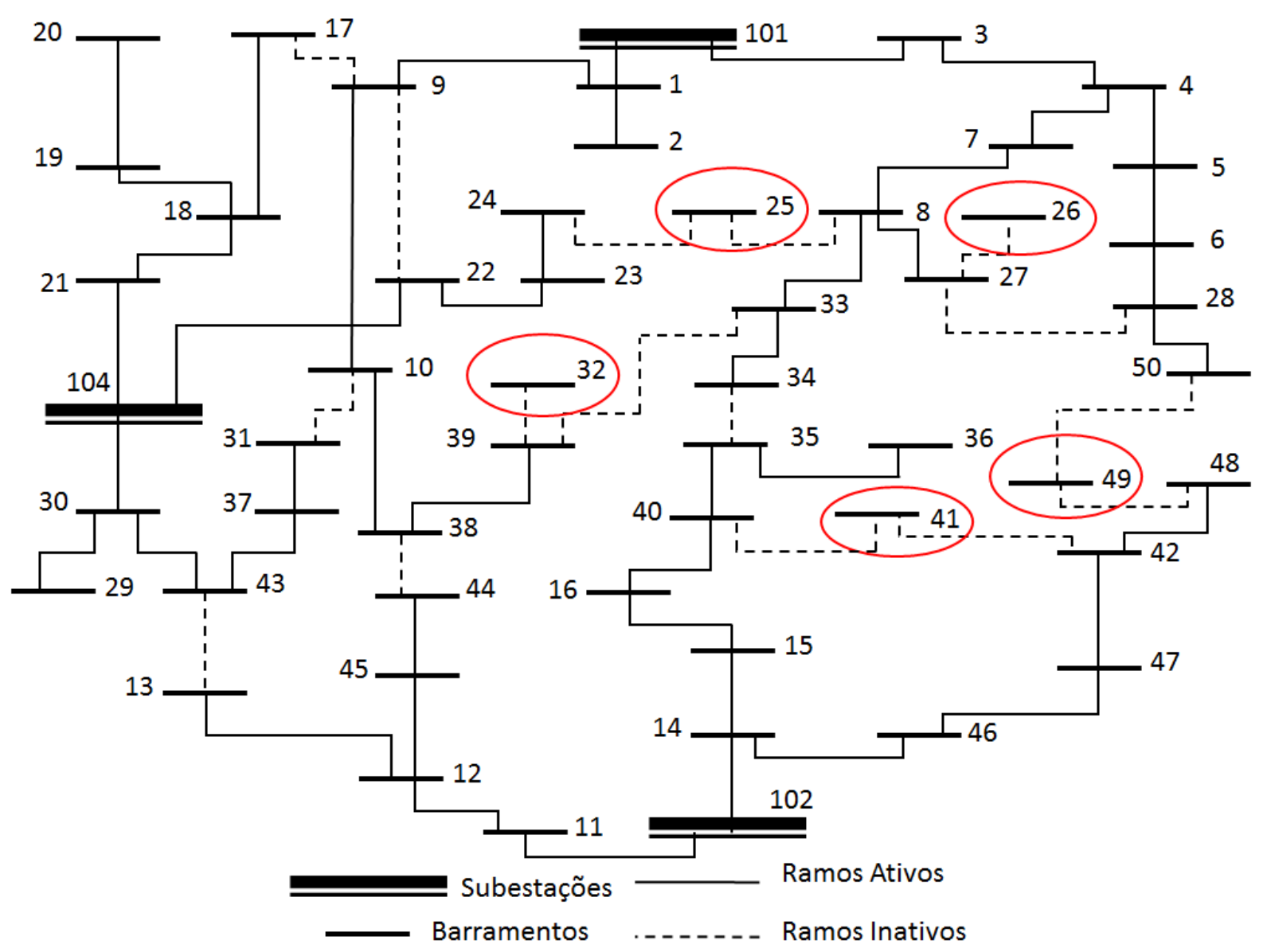

Figura 4.5 - Corte de carga de 4.000 kVA sem prioridade e minimização de chaveamento.

- Chaves que estavam fechadas foram abertas: 9-17, 9-22, 13-43, 33-39, 24$25,26-27,38-44,32-39,41-42,48-49$ e $49-50$. 
- Chaves que estavam abertas foram fechadas: 104-22, 12-13, 17-18, 10-38, 8-33, 35-40 e 28-50.

- As demais chaves tiveram seu estado inalterado.

Durante a realização do processo foram efetuados dezoito chaveamentos (11 chaves abriram e 7 fecharam). Com isso, o sistema passa a operar com 48 nós (sendo que 45 são nós de carga e 3 subestações) e 45 circuitos. 0 nó com a menor tensão foi o nó 34 , com tensão de 0,9801 pu. A solução ótima foi encontrada em 17,34 segundos.

\subsubsection{Segundo Cenário.}

A reconfiguração no SDEE é uma ferramenta de grande importância, pois ela é aplicada a vários cenários de problemas encontrados no sistema de distribuição: perda de energia, restauração de energia, corte de carga, etc.

No entanto, excessos de chaveamentos podem acarretar em mal funcionamento de equipamentos existentes. Isto deve-se ao fenômeno que ocorre ao realizar o chaveamento, a sobretensão (Overvoltage). Com isso, o cenário a ser estudado nesta seção visa minimizar o chaveamento das chaves automáticas, de maneira que as variáveis $\Omega_{a a}$ e $\Omega_{a f}$ formem conjuntos distintos, conjunto das chaves automáticas abertas e fechadas, respectivamente. Na Tabela 4.1 pode-se observar a disposição de cada conjunto com suas respectivas chaves. Com esta alteração é esperado que, após a realização do corte de carga, a reconfiguração do sistema modifique o mínimo com relação a estrutura inicial.

No entanto, neste estudo não é considerado a prioridade de carga. Assim como no cenário estudado anteriormente, em que todas as cargas têm a mesma 
prioridade de ser desligadas. De forma que o valor adotado para a variável $\alpha_{i j}$ é o mesmo.

Tabela 4.1 - Conjunto das chaves aberta e fechadas.

\begin{tabular}{|c|c|}
\hline Variáveis & Chaves do sistema \\
\hline$\Omega_{a a}$ & $\begin{array}{c}12-13,17-18,104-22,10-31,10-38,8-25,8-33,27-28,28-50,35- \\
40,40-41 .\end{array}$ \\
\hline$\Omega_{a f}$ & $\begin{array}{c}10-1,101-3,1-2,1-9,3-4,4-5,4-7,5-6,6-28,7-8,8-27,9-10,9-17 \\
10-31,102-11,11-12,12-45,13-43,102-14,14-15,14-46,15-16, \\
16-40,18-19,18-21,19-20,104-21,104-22,22-23,23-24,24-25, \\
26-27,29-30,104-30,31-37,32-39,33-34,33-39,34-35,35-36, \\
37-43,38-39,38-44,41-42,42-47,42-48,44-45,46-47,48-49,49- \\
50\end{array}$ \\
\hline
\end{tabular}

\subsubsection{Corte de Carga de 1.000 kVA.}

Neste primeiro teste, o corte de carga foi de $1.000 \mathrm{kVA}$. Ao comparar a Figura 4.1 com a Figura 4.6, observa-se que ocorreu uma reconfiguração do sistema de forma obter uma topologia radial para atender o corte de carga. Nota-se que ocorreram poucas alterações das chaves quando se comparado com o estado original do sistema. Com isso, os nós 49 e 50 estão desligados do sistema, totalizando uma quantidade de carga de 1.000,98 kVA. Porém, após a reconfiguração a chave 49-50 não é apresentada efetivamente manobrada por conectar duas barras desconexas do sistema desligado (barras ilhadas), dessa forma o chaveamento não deve ser contabilizado. Para se obter esta nova condição de operação foram realizadas as seguintes modificações na topologia:

- Chaves que estavam fechadas foram abertas: 48-49. 
- Chaves que estavam abertas foram fechadas: não houve alteração destas chaves.

- As demais chaves tiveram seu estado inalterado.

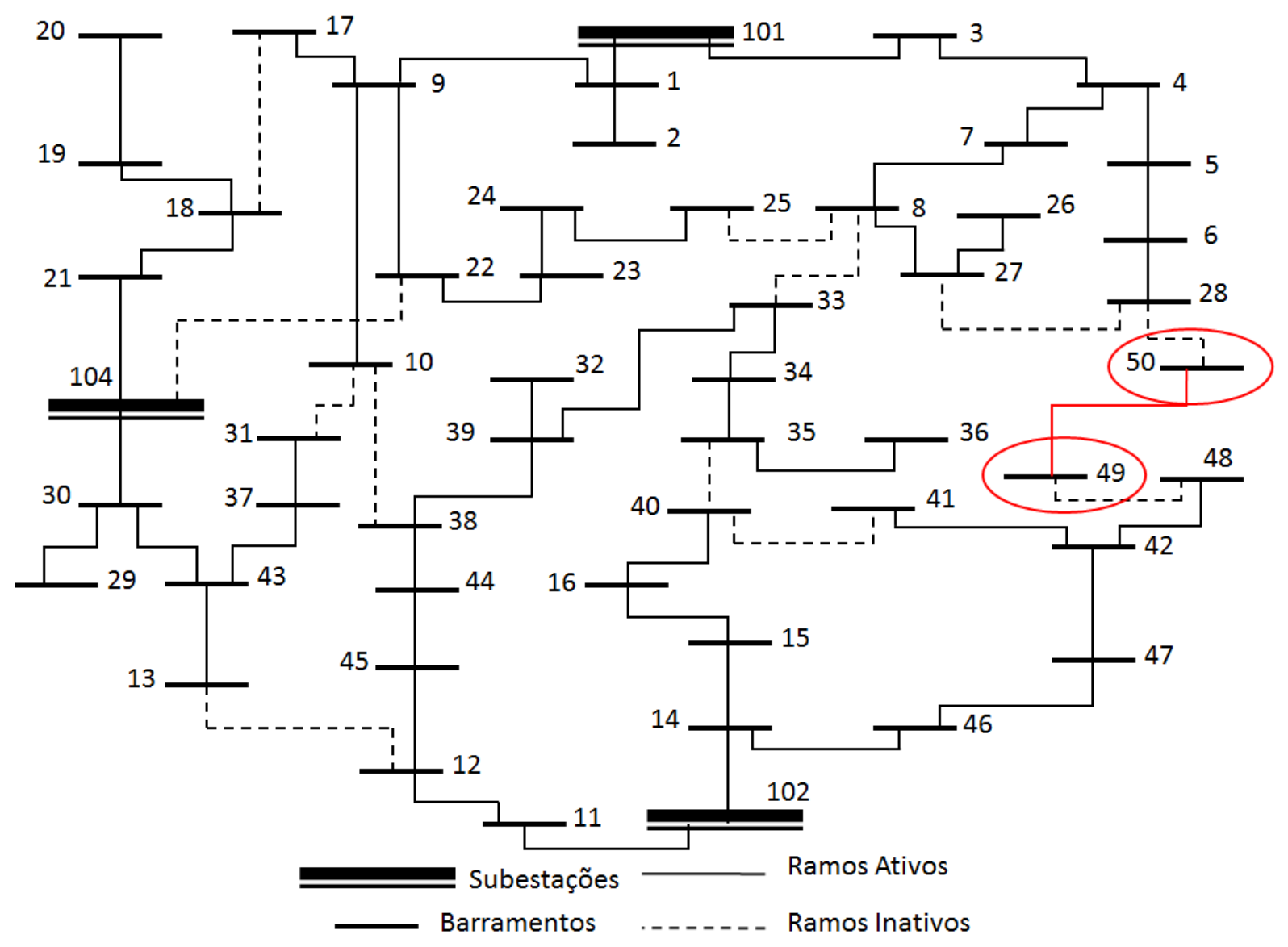

Figura 4.6 - Corte de carga de 1.000 kVA com minimização de chaveamento e sem prioridade.

A topologia do sistema, após o corte de carga, agora possui 51 nós (sendo que 48 são nós de carga e 3 subestações) e 48 circuitos. O nó com a menor tensão foi o nó 36 , com tensão de 0,9714 pu. A solução ótima foi encontrada em 0,39 segundos.

\subsubsection{Corte de Carga de 2.000 kVA.}

Nesta seção foi analisado o corte de carga fixado em 2.000 kVA. De maneira análoga a situação anteriormente analisada, o sistema obteve uma reconfiguração, 
que é mostrada na Figura 4.7, para que a menor quantidade de carga seja desligada da rede. Os nós que ficaram desenergizados foram 25 e 32, totalizando uma quantidade de carga de 2.001,99 kVA desconectada do sistema. Para se chegar a essa condição de operação, as modificações realizadas foram:

- Chaves que estavam fechadas foram abertas: 24-25 e 32-29.

- Chaves que estavam abertas foram fechadas: não houve alteração destas chaves.

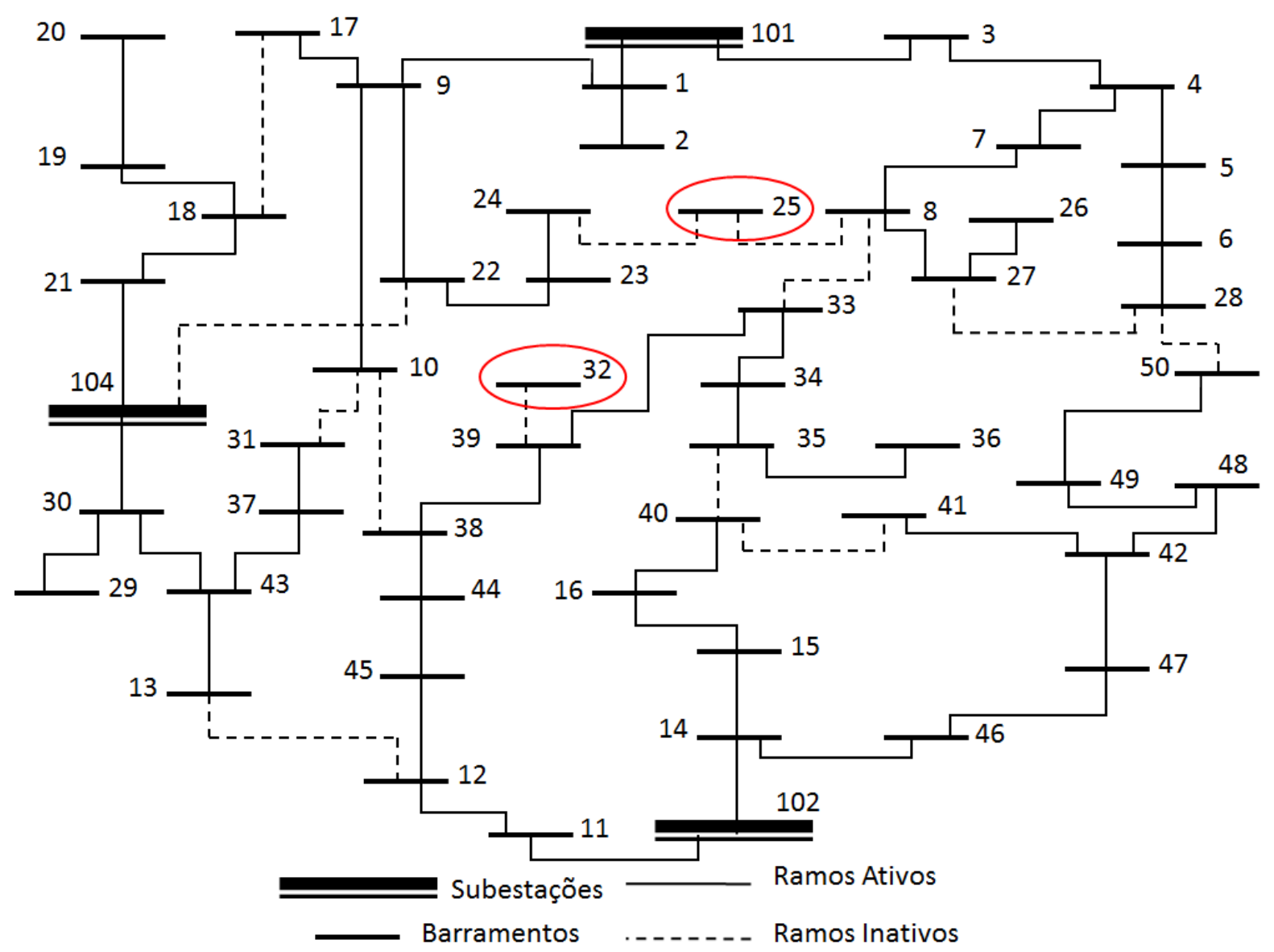

Figura 4.7 - Corte de carga de 2.000 kVA com minimização de chaveamento e sem prioridade.

- As demais chaves tiveram seu estado inalterado.

Dois chaveamentos foram realizados no processo ( 2 chaves abriram e nenhuma chave fechou). Com isso, o sistema passa a operar com 51 nós (sendo que 
48 são nós de carga e 3 subestações) e 48 circuitos. O nó com a menor tensão foi o nó 36, com tensão de 0,9749 pu. A solução ótima foi encontrada em 0,66 segundos.

\subsubsection{Corte de Carga de 3.000 kVA.}

Neste caso foi analisado o corte de carga fixado em 3.000 kVA. Como é mostrado na Figura 4.8, os nós que ficaram desenergizados foram 29, 32 e 50, totalizando uma quantidade de carga sem fornecimento de energia de 3.002,98 kVA. As alterações propostas pelo modelo matemático são:

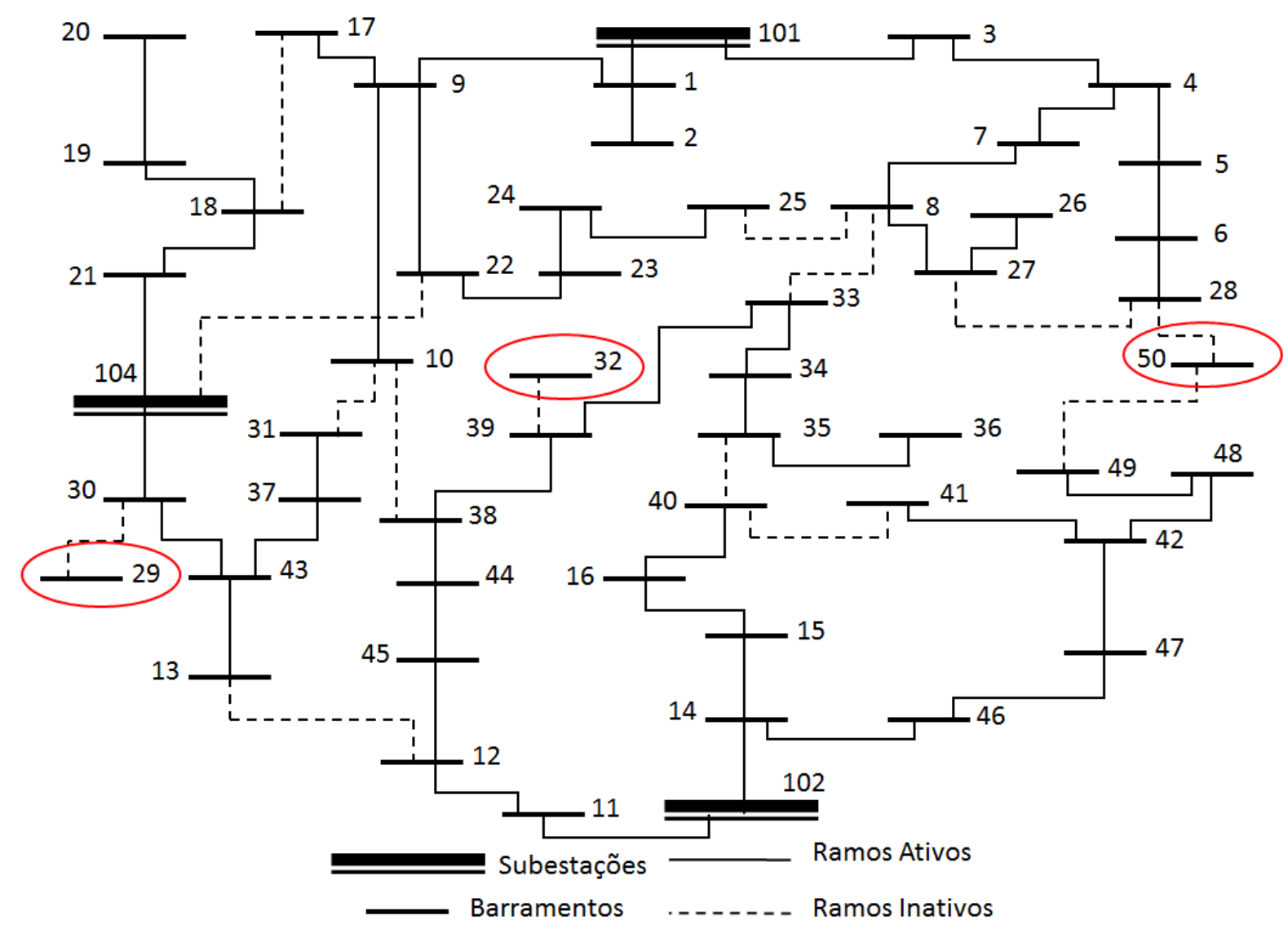

Figura 4.8 - Corte de carga de 3.000 kVA com minimização de chaveamento e sem prioridade.

- Chaves que estavam fechadas foram abertas: 29-30, 32-39 e 49-50.

- Chaves que estavam abertas foram fechadas: não houve alteração destas chaves. 
- As demais chaves tiveram seu estado inalterado.

Para essa situação três chaveamentos foram realizados no processo (3 chaves abriram e nenhuma chave fechou). Com isso o sistema passa a operar com 50 nós (sendo que 47 são nós de carga e 3 subestações) e 47 circuitos. O nó com a menor tensão foi o nó 36 , com tensão de 0,9749 pu. A solução ótima foi encontrada em 3,75 segundos.

\subsubsection{Corte de Carga de 4.000 kVA.}

Neste último caso o corte de carga foi de 4.000 kVA. A reconfiguração obtida é mostrada na Figura 4.9. Para este caso os nós que ficaram desenergizados foram 10, 40 e 41, totalizando um corte de carga de 4.003,99 kVA. A nova topologia foi obtida através das seguintes manobras:

- Chaves que estavam fechadas foram abertas: 9-10, 16-40 e 41-42.

-Chaves que estavam abertas foram fechadas: não houve alteração destas chaves.

- As demais chaves tiveram seu estado inalterado.

Durante a realização do processo foram efetuados 3 chaveamentos ( 3 chaves abriram e nenhuma chave fechou). Com isso o sistema passa a operar com 50 nós (sendo que 47 são nós de carga e 3 subestações) e 47 circuitos. O nó com a menor tensão foi o nó 36 , com tensão de 0,9714 pu. A solução ótima foi encontrada em 0,94 segundos. 


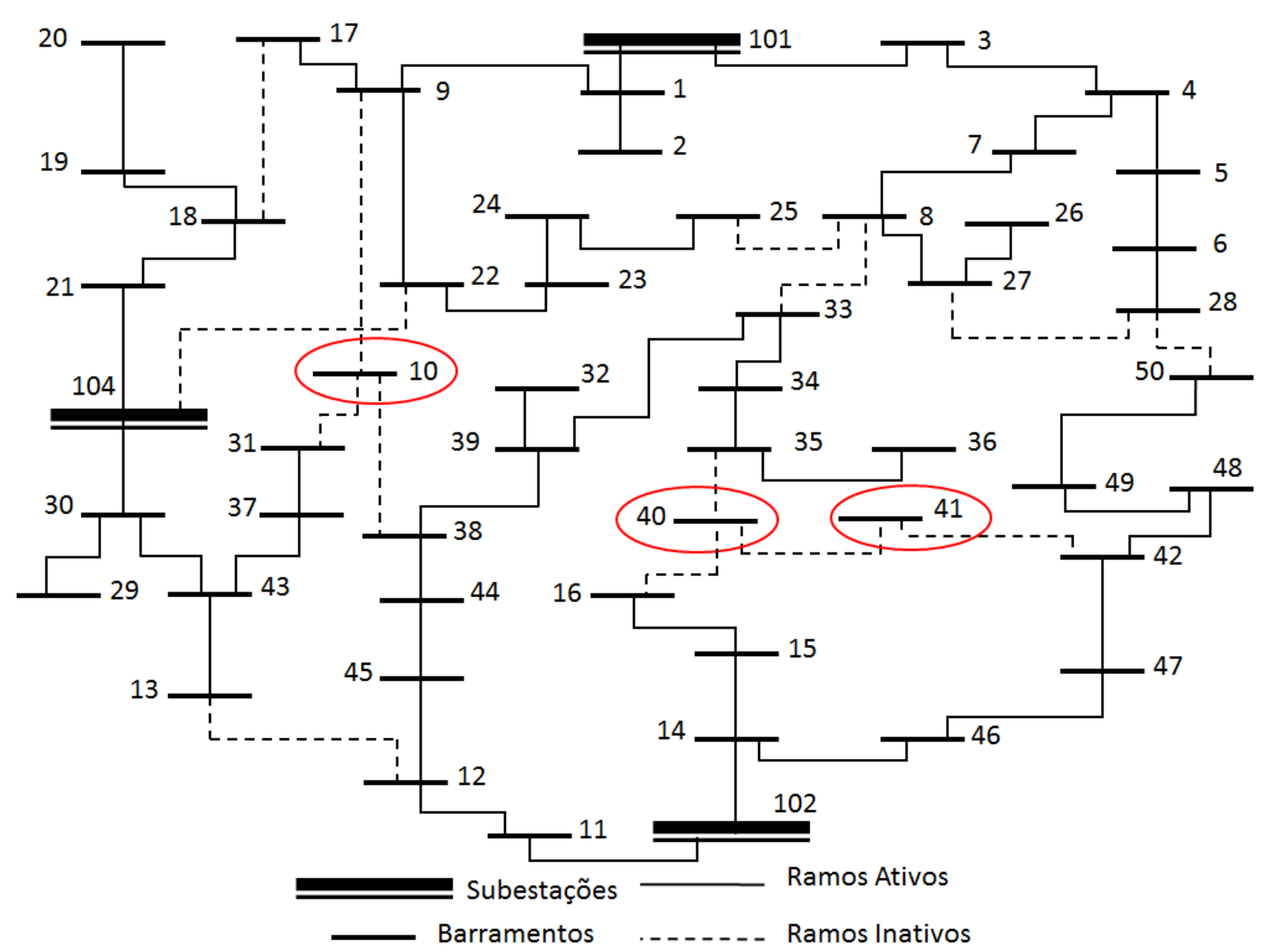

Figura 4.9 - Corte de carga de 4.000 kVA com minimização de chaveamento e sem prioridade.

\subsubsection{Terceiro Cenário.}

Nesta seção foi realizado o estudo mais completo do modelo matemático, que forneceu tanto a minimização dos chaveamentos, de forma que a estrutura inicial do sistema se modifique o mínimo possível, quanto a minimização do corte de carga com prioridade de carga. Dessa forma, cada nó de carga recebeu um valor de 1 a 3, que representará a prioridade da carga para ser desligada. Então, quanto maior este valor, menor é a probabilidade deste nó ser desligado, tornando este nó de alta prioridade, como por exemplo, hospital, transporte público, etc. Na Tabela 4.2, se está disposto os pesos para o desligamento de cada nó de carga. 
Tabela 4.2 - Pesos para prioridade dos nós de carga.

\begin{tabular}{cccc}
\hline Nó & $\boldsymbol{\alpha}_{\boldsymbol{i} \boldsymbol{j}}$ & $\mathrm{N}$ ó & $\boldsymbol{\alpha}_{\boldsymbol{i} \boldsymbol{j}}$ \\
\hline $\mathrm{N} 1$ & 3 & $\mathrm{~N} 26$ & 3 \\
$\mathrm{~N} 2$ & 2 & $\mathrm{~N} 27$ & 3 \\
$\mathrm{~N} 3$ & 2 & $\mathrm{~N} 28$ & 1 \\
$\mathrm{~N} 4$ & 1 & $\mathrm{~N} 29$ & 2 \\
$\mathrm{~N} 5$ & 1 & $\mathrm{~N} 30$ & 1 \\
$\mathrm{~N} 6$ & 2 & $\mathrm{~N} 31$ & 3 \\
$\mathrm{~N} 7$ & 2 & $\mathrm{~N} 32$ & 2 \\
$\mathrm{~N} 8$ & 3 & $\mathrm{~N} 33$ & 1 \\
$\mathrm{~N} 9$ & 2 & $\mathrm{~N} 34$ & 2 \\
$\mathrm{~N} 10$ & 2 & $\mathrm{~N} 35$ & 3 \\
$\mathrm{~N} 11$ & 3 & $\mathrm{~N} 36$ & 1 \\
$\mathrm{~N} 12$ & 2 & $\mathrm{~N} 37$ & 3 \\
$\mathrm{~N} 13$ & 1 & $\mathrm{~N} 38$ & 2 \\
$\mathrm{~N} 14$ & 2 & $\mathrm{~N} 39$ & 1 \\
$\mathrm{~N} 15$ & 2 & $\mathrm{~N} 40$ & 3 \\
$\mathrm{~N} 16$ & 3 & $\mathrm{~N} 41$ & 2 \\
$\mathrm{~N} 17$ & 2 & $\mathrm{~N} 42$ & 1 \\
$\mathrm{~N} 18$ & 3 & $\mathrm{~N} 43$ & 3 \\
$\mathrm{~N} 19$ & 2 & $\mathrm{~N} 44$ & 2 \\
$\mathrm{~N} 20$ & 1 & $\mathrm{~N} 45$ & 1 \\
$\mathrm{~N} 21$ & 2 & $\mathrm{~N} 46$ & 2 \\
$\mathrm{~N} 22$ & 1 & $\mathrm{~N} 47$ & 3 \\
$\mathrm{~N} 23$ & 1 & $\mathrm{~N} 48$ & 1 \\
$\mathrm{~N} 24$ & 3 & $\mathrm{~N} 49$ & 1 \\
$\mathrm{~N} 25$ & 2 & $\mathrm{~N} 50$ & 2 \\
\hline
\end{tabular}

Dessa forma, a seguir serão apresentados os cortes carga para o cenário proposto.

\subsubsection{Corte de Carga 1.000 kVA.}

Neste primeiro teste o corte de carga foi de 1.000 kVA. Ao comparar a Figura 4.1 com a Figura 4.10, observa-se que ocorreu uma reconfiguração do sistema de forma a obter uma topologia radial para atender ao corte de carga. Nota-se que ocorreram poucas alterações das chaves quando comparado com o estado original do sistema testado. Com isso, os nós 20 e 49 foram desligados do sistema, totalizando 
uma quantidade de carga de 1.000,98 kVA. Para se obter esta nova condição de operação foram realizadas as seguintes modificações na topologia:

- Chaves que estavam fechadas foram abertas: 19-20, 48-49 e 49-50.

- Chaves que estavam abertas foram fechadas: $28-50$.

- As demais chaves tiveram seu estado inalterado.

A topologia do sistema após o corte de carga agora possui 51 nós (sendo que 48 são nós de carga e 3 subestações) e 48 circuitos. O nó com a menor tensão foi o nó 36, com tensão de 0,9714 pu. A solução ótima foi encontrada em 0,19 segundos.

\subsubsection{Corte de Carga 2.000 kVA.}

Nesta seção foi analisado o corte de carga fixado em 2.000 kVA. De maneira análoga a situação anteriormente analisada, o sistema obteve uma reconfiguração, que é mostrada na Figura 4.11. Para que a menor quantidade de carga seja desligada da rede. Com isso, os nós que ficaram desenergizados foram 13, 20 e 28, totalizando uma quantidade de carga de 2.001,99 kVA desconectada do sistema. Para se chegar a essa condição de operação as modificações realizadas foram:

- Chaves que estavam fechadas foram abertas: 6-28, 13-43 e 19-20.

- Chaves que estavam abertas foram fechadas: não houve alteração destas chaves.

- As demais chaves tiveram seu estado inalterado.

Três chaveamentos foram realizados no processo ( 3 chaves abriram e nenhuma chave fechou). Com isso, o sistema passa a operar com 50 nós (sendo que 47 são nós de carga e 3 subestações) e 47 circuitos. O nó com a menor tensão foi o nó 36, com tensão de 0,9714 pu. A solução ótima foi encontrada em 0,21 segundos. 


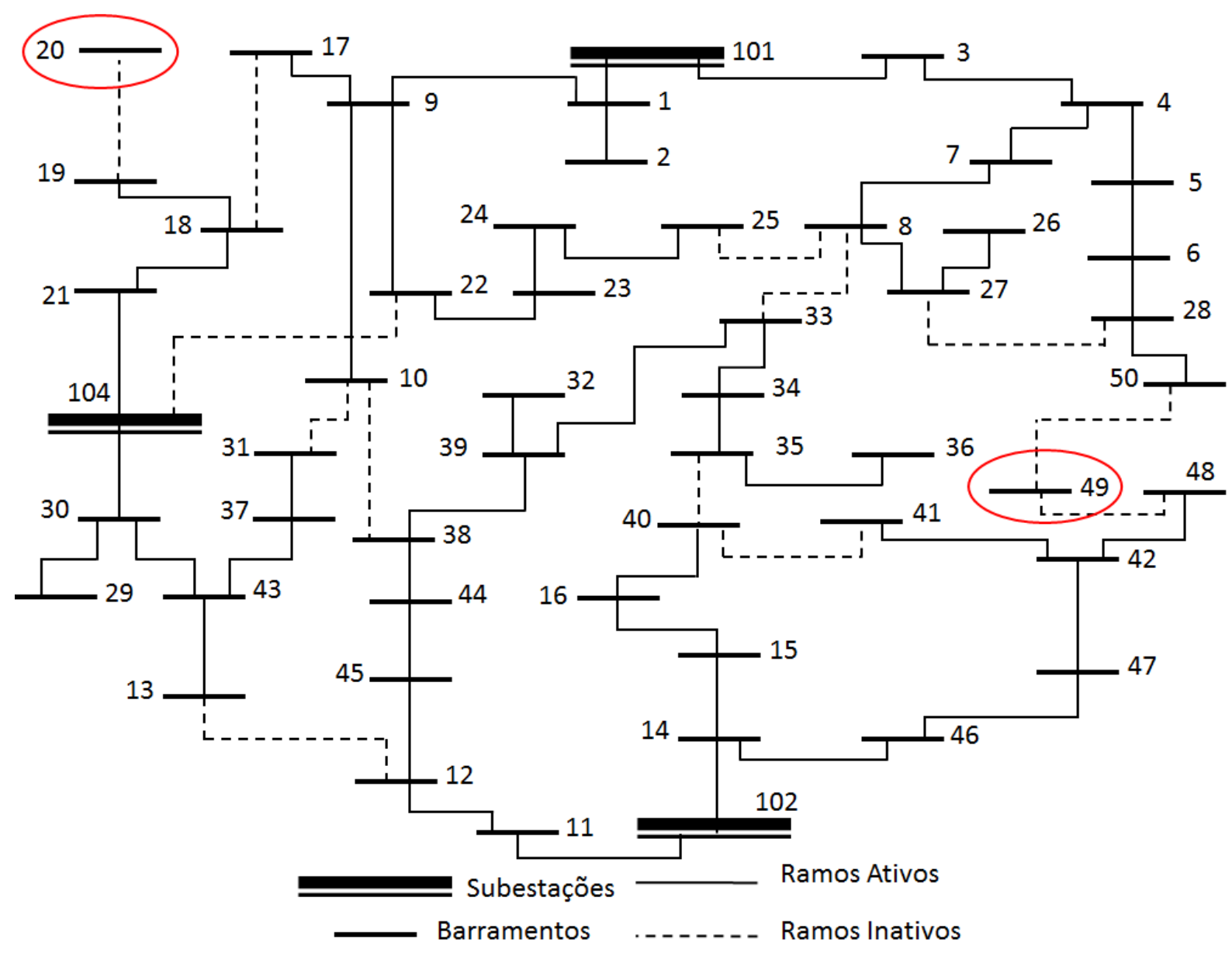

Figura 4.10 - Corte de carga de 1.000 kVA com prioridade e minimização de chaveamento.

\subsubsection{Corte de Carga 3.000 kVA.}

Neste caso foi analisado o corte de carga fixado em 3000 kVA. Como se pode observar na Figura 4.12, os nós que ficaram desenergizados foram 20, 22, 23, 28 e 36, totalizando uma quantidade de carga sem fornecimento de energia de $3.003,01$ kVA. Porém, após a reconfiguração, a chave 22-23 não é apresentada efetivamente manobrada por conectar duas barras desconexas do sistema desligado (barras ilhadas), portanto o chaveamento não deve ser contabilizado. As alterações propostas pelo modelo matemático são:

- Chaves que estavam fechadas foram abertas: 6-28, 9-22, 19-20, 23-24 e 3435. 


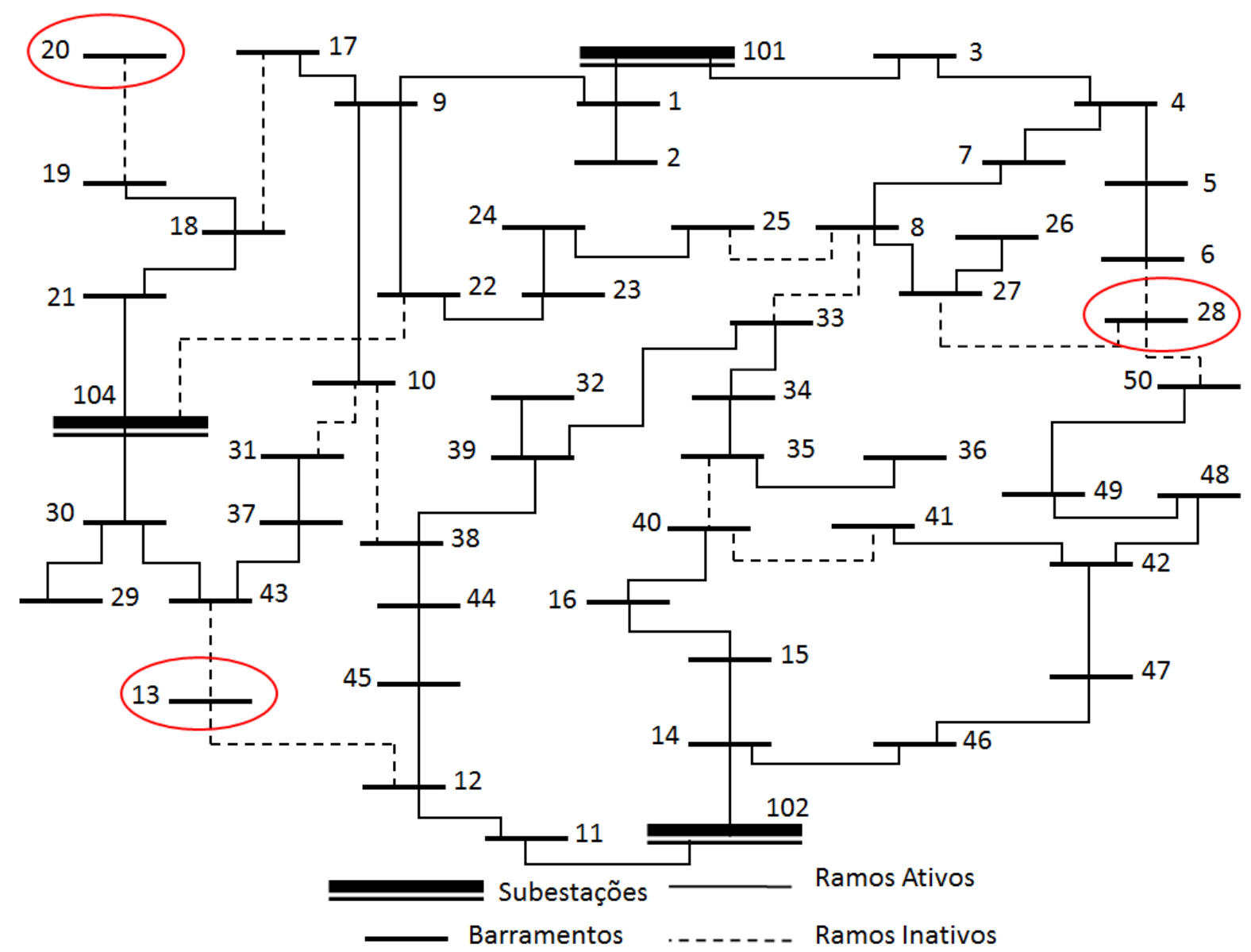

Figura 4.11 - Corte de carga de 2.000 kVA com prioridade e minimização de chaveamento.

- Chaves que estavam abertas foram fechadas: 8-25.

- As demais chaves tiveram seu estado inalterado.

Para essa situação seis chaveamentos foram realizados no processo (5 chaves abriram e 1 fechou). Com isso, o sistema passa a operar com 48 nós (sendo que 45 são nós de carga e 3 subestações) e 45 circuitos. O nó com a menor tensão foi o nó 35 , com tensão de 0,9729 pu. A solução ótima foi encontrada em 1,41 segundos. 


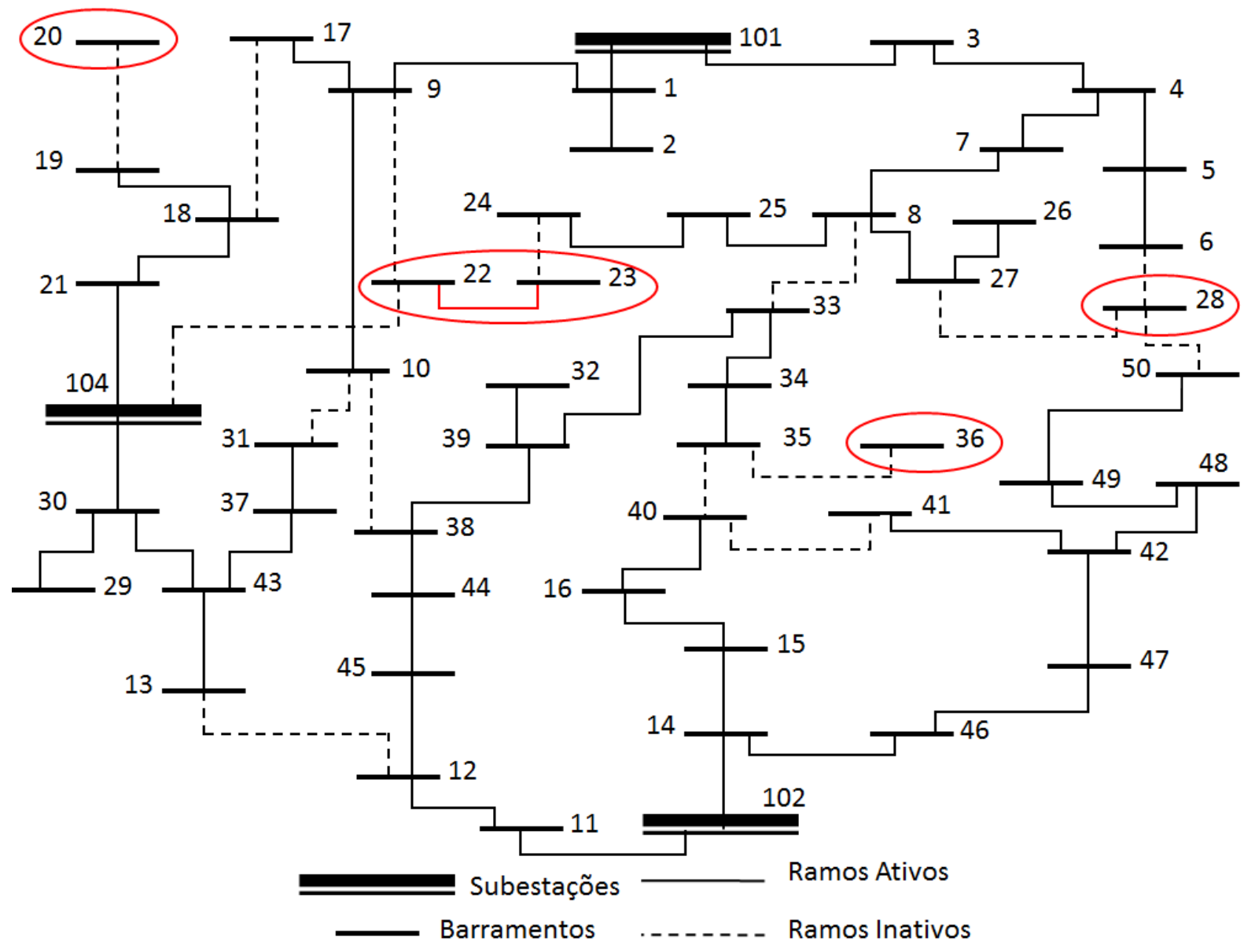

Figura 4.12 - Corte de carga de 3000 kVA com prioridade e minimização de chaveamento.

\subsubsection{Corte de Carga 4.000 kVA.}

Neste último caso o corte de carga é de 4.000 kVA. A reconfiguração obtida é mostrada na Figura 4.13. Para este caso os nós que ficaram desenergizados foram 23, 33, 48 e 49, totalizando um corte de carga de 4.003,99 kVA. Porém, após a reconfiguração, a chave 48-49 não é apresentada efetivamente manobrada por conectar duas barras desconexas do sistema desligado (barras ilhadas), portanto o chaveamento não deve ser contabilizado. A nova topologia foi obtida através das seguintes manobras:

- Chaves que estavam fechadas foram abertas: 22-23, 23-24, 33-34, 33-39, $42-48$ e $49-50$.

- Chaves que estavam abertas foram fechadas: 8-25, 28-50 e 35-40. 


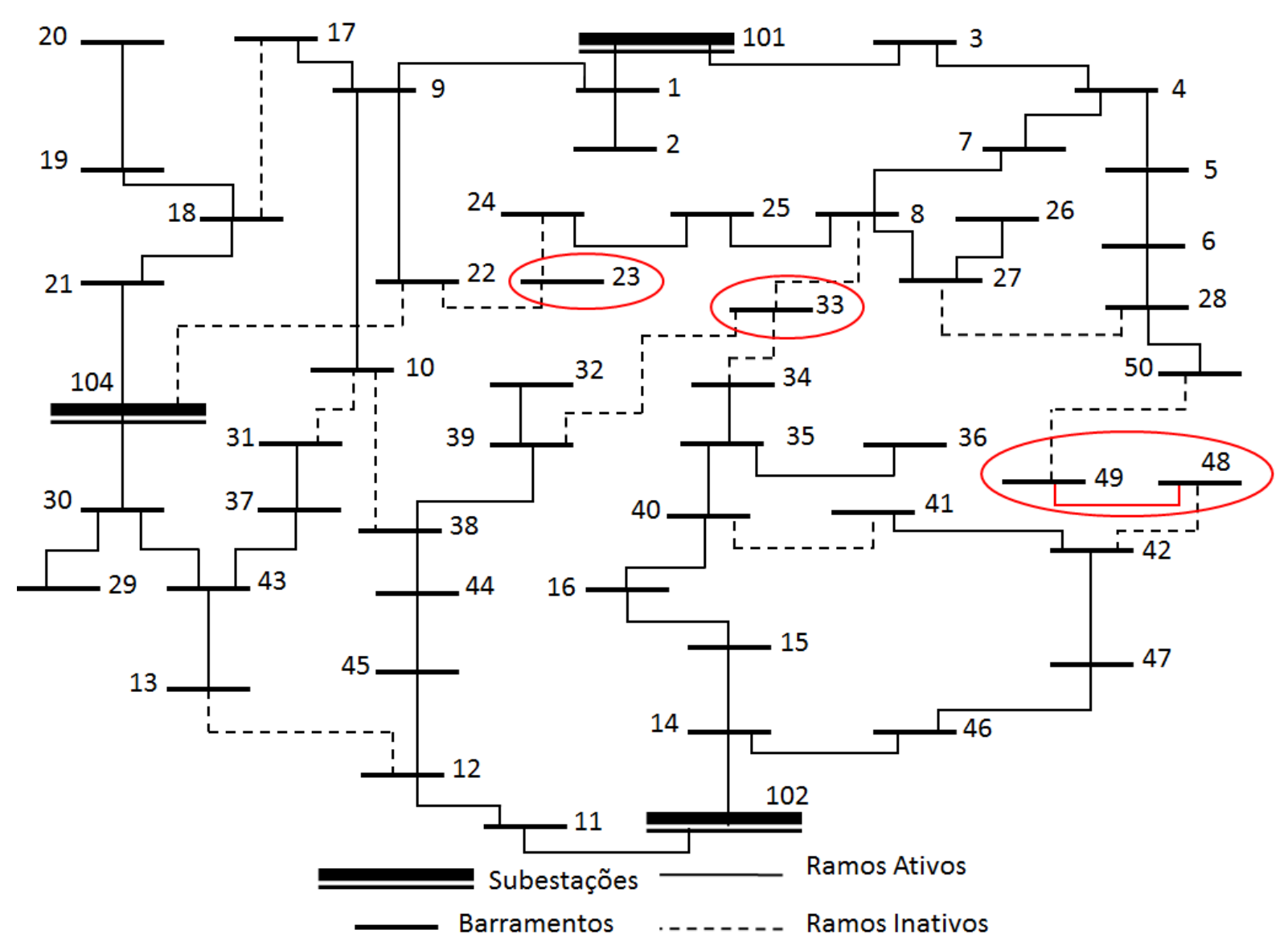

Figura 4.13 - Corte de carga de 4.000 kVA com prioridade e minimização de chaveamento.

- As demais chaves tiveram seu estado inalterado.

Durante a realização do processo foram efetuados 9 chaveamentos ( 6 chaves abriram e 3 chaves fecharam). Com isso, o sistema passa a operar com 49 nós (sendo que 46 são nós de carga e 3 subestações) e 46 circuitos. O nó com a menor tensão foi o nó 34, com tensão de 0,9773 pu. A solução ótima foi encontrada em 2,45 segundos.

\subsection{Considerações Finais.}

No primeiro cenário de teste, que busca minimizar a quantidade de carga desligada do sistema de energia, sem considerar prioridade de carga, e sem minimização de chaveamento, observou-se que ocorre excessiva quantidade de chaveamentos para atingir o ponto ótimo. No segundo cenário ocorre uma redução 
significativa nos chaveamentos para determinação do ponto ótimo. Assim como na situação anterior, no terceiro cenário os chaveamentos foram minimizados.

A quantidade de carga cortada feita nos três cenários não teve variação, apenas no corte de carga de 3.000 kVA considerando a prioridade de carga e a mínima variação da condição inicial do sistema. Isso aconteceu devido ao fato da restrição das cargas a serem desligadas.

A tolerância de convergência adotada para todos os testes realizados foi de $10^{-3}$. Na Tabela 4.3 encontra-se a capacidade de cada subestação para cada caso de corte de carga e seus respectivos limite máximo de capacidade, nota-se que não ocorreu violação dos limites de capacidade para nenhuma situação. Na Tabela 4.4 encontram-se todos os números de chaveamentos ocorridos durante os cortes de carga. No primeiro cenário percebe-se que ocorreram o maior número de chaveamentos, no segundo cenário a quantidade de comutação reduz, significativamente. Isso ocorreu devido à penalização imposta sobre as chaves. Por fim, no terceiro cenário também ocorreu uma redução de chaveamento se comparado com o primeiro cenário. Ao comparar com o segundo cenário ocorreu um aumento de chaveamento, devido a inserção da restrição de prioridade de carga a serem desligadas.

Tabela 4.3 - Capacidade das subestações.

\begin{tabular}{|c|c|c|c|c|c|c|c|c|c|c|c|c|c|}
\hline \multirow{2}{*}{ Barras } & \multirow{2}{*}{$\begin{array}{l}\text { Limite Máx. } \\
\text { de } \\
\text { carregamento } \\
\text { (kVA) }\end{array}$} & \multicolumn{4}{|c|}{$\begin{array}{l}\text { Cenário } 1 \text { em } \\
\text { (MVA) }\end{array}$} & \multicolumn{4}{|c|}{$\begin{array}{l}\text { Cenário } 2 \text { em } \\
\text { (MVA) }\end{array}$} & \multicolumn{4}{|c|}{$\begin{array}{c}\text { Cenário } 3 \text { em } \\
\text { (MVA) }\end{array}$} \\
\hline & & 1 & 2 & 3 & 4 & 1 & 2 & 3 & 4 & 1 & 2 & 3 & 4 \\
\hline 101 & 33.400 & 21,1 & 25,1 & 15,1 & 21,1 & 19,8 & 19,1 & 19,8 & 17,5 & 20,4 & 19,2 & 17,6 & 19,6 \\
\hline 102 & 30.000 & 20,3 & 17,7 & 17,2 & 13,3 & 19,4 & 19,1 & 18,4 & 18,6 & 19,4 & 20,4 & 20,2 & 16,2 \\
\hline 104 & 22.000 & 8,99 & 6,57 & 16,1 & 12,9 & 11,2 & 11,2 & 10,1 & 11,2 & 10,5 & 9,67 & 10,5 & 11,2 \\
\hline
\end{tabular}


Tabela 4.4 - Número de chaveamento para cada cenário de corte de carga.

\begin{tabular}{lcccc}
\hline & Número de & Número de & Número de & Número de \\
Cenários & chaveamento para & chaveamento para & chaveamento para & chaveamento para \\
& $\mathbf{1 . 0 0 0}$ kVA & $\mathbf{2 . 0 0 0 ~ k V A}$ & $\mathbf{3 . 0 0 0 ~ k V A}$ & $\mathbf{4 . 0 0 0 ~ k V A ~}$ \\
\hline Primeiro & 10 & 16 & 11 & 18 \\
Segundo & 1 & 2 & 3 & 3 \\
\hline Terceiro & 4 & 3 & 6 & 9 \\
\hline
\end{tabular}

Desta forma, os resultados obtidos comprovaram a eficiência da modelagem matemática proposta, pois todos os cortes de carga sugeridos foram atendidos, sem violar as restrições operacionais do SDEE. 


\section{Conclusão}

O objetivo principal deste trabalho foi contribuir com o desenvolvimento de uma modelagem matemática que seja capaz de realizar o corte de carga, quando necessário, com o mínimo de demanda desligada. Outra proposta foi a minimização de chaveamento.

Uma modelagem foi proposta como forma alternativa a programação nãolinear inteira mista, de modo que, a convergência do resultado final é a mesma. O trabalho abordou diferentes funções objetivo como propostas de otimização, discutindo o problema de corte de carga sob diferentes cenários.

Os resultados foram obtidos a partir de um sistema teste de 53 barras ( 3 subestações e 50 barras de cargas). Dentro do ambiente de programação matemática GAMS, este modelo foi resolvido utilizando o solver comercial CPLEX. Os testes realizados evidenciaram a eficiência e a consistência do modelo matemático proposto para elaboração do corte de carga em termos da função objetivo e de cumprimento das restrições do problema.

\subsection{Trabalhos Futuros}

- Desenvolver uma metodologia capaz de realizar o corte de carga por zonas, ao invés de realizar a suspensão de energia por cada alimentador. Aproximando-se da realidade, pois dessa forma, se considera que cada ramo não tenha uma chave. 
- Desenvolver uma heurística que realize o corte de carga, esperando que se possa melhorar o tempo computacional. E poder se aplicar em situações de estudo online. 


\section{Referências Bibliográficas}

A. M. LEITE DA SILVA, A.M. CASSULA, R. BILLINTON, L. A. F. M. OPTIMUM LOAD SHEDDING STRATEGIES IN DISTRIBUTIOSNY SYSTEMS. Power Tech Proceedings, 2001 IEEE Porto, v. 2, p. 1-6, 2001.

ALVES, R. P. Alocação Ótima de Reguladores de Tensão em Sistemas de Distribuição de Energia Elétrica Radiais Usando uma Formulação Linear Inteira Mista. Ilha Solteira-SP: Dissertação de mestrado apresentada ao Programa de PósGraduação em Engenharia Elétrica. Ilha Solteira-SP, 2012.

ANDERSSON, D. et al. Intelligent load shedding to counteract power system instability. IEEE/PES Transmision and Distribution Conference and Exposition: Latin America, p. 570-574, 2004.

AOKI, K. et al. A New Algorithm for Service Restoration in Distribution Systems. IEEE Power Engineering Review, v. 9, n. 7, p. 1832-1839, 1989.

BARAN, M.; WU, F. Optimal capacitor placement on radial distribution systems. Power Delivery, IEEE Transactions on, v. 4, n. 1, 1989.

BAZARAA, M. S.; SHETTY, C. M. Nonlinear Programming Theory and Algorithms. p. 80, 1943.

Boletim Mensal de Monitoramento do Sistema Elétrico Brasileiro. Disponível em: $<$ http://www.mme.gov.br/documents/10584/1256627/--

+Boletim+de+Monitoramento+do+Sistema+El\%C3\%A9trico+-+Janeiro-

2015_/b6795ba5-2d05-4a27-aafe-cd671b963761>.

BORBA, J. et al. Apagão atinge 11 Estados e DF; causa seria consumo em razão do calor. Jornal Folha de São Paulo, 2015.

CESPEDES, R. New method for the analysis of distribution networks. IEEE Transactions on Power Delivery, v. 5, n. 1, p. 391-396, 1990.

CHEN, C. S. et al. Design of tie line tripping and load shedding scheme for distribution microgrid systems with wind power generation. Conference Record - Industrial and Commercial Power Systems Technical Conference, p. 3-8, 2011.

CINVALAR, S. et al. Distribution feeder reconfiguration for loss reduction s. v. 3, n. 3, p. 1217-1223, 1988.

CUTSEM, T. VAN; MOORS, C.; LEFEBVRE, D. Design of load shedding schemes against voltage instability using combinatorial optimization. 2002 IEEE Power Engineering Society Winter Meeting. Conference Proceedings (Cat. No.02CH37309), v. 2, n. c, p. 1495-1500, 2002.

DELGADO, M. A. DE J. OTIMIZAÇÃo DE SISTEMAS DE DISTRIBUIÇÃo DE 
ENERGIA ELÉTRICA RADIAIS USANDO PROGRAMAÇÃO CÔNICA DE SEGUNDA ORDEM INTEIRA MISTA. Ilha Solteira: Tese de Doutorado Programa de Pós-Graduação em Engenharia Elétrica. Ilha Solteira-SP, 2015.

GAULKE, E. METODOLOGIA PARA DETERMINAÇÃO DO CORTE DE CARGA EM SISTEMAS DE DISTRIBUIÇÃO UTILIZANDO INTELIGÊNCIA ARTIFICIAL E MÚLTIPLOS CRITÉRIOS. Florianópolis - SC: Dissertação de mestrado apresentada ao Programa de Pós-Graduação em Engenharia Elétrica. Florianópolis - SC, 2007.

GHORBANI, M. J.; CHOUDHRY, M. A.; FELIACHI, A. Distributed Multi-Agent Based Load Shedding in Power Distribution Systems. p. 1-6, 2014.

GOSWAMI, S. K.; BASU, S. K. A new algorithm for the reconfiguration of distribution feeders for loss minimization. IEEE Transactions on Power Delivery, v. 7, n. 3, p. 1484-1491, 1992.

GOUIN, V.; ALVAREZ-HERAULT, M. C.; RAISON, B. Benefits of Load Shedding for Distribution Grids Investments Planning. Denver, USA: IEEE Power and Energy Society General Meeting, 2015

GREWAL, G. S.; KONOWALEC, J. W.; HAKIM, M. Optimization of a load shedding scheme. IEEE Industry Applications Magazine, v. 4, n. 4, p. 25-30, 1998.

IBM. V12. 1: User's Manual for CPLEXInternational Business Machines Corporation, $2009 . \quad$ Disponível em: $<\mathrm{http}: / /$ scholar.google.co.uk/scholar?hl=en\&q=cplex+manual\&btnG=\&as_sdt=1,5\&as sdtp=\#4>

JALILZADEH, S.; HOSSEINI, S. H.; DERAFSHIAN-MARAM, M. Optimal load shedding to prevent voltage instability based on multi-objective optimization using modal analysis and PSO. Ultra Modern Telecommunications and Control Systems and Workshops (ICUMT), 2010 International Congress on, p. 371-376, 2010.

LAVORATO, M. et al. Imposing radiality constraints in distribution system optimization problems. IEEE Transactions on Power Systems, v. 27, n. 1, p. 172-180, 2012.

LOBO, M. S. et al. Applications of second-order cone programming. Linear Algebra and its Applications, v. 284, n. 1-3, p. 193-228, 1998.

MANTOVANI, J. R. S.; CASARI, F.; ROMERO, R. A. Reconfiguração de Sistemas de Distribuição Radiais Utilizando o Critério de Queda de Tensão. SBA Controle e Automação, v. 11, n. 03, p. 150-159, 2000.

MONTICELLI, A. Fluxo de Carga em Rede de Energia Elétrica. Edgard Blu ed. São Paulo-SP: [s.n.].

NAGATA, T. et al. An efficient method for power distribution system restoration basedon mathematical programming and operation strategy. PowerCon 2000. 2000 International Conference on Power System Technology. Proceedings (Cat. No.00EX409), v. 3, p. 1545-1550, 2000.

PANASETSKY, D. et al. A New Intelligent Algorithm for Load Shedding Against Overload in Active Distribution Networks. n. Powercon, p. 20-22, 2014.

PARNIANI, M.; NASRI, A. SCADA based under frequency load shedding integrated with rate of frequency decline. 2006 IEEE Power Engineering Society General Meeting, 2006. 
PEPONIS, G. Reconfiguration of radial distribution networks: application of heuristic methods on large-scale networksIEE Proceedings - Generation, Transmission and Distribution, 1995.

PEREIRA, F. S. Reconfiguração ótima de sistemas de distribuição de energia elétrica baseado no comportamento de colônias de formigas. São Carlos - SP: Tese de Doutorado apresentada à Escola de Engenharia de São Carlos da Universidade de São Paulo, 2010.

RAO, P. S. N.; RAO, K. S. P. An efficient load shedding algorithm for radial systems. TENCON 2003. Conference on Convergent Technologies for Asia-Pacific Region, v. 2, 2003.

REPORT, A. C. Automatic Load Shedding. n. December, p. 1143-1146, 1955.

RIBEIRO, É. T. A. “ Modelos de Programação Inteira Mista para a Alocação Ótima de Bancos de Capacitores em Sistemas de Distribuição de Energia Elétrica Radiais ". Ilha Solteira: Dissertação de mestrado apresentada ao Programa de PósGraduação em Engenharia Elétrica. Ilha Solteira-SP, 2013.

ROMAIS, R. Reconfiguração Ótima dos Sistemas de Distribuição de Energia Elétrica Usando uma Formulação Cônica de Segunda Ordem Inteira Mista. Ilha Solteira-SP: Dissertação de mestrado apresentada ao Programa de Pós-Graduação em Engenharia Elétrica. Ilha Solteira-SP, 2013.

ROMERO, R. et al. A New Mathematical Model for the Restoration Problem in Balanced Radial Distribution Systems. IEEE Transactions on Power Systems, v. 31, p. 1-10, 2015.

ROSENTHAL, R. E. GAMS - A User 's Guide, 2015. Disponível em: <http://www.gams.com/dd/docs/bigdocs/GAMSUsersGuide.pdf>

RUPOLO, D. Reconfiguração de Redes de Distribuição de Energia Elétrica Através de um Algoritmo de Busca Dispersa. Ilha Solteira-SP: Dissertação de mestrado apresentada ao Programa de Pós-Graduação em Engenharia Elétrica. Ilha Solteira-SP, 2013.

SHIRMOHAMMADI, D.; HONG, H. W. Reconfiguration of electric distribution networks for resistive line losses reduction. IEEE Transactions on Power Delivery, v. 4, n. 2, p. 1492-1498, 1989.

SHIRMOHARMNADI, D. et al. A COMPENSATION-BASED POWER FLOW METHdD FOR WEAKLY MESHED DISTRIBUTION AND TRANSMISSION NETWORKS. IEEE Transactions on Power Systems, v. 3, n. 2, p. 753-762, 1988.

$\mathrm{SHOKOOH}, \mathrm{F}$. et al. An intelligent load shedding (ILS) system application in a large industrial facility. Conference Record - IAS Annual Meeting (IEEE Industry Applications Society), v. 1, n. 949, p. 417-425, 2005.

SOUZA, E. S. DE. PROPOSTAS DE MODELAGEM MATEMÁtICA PARA O PROBLEMA DE RESTAURAÇÃO DE SISTEMAS DE DISTRIBUIÇÃO DE ENERGIA ELÉTRICA RADIAISIlha SolteiraDissertação de mestrado apresentada ao Programa de Pós-Graduação em Engenharia Elétrica. Ilha Solteira-SP, 2009.

WANG, P.; BILLINTON, R. Optimum load-shedding technique to reduce the total customer interruption cost in a distribution system. IEE Proceedings - Generation, Transmission and Distribution, v. 147, n. 1, p. 51, 2000. 
WANGDEE, W.; BILLINTON, R. Utilization of time varying event-based customer interruption cost load shedding schemes. International Journal of Electrical Power and Energy Systems, v. 27, n. 9-10, p. 674-681, 2005.

WEI, W. et al. Service Restoration of Distribution System with Priority Customers and Distributed Generation. IEEE PES Innovative Smart Grid Technologies, p. 1-6, 2012. 


\section{Apêndice A - Dados dos Sistemas de Distribuição.}

Tabela A.1 - Dados relacionados aos cabos.

\begin{tabular}{cccc}
\hline Tamanho & $\mathbf{R}(\mathbf{\Omega} / \mathbf{K m})$ & $\mathbf{X}(\mathbf{\Omega} / \mathbf{K m})$ & Imáx $(\mathbf{A})$ \\
\hline $\mathbf{1}$ & 0,3655 & 0,2520 & 150 \\
$\mathbf{3}$ & 0,2359 & 0,2402 & 250 \\
$\mathbf{4}$ & 0,1827 & 0,1260 & 350 \\
$\mathbf{5}$ & 0,1460 & 0,1233 & 400 \\
$\mathbf{6}$ & 0,1180 & 0,1201 & 500 \\
\hline
\end{tabular}

Tabela A.2 - Capacidade de Carregamento das Subestações

\begin{tabular}{cc}
\hline SE & Potência (kVA) \\
\hline N101 & 33400 \\
N102 & 30000 \\
N104 & 22000 \\
\hline
\end{tabular}


Tabela A.3 - Dados das linhas.

\begin{tabular}{cccccccc}
\hline $\begin{array}{c}\text { Nó } \\
\text { Inicial }\end{array}$ & $\begin{array}{c}\text { Nó } \\
\text { Final }\end{array}$ & Cabo & $\begin{array}{c}\text { Distância } \\
(\mathbf{m})\end{array}$ & $\begin{array}{c}\text { Nó } \\
\text { Inicial }\end{array}$ & $\begin{array}{c}\text { Nó } \\
\text { Final }\end{array}$ & Cabo & $\begin{array}{c}\text { Distância } \\
(\mathbf{m})\end{array}$ \\
\hline $\mathbf{1 0 1}$ & $\mathbf{1}$ & 6 & 562 & $\mathbf{2 8}$ & $\mathbf{6}$ & 1 & 1000 \\
$\mathbf{1 0 1}$ & $\mathbf{3}$ & 6 & 436 & $\mathbf{1 0 4}$ & $\mathbf{3 0}$ & 6 & 562 \\
$\mathbf{4}$ & $\mathbf{3}$ & 6 & 624 & $\mathbf{2 9}$ & $\mathbf{3 0}$ & 1 & 624 \\
$\mathbf{7}$ & $\mathbf{4}$ & 6 & 500 & $\mathbf{4 3}$ & $\mathbf{3 0}$ & 2 & 812 \\
$\mathbf{5}$ & $\mathbf{4}$ & 2 & 624 & $\mathbf{3 7}$ & $\mathbf{4 3}$ & 1 & 500 \\
$\mathbf{8}$ & $\mathbf{7}$ & 6 & 624 & $\mathbf{3 1}$ & $\mathbf{3 7}$ & 1 & 374 \\
$\mathbf{6}$ & $\mathbf{5}$ & 2 & 500 & $\mathbf{1 0}$ & $\mathbf{3 1}$ & 1 & 624 \\
$\mathbf{9}$ & $\mathbf{1}$ & 6 & 686 & $\mathbf{4 3}$ & $\mathbf{1 3}$ & 4 & 750 \\
$\mathbf{2}$ & $\mathbf{1}$ & 2 & 624 & $\mathbf{4 5}$ & $\mathbf{1 2}$ & 6 & 500 \\
$\mathbf{1 0}$ & $\mathbf{9}$ & 2 & 1436 & $\mathbf{4 4}$ & $\mathbf{4 5}$ & 6 & 436 \\
$\mathbf{1 0 2}$ & $\mathbf{1 4}$ & 6 & 750 & $\mathbf{3 8}$ & $\mathbf{4 4}$ & 6 & 624 \\
$\mathbf{1 5}$ & $\mathbf{1 4}$ & 2 & 750 & $\mathbf{3 9}$ & $\mathbf{3 8}$ & 5 & 686 \\
$\mathbf{1 6}$ & $\mathbf{1 5}$ & 2 & 562 & $\mathbf{3 2}$ & $\mathbf{3 9}$ & 1 & 812 \\
$\mathbf{1 0 2}$ & $\mathbf{1 1}$ & 6 & 562 & $\mathbf{3 3}$ & $\mathbf{3 9}$ & 2 & 562 \\
$\mathbf{1 2}$ & $\mathbf{1 1}$ & 6 & 624 & $\mathbf{8}$ & $\mathbf{3 3}$ & 2 & 936 \\
$\mathbf{1 3}$ & $\mathbf{1 2}$ & 1 & 874 & $\mathbf{3 3}$ & $\mathbf{3 4}$ & 1 & 374 \\
$\mathbf{2 0}$ & $\mathbf{1 9}$ & 1 & 624 & $\mathbf{3 4}$ & $\mathbf{3 5}$ & 1 & 436 \\
\hline $\mathbf{1 9}$ & $\mathbf{1 8}$ & 1 & 500 & $\mathbf{3 5}$ & $\mathbf{3 6}$ & 1 & 436 \\
\hline $\mathbf{1 8}$ & $\mathbf{1 7}$ & 1 & 812 & $\mathbf{4 0}$ & $\mathbf{4 1}$ & 1 & 750 \\
$\mathbf{1 7}$ & $\mathbf{9}$ & 4 & 860 & $\mathbf{1 6}$ & $\mathbf{4 0}$ & 1 & 500 \\
$\mathbf{2 1}$ & $\mathbf{1 8}$ & 2 & 624 & $\mathbf{4 2}$ & $\mathbf{4 1}$ & 1 & 750 \\
$\mathbf{1 0 4}$ & $\mathbf{2 1}$ & 4 & 500 & $\mathbf{4 8}$ & $\mathbf{4 2}$ & 1 & 500 \\
$\mathbf{1 0 4}$ & $\mathbf{2 2}$ & 2 & 750 & $\mathbf{4 9}$ & $\mathbf{4 8}$ & 1 & 750 \\
$\mathbf{2 2}$ & $\mathbf{9}$ & 2 & 936 & $\mathbf{5 0}$ & $\mathbf{4 9}$ & 1 & 436 \\
$\mathbf{2 3}$ & $\mathbf{2 2}$ & 1 & 686 & $\mathbf{4 7}$ & $\mathbf{4 2}$ & 4 & 624 \\
$\mathbf{2 4}$ & $\mathbf{2 3}$ & 1 & 562 & $\mathbf{4 6}$ & $\mathbf{4 7}$ & 2 & 624 \\
$\mathbf{2 5}$ & $\mathbf{2 4}$ & 1 & 436 & $\mathbf{1 4}$ & $\mathbf{4 6}$ & 4 & 686 \\
$\mathbf{8}$ & $\mathbf{2 5}$ & 1 & 562 & $\mathbf{3 5}$ & $\mathbf{4 0}$ & 1 & 356 \\
$\mathbf{2 7}$ & $\mathbf{8}$ & 2 & 750 & $\mathbf{1 0}$ & $\mathbf{3 8}$ & 1 & 500 \\
$\mathbf{2 6}$ & $\mathbf{2 7}$ & 1 & 686 & $\mathbf{2 8}$ & $\mathbf{5 0}$ & 1 & 308 \\
$\mathbf{2 8}$ & $\mathbf{2 7}$ & 1 & 624 & & & & \\
\hline & & & & & & & \\
\hline
\end{tabular}


Tabela A.4 - Dados das barras.

\begin{tabular}{|c|c|c|c|c|c|}
\hline Nó & $\begin{array}{c}\text { Potência } \\
\text { Ativa (kW) }\end{array}$ & $\begin{array}{l}\text { Potência } \\
\text { Reativa } \\
\text { (kVAr) }\end{array}$ & Nó & $\begin{array}{c}\text { Potência } \\
\text { Ativa (kW) }\end{array}$ & $\begin{array}{c}\text { Potência } \\
\text { Reativa } \\
\text { (kVAr) }\end{array}$ \\
\hline N101 & 0 & 0 & N25 & 623.7 & 302.07 \\
\hline N102 & 0 & 0 & N26 & 831.6 & 402.78 \\
\hline N104 & 0 & 0 & N27 & 1039.5 & 503.42 \\
\hline N1 & 2910.6 & 1409.64 & N28 & 485.1 & 234.93 \\
\hline N2 & 1039.5 & 503.43 & N29 & 970.2 & 469.85 \\
\hline N3 & 485.1 & 234.93 & N30 & 1801.8 & 872.64 \\
\hline N4 & 762.3 & 369.22 & N31 & 485.1 & 234.93 \\
\hline N5 & 1801.8 & 872.64 & N32 & 1178.1 & 570.57 \\
\hline N6 & 485.1 & 234.93 & N33 & 2009.7 & 973.36 \\
\hline N7 & 693.0 & 335.64 & N34 & 831.6 & 402.79 \\
\hline N8 & 1316.7 & 637.71 & N35 & 623.7 & 302.07 \\
\hline N9 & 831.6 & 402.79 & N36 & 207.9 & 100.72 \\
\hline N10 & 2009.7 & 973.36 & N37 & 1455.3 & 704.86 \\
\hline N11 & 207.9 & 100.72 & N38 & 762.3 & 369.21 \\
\hline N12 & 1247.4 & 604.14 & N39 & 693.0 & 335.64 \\
\hline N13 & 762.3 & 369.22 & N40 & 970.2 & 469.85 \\
\hline N14 & 693.0 & 335.64 & N41 & 623.7 & 302.07 \\
\hline N15 & 970.2 & 469.85 & N42 & 831.6 & 402.79 \\
\hline N16 & 1316.7 & 637.71 & N43 & 900.9 & 436.36 \\
\hline N17 & 485.1 & 234.93 & N44 & 970.2 & 469.85 \\
\hline N18 & 831.6 & 402.79 & N45 & 554.4 & 268.5 \\
\hline N19 & 970.2 & 469.85 & N46 & 1247.4 & 604.14 \\
\hline N2O & 554.4 & 268.5 & N47 & 693.0 & 335.64 \\
\hline N21 & 1247.4 & 604.14 & N48 & 554.4 & 268.5 \\
\hline N22 & 762.3 & 369.22 & N49 & 346.5 & 167.78 \\
\hline N23 & 693.0 & 335.64 & N50 & 554.4 & 268.5 \\
\hline N24 & 346.5 & 167.78 & & & \\
\hline
\end{tabular}

Tabela A.5 - Dados das impedâncias das linhas.

\begin{tabular}{ccccc}
\hline $\begin{array}{c}\text { Nó } \\
\text { Inicial }\end{array}$ & Nó Final & $\begin{array}{c}\text { Resistência } \\
(\boldsymbol{\Omega})\end{array}$ & Reatância $(\boldsymbol{\Omega})$ & $\begin{array}{c}\text { Corrente Máx } \\
(\mathbf{A})\end{array}$ \\
\hline $\mathbf{1 0 1}$ & $\mathbf{1}$ & 0.0543 & 0.0675 & 600 \\
$\mathbf{1 0 1}$ & $\mathbf{3}$ & 0.0421 & 0.0524 & 600 \\
$\mathbf{4}$ & $\mathbf{3}$ & 0.0603 & 0.0749 & 600 \\
$\mathbf{7}$ & $\mathbf{4}$ & 0.0483 & 0.06 & 600 \\
$\mathbf{5}$ & $\mathbf{4}$ & 0.1472 & 0.1499 & 250 \\
$\mathbf{8}$ & $\mathbf{7}$ & 0.0603 & 0.0749 & 600 \\
$\mathbf{6}$ & $\mathbf{5}$ & 0.1179 & 0.1201 & 250 \\
$\mathbf{9}$ & $\mathbf{1}$ & 0.0663 & 0.0824 & 600 \\
$\mathbf{2}$ & $\mathbf{1}$ & 0.1472 & 0.1499 & 250 \\
\hline
\end{tabular}




\begin{tabular}{|c|c|c|c|c|}
\hline 10 & 9 & 0.3388 & 0.3449 & 250 \\
\hline 102 & 14 & 0.0725 & 0.0901 & 600 \\
\hline 15 & 14 & 0.1769 & 0.1802 & 250 \\
\hline 16 & 15 & 0.1326 & 0.1350 & 250 \\
\hline 102 & 11 & 0.0543 & 0.0675 & 600 \\
\hline 12 & 11 & 0.0603 & 0.0749 & 600 \\
\hline 13 & 12 & 0.3194 & 0.2202 & 150 \\
\hline 20 & 19 & 0.2281 & 0.1572 & 150 \\
\hline 19 & 18 & 0.1828 & 0.1260 & 150 \\
\hline 18 & 17 & 0.2968 & 0.2046 & 150 \\
\hline 17 & 9 & 0.1256 & 0.1060 & 400 \\
\hline 21 & 18 & 0.1472 & 0.1499 & 250 \\
\hline 104 & 21 & 0.0730 & 0.0617 & 400 \\
\hline 104 & 22 & 0.1769 & 0.1802 & 250 \\
\hline 22 & 9 & 0.2208 & 0.2248 & 250 \\
\hline 23 & 22 & 0.2507 & 0.1729 & 150 \\
\hline 24 & 23 & 0.2054 & 0.1416 & 150 \\
\hline 25 & 24 & 0.1594 & 0.1099 & 150 \\
\hline 8 & 25 & 0.2054 & 0.1416 & 150 \\
\hline 27 & 8 & 0.1769 & 0.1802 & 250 \\
\hline 26 & 27 & 0.2507 & 0.1729 & 150 \\
\hline 28 & 27 & 0.2281 & 0.1572 & 150 \\
\hline 28 & 6 & 0.3655 & 0.2520 & 150 \\
\hline 104 & 30 & 0.0543 & 0.0675 & 600 \\
\hline 29 & 30 & 0.2281 & 0.1572 & 150 \\
\hline 43 & 30 & 0.1916 & 0.1950 & 250 \\
\hline 37 & 43 & 0.1828 & 0.1260 & 150 \\
\hline 31 & 37 & 0.1367 & 0.0942 & 150 \\
\hline 10 & 31 & 0.2281 & 0.1572 & 150 \\
\hline 43 & 13 & 0.1095 & 0.0925 & 400 \\
\hline 45 & 12 & 0.0483 & 0.06 & 600 \\
\hline 44 & 45 & 0.0421 & 0.0524 & 600 \\
\hline 38 & 44 & 0.0603 & 0.0749 & 600 \\
\hline 39 & 38 & 0.0809 & 0.0824 & 500 \\
\hline 32 & 39 & 0.2968 & 0.2046 & 150 \\
\hline 33 & 39 & 0.1326 & 0.1350 & 250 \\
\hline 8 & 33 & 0.2208 & 0.2248 & 250 \\
\hline 33 & 34 & 0.1367 & 0.0942 & 150 \\
\hline 34 & 35 & 0.1594 & 0.1099 & 150 \\
\hline 35 & 36 & 0.1594 & 0.1099 & 150 \\
\hline 40 & 41 & 0.2741 & 0.1890 & 150 \\
\hline 16 & 40 & 0.1828 & 0.1260 & 150 \\
\hline 42 & 41 & 0.2741 & 0.1890 & 150 \\
\hline 48 & 42 & 0.1828 & 0.1260 & 150 \\
\hline 49 & 48 & 0.2741 & 0.1890 & 150 \\
\hline 50 & 49 & 0.1594 & 0.1099 & 150 \\
\hline 47 & 42 & 0.0911 & 0.0769 & 400 \\
\hline
\end{tabular}




\begin{tabular}{lllll}
\hline 46 & 47 & 0.1472 & 0.1499 & 250 \\
14 & 46 & 0.1002 & 0.0846 & 400 \\
35 & 40 & 0.1301 & 0.0897 & 150 \\
10 & 38 & 0.1828 & 0.1260 & 150 \\
$\mathbf{2 8}$ & $\mathbf{5 0}$ & 0.1126 & 0.0776 & 150 \\
\hline
\end{tabular}




\section{Apêndice B - Fluxograma do Programa Desenvolvido.}

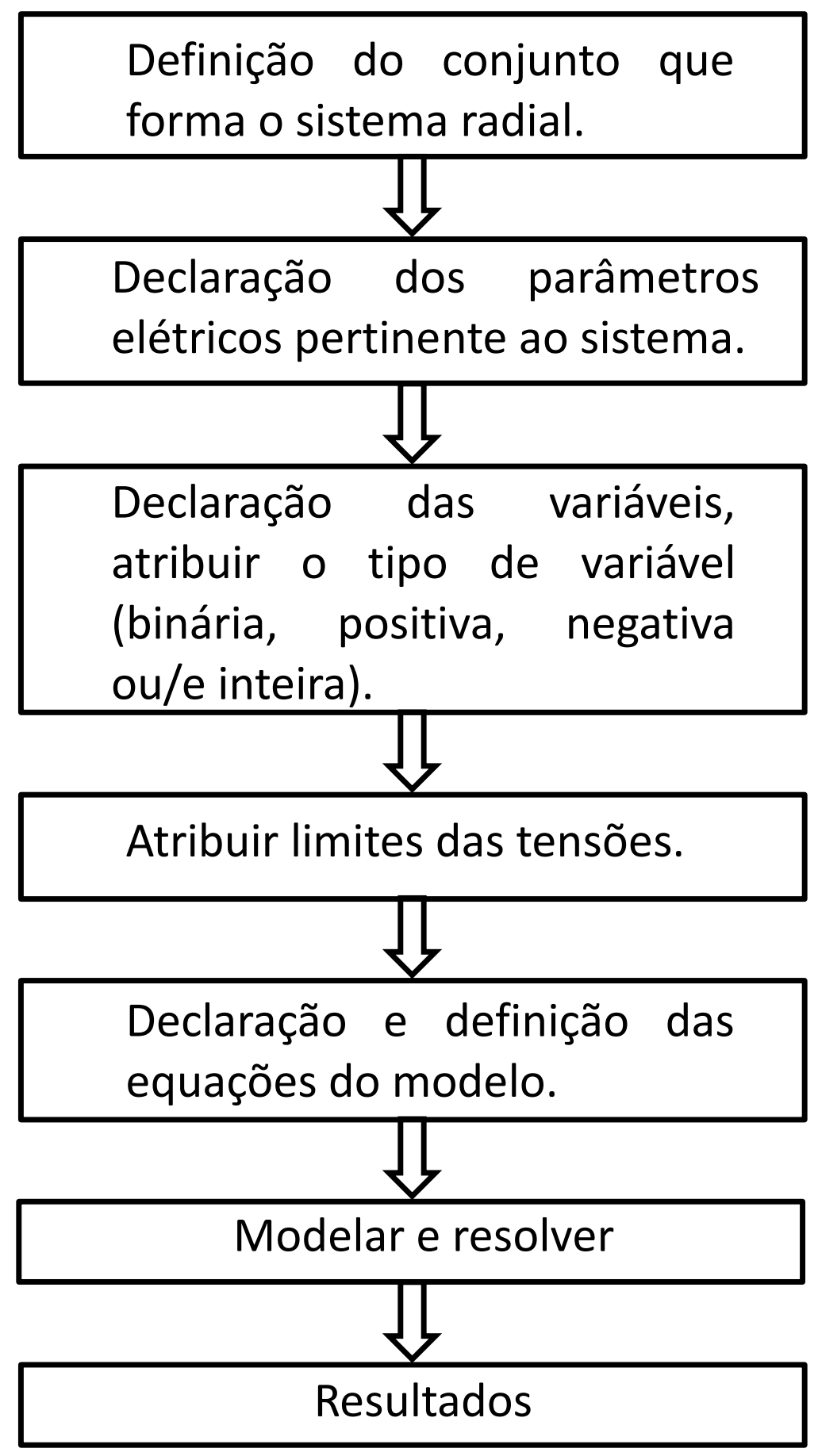

Figura B.1 - Fluxograma do programa desenvolvido no GAMS 